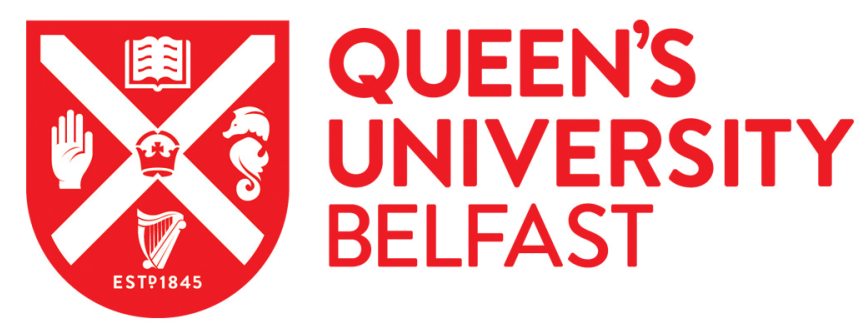

\title{
Reusing, recycling and up-cycling of biomass: A review of practical and kinetic modelling approaches
}

Osman Ahmed, A. I., Abdelkader, A., Farrell, C., Rooney, D., \& Morgan, K. (2019). Reusing, recycling and upcycling of biomass: A review of practical and kinetic modelling approaches. Fuel Processing Technology, 192, 179-202. https://doi.org/10.1016/j.fuproc.2019.04.026

Published in:

Fuel Processing Technology

Document Version:

Peer reviewed version

Queen's University Belfast - Research Portal:

Link to publication record in Queen's University Belfast Research Portal

Publisher rights

Copyright 2019 Elsevier

This manuscript is distributed under a Creative Commons Attribution-NonCommercial-NoDerivs License

(https://creativecommons.org/licenses/by-nc-nd/4.0/), which permits distribution and reproduction for non-commercial purposes, provided the author and source are cited.

\section{General rights}

Copyright for the publications made accessible via the Queen's University Belfast Research Portal is retained by the author(s) and / or other copyright owners and it is a condition of accessing these publications that users recognise and abide by the legal requirements associated with these rights.

Take down policy

The Research Portal is Queen's institutional repository that provides access to Queen's research output. Every effort has been made to ensure that content in the Research Portal does not infringe any person's rights, or applicable UK laws. If you discover content in the Research Portal that you believe breaches copyright or violates any law, please contact openaccess@qub.ac.uk. 


\section{kinetic modelling approaches}

3 Ahmed I. Osman ${ }^{\mathrm{a}, \mathrm{b}^{*}}$, Adel Abdelkader ${ }^{\mathrm{b}}$, Charlie Farrell ${ }^{\mathrm{c}, \mathrm{d}}$, David Rooney ${ }^{\mathrm{a}}$ and Kevin Morgan ${ }^{\mathrm{a}^{*}}$

aSchool of Chemistry and Chemical Engineering, Queen's University Belfast, Belfast BT9

$6 \quad 5 \mathrm{AG}$, Northern Ireland, UK

$7 \quad{ }^{\mathrm{b}}$ Chemistry Department, Faculty of Science - Qena, South Valley University, Qena 83523 -

8 Egypt.

$9 \quad{ }^{\mathrm{c}}$ South West College, Cookstown, Co. Tyrone, BT80 8DN, Northern Ireland, UK

d School of Mechanical and Aerospace Engineering, Queen's University Belfast, Belfast BT9 5AH, Northern Ireland, UK.

Corresponding Authors: Ahmed Osman and Kevin Morgan Email: aosmanahmed01@qub.ac.uk; kmorgan08@qub.ac.uk Keir Building, Stranmillis Road, Belfast BT9 5AG, Northern Ireland, United Kingdom 


\section{Abstract}

22 There is a growing interest in the utilisation of biomass for a range of applications. Coupled with

23 this is the appeal of improving the circular economy and as such, there is a focus on reusing,

24 recycling and upcycling of many materials, including biomass. This has been driven by society

25 in terms of demand for more sustainable energy and products, but also by a paradigm shift in

26 attitudes of the population to reduce their personal carbon footprint. Herein we have selected a number of types of biomass (woody, herbaceous, etc.) and surveyed the ways in which they are utilised. We have done this in combination with assessing some kinetic modelling approaches which been reported for the evaluation of different processes for the recycling, reuse and upcycling of biomass.

Keywords: Biomass, Recycling, Valorisation, Circular Economy, Kinetic Modelling, 


\section{Introduction}

44 Worldwide, there are issues around "waste" that are prevalent. Perhaps the most pressing issue 45 is the attitudes and behavioural issues in terms of designating something as "waste". From a chemical, and in turn energy, perspective there is normally an intrinsic (carbon) value in such materials; so that it would be better to deem this as "resources" rather than waste. This way of thinking can be considered part of the circular economy, a model by which as much value (and quality) as possible is retained via reuse, recycling, repurposing and up-cycling with aspirations towards zero waste. As such, there is interest in evaluating the potential value in the circular economy that was highlighted recently by Zacho [1].

The attitude of developing economies is much better suited to a circular economy perspective, since there is already an emphasis of extraction of maximum value from finite resources, despite the fact that challenges still need to be overcome to further support a transition to circular economies [2]. In more developed economies there has been more of a throwaway culture and this has had an impact in terms of landfill and environmental issues associated with nonbiodegradable materials (e.g. plastics). Consequently, there have been increased movements to address issues around non-biodegradable materials [3].

It should be recalled that it is not ideal to send organic materials (e.g. biomass) to landfill since the degradation process will result in the production of methane gas which can escape to the

61 atmosphere, thereby contributing to the Greenhouse Gas (GHG) effect [4-6]. As part of the 62 circular economy, biomass resources should be utilised either by reuse (same 63 purpose/application), recycled (repurposed for further use, typically in an application of similar value or below) or up-cycled/valorised (repurposed for an application of higher value e.g. extraction of biofuels and biochemical feedstocks as part of the bio-refinery concept). 
67 In general, biomass can be classified as primary, secondary and tertiary, where:

68 Primary biomass is produced directly via photosynthesis and is taken directly from the land. For

69 instance, herbaceous and woody biomass along with the seeds of oil crops and the residues after

70 the harvesting of forest trees and agricultural crops (corn stover, limbs, bark and wheat straw)

71 are all considered primary biomass source [7].

72 Secondary biomass results from the processing of the primary biomass such as sawdust (physical 73 processing), black liquor (chemical processing) or manure production by animals (biological 74 processing).

75 Tertiary biomass is post-consumer byproducts such as animal fat, used vegetable oils, 76 construction and demolition debris and packing byproducts.

\subsection{Classification of biofuel generations}

Biomass, when used as a biofuel, can also be classified to the first, second, third and fourth generation where:

- $1^{\text {st }}$ generation biofuels come from edible biomass such as the ethanol production from fermenting sugars. There are majour drawbacks of this generation in terms of the food

- $2^{\text {nd }}$ generation biofuels are derived from lignocellulosic biomass, either non-edible of food crop (rice husks) or non-edible whole plant biomass resources (grasses). The majour challenge related to this generation is that processing can be expensive and a technological breakthrough is still required to make them more feasible. 
- $3^{\text {rd }}$ generation biofuels are produced using non-arable land such as algae and typically need a high capital cost to operate.

- $4^{\text {th }}$ generation biofuels can be made using non-arable land and do not require the destruction of biomass to be converted into fuel such as the photobiological solar fuels [7].

In 2015, it was reported that the UK has reached an annual food "waste" of 7.3 million tonnes compared to only 1 million tonnes in the Republic of Ireland $[8,9]$. This is not considering the abundance of other potential biomass resources, for example:

- Herbaceous materials (such as grass cuttings)

- Wood materials (such as hedges and trees)

- Consumer/manufacturing by-products (such as cork wine stoppers and sawdust);

- Aquatic/marine debris

- Agricultural manures.

100 The sheer volumes of biomass which would traditionally be designated as waste have prompted

101 much action in terms of resource management worldwide. The European Union (amongst others) have been at the forefront of promoting the circular economy to avoid the production of waste

$103[10-14]$ and the increased use of renewable resources $[15,16]$. Significantly, there has been

104 substantial research funds delegated to this area, e.g. the Resource Innovation Network for 105 European Waste (ReNEW) was a $€ 4.88$ million project funded by The European Union's Interreg 106 programme [17].

\section{$107 \quad 1.3$ Processing of biomass resources}

108 Typically biomass resources can be processed in a number of ways such as: 
109 (i) Combustion, which is the burning of biomass in the air to produce hot gases, ash and consequently converting the stored chemical energy into heat which can be then converted to kinetic energy through heating water to produce vapour which is used for

(ii) Gasification, which is the partial oxidation of rice husk biomass at high temperatures to gas engines $[18,19]$.

117 (iii) Pyrolysis, which is the thermal degradation of the biomass in an oxygen-free

(iv) Liquefaction, which is the conversion of biomass into stable liquid hydrocarbons at low

(vi) Steam explosion: which is a process where the biomass is treated under pressure with high pressure (2-10 MPa) method with water that converts biomass to biochar, a carbonrich material. It is a combination of a number of chemical processes including polymerization, hydrolysis, dehydration and decarboxylation [22]. It is a wet treatment 
process to upgrade solid fuel for the production of more energy dense hydrophobic hydrochar while reducing the sulfur and ash contents [23].

(viii) Anaerobic Digestion (AD): which is a biological process where microorganisms break down biodegradable material in an oxygen-free environment to produce biogas ( a mixture of methane and carbon dioxide) which is combusted to generate electricity and heat or upgraded into biomethane [22].

\section{2. Introductory piece to reusing and recycling approaches}

\subsection{Practical applications:}

139 Firstly, using biomass for combustion in the energy sector depends upon the quality, chemical

140 and physical parameters of the feedstock or feedstocks in question. Mancini et al.[24] developed

141 a combined technique of near-infrared spectroscopy with multivariate analysis to predict the 142 gross calorific value (GCV) and the ash content in the biomass feedstock, with a standard error

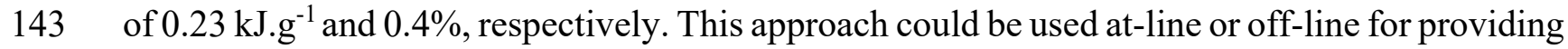
144 an indication of the quality of the feedstock and its suitability for the industrial application.

145 Unlike coal, biomass is characterised by its larger volatile content while also being a porous 146 material i.e. biomass allows the ingress of bacteria and $\mathrm{O}_{2}$, thus, increasing the risk of self147 heating and ignition in storage and transportation [25]. Therefore, monitoring the temperature, 148 volatile organic compounds (VOC), carbon monoxide (CO) and controlling the moisture is 149 crucial to avoid the ignition [25].

\subsection{Introductory piece on kinetic modelling:}

151 Understanding the thermal kinetic behaviour of the thermal decomposition of biomass is crucial

152 in order to identify the physicochemical combustion characteristics that hinder some of the 153 energy generation applications. Thus, determining the activation energy $\left(E_{a}\right)$ and the pre- 
154 exponential factor using either model-fitting or model-free (iso-conversional) approaches, which 155 are the two common methods for studying the Differential scanning 156 calorimetry/Thermogravimetric analysis (DSC/TGA) solid-state kinetic data, is important. The 157 model-fitting method is based on the best fit of the different models with the experimental 158 thermogravimetric data using a single TGA/DSC curve, which might actually fit with more than 159 one model. Conversely, the model-free iso-conversional method is a simple method that 160 eliminates the error related to the model fitting [26]. In the iso-conversional method, different 161 heating rate curves are required to calculate the kinetic parameters as a function of the extent of 162 conversion $(\alpha)$ i.e. the $E_{a}$ is calculated for a serious of different conversion points. It is well 163 known that the thermal analysis mechanism is complicated as it tends to take place in multiple 164 steps with different reaction rates and, as such, an iso-conversional method is the most suitable method and, consequently, the most commonly used in this case. As the biomass composed of three different components (cellulose, hemicellulose and lignin), where each behave differently

167 and separately during the biomass thermal decomposition. Thus, this complex behaviour of 168 biomass decomposition should be considered in kinetic modelling. It was reported that there is a 169 possibility of nine mechanisms of smoldering combustion during the thermochemical conversion 170 of biomass $[27,28]$. The Kissinger method is the only method in the model-free approach that 171 does not determine the $E_{a}$ as a function of progressive conversion ( $\alpha$ ), so it is not considered as 172 an iso-conversional method as it instead assumes a constant $E a$ along the reaction progress [28, 173 29]. The basic principles of iso-conversional methods are outlined below.

174 The rate of thermal decomposition of the biomass can be described in terms of conversion $(\alpha)$ 175 and temperature (T), as shown in Equation 1:

$$
\frac{d \alpha}{d t}=k(T) f(\alpha)
$$

177 where: $\alpha$ can be expressed as the decomposed mass fraction of the biomass as shown in Equation $178 \quad 2:$ 


$$
\alpha=\frac{m_{i}-m_{a}}{m_{i}-m_{f}}
$$

180 where: $m_{i}, m_{a}$ and $m_{f}$ are initial, actual and final masses, respectively.

181 The Arrhenius equation describes the temperature dependent function in terms of the activation 182 energy $\left(E_{a}\right)$ and the pre-exponential factor $\left(k_{0}\right)$ as shown in Equation $3[30,31]$.

$$
k(T)=k_{0} e^{\left(\frac{-E_{a}}{R T}\right)}
$$

\section{Equation 3}

184 where: $E_{a}$ is the activation energy in $\mathrm{kJ} \mathrm{mol}^{-1}, \mathrm{~T}$ is the absolute temperature in Kelvin $(\mathrm{K}), \mathrm{R}$ is 185 the ideal gas constant $\left(8.314 \mathrm{~J} \cdot \mathrm{K}^{-1} \cdot \mathrm{mol}^{-1}\right)$ and $k_{0}$ is the pre-exponential factor $\left(\mathrm{min}^{-1}\right)$.

186 By combining Equations 1 and 3, the thermal decomposition equation of biomass can be 187 expressed as shown in Equation 4.

$$
\frac{d \alpha}{d t}=k_{0} e^{\left(\frac{-E_{a}}{R T}\right)} f(\alpha) \quad \text { Equation } 4
$$

189 In the non-isothermal iso-conversional method, using different linear heating rates $\left(\beta=\mathrm{dT}^{\mathrm{dt}}{ }^{-}\right.$

$19{ }^{1}$ ), the thermal decomposition equation can be expressed as shown in Equation 5.

$$
\frac{d \alpha}{d T}=\frac{k_{0}}{\beta} e^{\left(\frac{-E_{a}}{R T}\right)} f(\alpha) \quad \text { Equation } 5
$$

192 Non-isothermal iso-conversional methods such as the ASTM- E698 method is suitable for a

193 single step reaction and can be expressed as shown in Equation 6.

$$
\beta \frac{d \alpha}{d t}=k_{0} e^{\left(\frac{-E_{a}}{R T}\right)}(1-\alpha) \quad \text { Equation } 6
$$

The Flynn-Wall and Ozawa (FWO) method propose the calculations of the variations in the apparent activation energy in terms of different linear thermogravimetric curves using the

198 integral iso-conversional analysis method $[32,33]$. The $E_{a}$ can be calculated by plotting the

199 natural logarithm of the heating rates $(\ln \beta)$ versus inversely $\mathrm{T}$, which represents a linear relationship with a corresponding $\alpha$ at different heating rates as shown in Equation 7. 


$$
\ln \beta=\ln \left(\frac{k_{0} \cdot E_{a}}{R \cdot g(\alpha)}\right)-5.331-1.052 \frac{E_{a}}{R . T} \quad \text { Equation } 7
$$

202 where: $\mathrm{g}(\alpha)$ is constant at a given value of $\alpha$.

203 In Kissinger-Akahira-Sunose method (KAS), the $E_{a}$ can be calculated by plotting the natural 204 logarithm of $\beta \cdot \mathrm{T}^{-2}$ versus the inverse temperature [34] as shown in Equation 8.

$$
\frac{\ln \beta}{T^{2}}=\ln \left[\frac{k_{0} \cdot R}{E_{a} \cdot g(\alpha)}\left(1-\frac{2 R T}{E_{a}}\right)\right]-\left(\frac{E_{a}}{R . T}\right) \quad \text { Equation } 8
$$

206 On the other hand, isothermal iso-conversional methods, such as the isothermal Friedman method, assume that the thermal decomposition is independent of the temperature but, dependent on the reaction progress (rate of the mass loss), hence $f(\alpha)$ is constant at any given $\alpha$. By taking the natural logarithm of both sides of Equation 5, yields Equation 9. Thus, by plotting $\ln \beta \frac{d \alpha}{d T}$

210 versus $\mathrm{T}^{-1}, E_{a}$ can be calculated from the gradinet $\frac{E_{a}}{R}$.

$$
\ln \beta \frac{d \alpha}{d T}=\ln \left[k_{0} f(\alpha)\right]-\frac{E_{a}}{R T} \quad \text { Equation } 9
$$

213 Vyazovkin discussed the common misconceptions related to the modern iso-conversional

214 kinetics which are the estimation of the preexponential factor and reaction model, meaning of 215 iso-conversional activation energy, single-step approximation and the application of iso216 conversional methods to the process taking place on cooling [35]. Vyazovkin mentioned that the 217 most significant advance in modern iso-conversional kinetics is associated with the quantitative 218 interpretation of variations in the iso-conversional $\mathrm{Ea}$ as a sign of a multistep reaction 219 mechanism. 


\section{Reusing and recycling}

\subsection{Woody biomass}

226 There are significant opportunities to recycle and reuse wood. Many items, such as furniture, can

227 be sold second-hand and used again; and there has been human behavioural/attitude changes with regards to secondhand consumption/use [36] which had been typical during the $19^{\text {th }}$ Century [37], but became stigmatized in the $20^{\text {th }}$ Century [38]. More recently there has been a marked increase in secondhand use $[39,40]$, which may have been financially driven by the impact on consumers from the 2008 economic crisis [41]. This was likely not the only driver in such a paradigm shift. Consumers are typically much more informed now than previous generations and are aware of environmental issues such as land use concerns such as deforestation for agriculture, the eat versus heat debate and landfill capacity. As such, consumers are very conscious of their carbon footprint and consequently, this is also being factored into their decisions. For example, it has been reported that the reuse/recycle pathways can help reduce GHG emissions [42], thereby reducing environmental impact.

This awareness has created an acceptance and, perhaps, even a demand for materials and products which originate from recycled/sustainable or deconstructed resources. Such materials include:

- Composites from by-products (e.g. sawdust) of the forestry/timber industry [43-45].

- Building materials from recovered/deconstructed solid wood [37, 46-48].

- Packaging/joinery/furniture/pallets from recovered solid wood [49].

244 Generally, with the reuse and recycling of woody biomass there is little, if any, chemical conversion and so there are not many examples of kinetic studies or modelling for such 246 processes. 
247 With fossil fuel reserves being depleted there has been a significant movement to 248 sustainable/renewable energy, and bio-energy is now a majour contributor to this [22]. Given 249 that ability of biomass to be converted to solid, liquid and gas fuels, biomass is a suitable energy 250 resource for heat, power and transport [22, 50]. While the utilisation of liquid and gaseous 251 biofuels typically requires some chemical transformation/valorisation of the biomass, this is not 252 necessarily the same for solid fuels [50]. In order to use unprocessed biomass as a solid fuel, it 253 is normally blended with other fuels, such as coal, in order to compensate for the low calorific 254 value and high moisture content inherent in the biomass source [50, 51]. Woody biomass, can, 255 in theory, be combusted without much processing and as such, the application of woody biomass 256 as a fuel can still be considered a low-grade use [16] (i.e. no valorisation/up-cycling).

257 There are a number of methods by which fuel pellets can be prepared from heterogeneous 258 compositions of biomass including wood; size reduction, torrefaction, steam explosion, 259 hydrothermal carbonisation and biological treatment [22]. Some of these methods can be used in 260 isolation or in combination with each other.

261 Size reduction: Typically, this is a mechanical transformation via force/compression/pressure or 262 by cutting/shearing/grinding. The intention of this process is to increase surface area [22, 52-54]. 263 These processes can be quite an energy intensive and while high energy costs can be covered 264 when the biomass is been used for value-added processing, the energy costs for producing pellets 265 for combustion needs to be kept to a minimum [52].

266 Torrefaction was used for the dehydration and decarboxylation in order to increase energy 267 density and improve the heating value whilst removing moisture and improving the 268 hydrophobicity of the pellets $[22,50]$. This process does induce chemical changes and there are 269 some reports of kinetic studies of the torrefaction of woody biomass [55-59]. 
270 Sarvaramini et al. [55] studied mild $\left(240^{\circ} \mathrm{C}\right)$ and severe $\left(280^{\circ} \mathrm{C}\right)$ isothermal torrefaction of 271 trembling aspen and birch woody biomass compared with samples of cellulose, xylan and lignin.

272 Samples were heated inductively and samples were held at the target temperatures for 15 and 60

273 minutes in order to study the time dependency. C, H, N and S elemental analysis of the residual

274 solids after the torrefaction was conducted while heating values were derived based on a method 275 reported in the literature [60]. A kinetic model was derived which was determined from the 276 weight loss of the samples as a function of time as observed using a thermogravimetric analyser

277 (TGA), a method which was also previously reported in the literature [61]. The model was 278 developed taking the distributed activation energy model (DAEM) approach. Using a log-normal 279 distribution function the maximum activation energies of cellulose, xylan and lignin torrefaction 280 were found to be $207 \mathrm{~kJ} \cdot \mathrm{mol}^{-1}, 132 \mathrm{~kJ} \cdot \mathrm{mol}^{-1}$ and $196 \mathrm{~kJ} \cdot \mathrm{mol}^{-1}$, respectively. The DAEM was 281 found to accurately predict the volatile release observed by TGA for xylan and lignin, and less 282 so for cellulose. Significantly, combining the individual activation energy models in three283 parallel reaction meta-models could accurately model the experimental torrefaction data for the 284 aspen and the birch.

285 Ren et al. also utilised thermogravimetric analysis for the torrefaction of douglas fir sawdust, but 286 applied a two-step reaction model developed previously for xylan [62], which has also been 287 applied to willow [63], to their study. The first and second reaction stage activation energies 288 were determined to be $112 \mathrm{~kJ} \mathrm{~mol}^{-1}$ and $150 \mathrm{~kJ} \cdot \mathrm{mol}^{-1}$, respectively and the two-step model was 289 deemed to fit the torrefaction process well. Ren et al. [56] also reported a comparison of the 290 pyrolytic decompositions of raw and torrefied biomass using a one-step, first order model and it 291 was found that biomass which had undergone severe torrefaction were more likely to undergo 292 multi-step pyrolysis. 
293 Bates et al. [57] have reported a detailed one-dimensional model for the heat transfer, mass

294 transfer, chemical kinetics and drying for the torrefaction of a single particle of woody biomass;

295 a model which has been based on measured and/or previously determined characteristics from

296 literature (for beech and willow) as opposed to utilising fitting parameters. Solved using

297 MATLAB, it was reported that the model could accurately describe the torrefaction process in

298 terms of the thermal behaviour, the residual mass and the initial energy yield of raw single woody

299 biomass particles. Gul et al. [59] have reported a similar methodology to incorporate kinetic,

300 volatile species release model and average solid composition models, but applied to beech, pine,

301 wheat straw and willow.

302 Klinger et al. [58] conducted their aspen torrefaction experiments between 260 and $300{ }^{\circ} \mathrm{C}$ (at

$30310{ }^{\circ} \mathrm{C}$ intervals) for a period of 90 minutes in a micro-pyrolysis unit with the released volatiles

304 analysed with a gas chromatograph (GC) and quadrupole mass spectrometer (QMS) to determine

305 a mass normalized intensity, i.e. the MS signal divided by the initial mass of aspen. The reported

306 model was comprised of a consecutive 3-step degradation which was deemed to be representative

307 of the early stages of torrefaction (i.e up to $30 \%$ weight loss). This 3 -step degradation model was

308 found to accurately predict gas phase product kinetics, with water evolving initially and organic

309 compounds evolving later on. An Arrhenius correlation was observed for this reaction model and

310 so pre-exponential factors and activation energies were determined for the three steps.

311 It should be noted that there is no consensus in terms of the kinetics reported in any of the

312 torrefaction studies, but given that different wood species were studied, from different

313 geographic locations and with no accounting for seasonal variations for harvesting, this is not

314 unexpected.

315 Steam explosion has been used to produce pellets with increased bulk density and higher

316 mechanical strength by activating the lignin and changing the cellulose structure to enhance the 
317 binding within the biomass $[22,64]$. Lam et al. utilised drying and size reduction prior to the 318 steam explosion of Douglas-fir which was conducted at 200 and $220{ }^{\circ} \mathrm{C}$ for 5 minutes in a $1 \mathrm{~L}$ 319 high-pressure steam vessel [64]. Tooyserkani et al. [65] used conditions of similar severity $320\left(220^{\circ} \mathrm{C} ; 5\right.$ mins $)$ for Spruce, Douglas-fir and Pine. Wojtasz-Mucha et al. conducted a mild steam 321 explosion on Norway spruce at $150^{\circ} \mathrm{C}$ for 15 and $30 \mathrm{~min}$ [66]. Significantly, the steam explosion method was found to improve the calorific value [65]. Higher performance of steam explosion was observed when high temperature was used for short durations and conversely at low temperatures for longer periods [67].

325 There are limited kinetic studies associated with a steam explosion, though Lam et al. [68] have 326 reported a kinetic model using ordinary differential equations (and solved in MATLAB) for the 327 pseudo-lignin formation during the steam explosion of aspen wood.

328 Steam explosion is also used as a biomass pre-treatment to aid the optimisation of other processes 329 including anaerobic digestion [69, 70] and bio-refinery applications [71-73]. Steam explosion 330 can be enhanced with the addition of catalysts (e.g. acids) in order to improve hemicellulose 331 recovery and/or the enzymatic hydrolysis [67]. The addition of any catalyst, however, tends to 332 increase costs and so would only really be feasible in instances of higher grade use of the pellets 333 than combustion.

334 Jung and Kruse [74] have taken an Arrhenius-type approach of the previously reported 335 coalification model proposed by Ruyter [75] to evaluate the kinetics of HTC based on an 336 extensive range of HTC experimental data from the literature, which has included various 337 feedstocks including woods such as fir, poplar, pine, massaranduba and garapa [76-78]. The 338 approach calculates carbon content, oxygen content and hydrochar mass yield and it was reported 339 that the modelling is accurate enough to make predictions on the hydrochar yield. 
340 Reza et al. [79] have reported an Arrhenius-type kinetic model based on their own experiments

341 of HTC of loblolly pine. For the reported method, it is important to have accurate structural

342 compositions of the biomass (cellulose, hemicellulose, lignin, and water extractives). A two-

343 chamber reactor was used for the HTC which was studied at 200,230 , and $260{ }^{\circ} \mathrm{C}$ and weight

344 loss measurements taken at 11-time points in the 0-30 mins interval. While all treatments resulted

345 in biochar with improved higher heating values, the higher temperature HTC processes achieved

346 greater improvements. It has been determined that the HTC process proceeds via two parallel

347 first order reactions; cellulose degradation (activation energy of $73 \mathrm{~kJ} \cdot \mathrm{mol}^{-1}$ ) and hemicellulose 348 degradation (activation energy of $30 \mathrm{~kJ} \cdot \mathrm{mol}^{-1}$ ).

349 There are various studies which have reported the kinetics of the combustion of woody biomass.

350 While the studies discussed below are mostly focused on directly harvested wood and primary

351 by-products, it should be noted that there are many other examples in the literature, including for 352 different grades of waste wood [80] and reclaimed wood from used furniture [81, 82].

Fang et al. [83] reported a kinetic model for the two-stage combustion of red pine (as well as corn straw, Bermuda grass and bamboo). TGA was utilised to study the combustion characteristics in the temperature range from $80-815^{\circ} \mathrm{C}$ at a heating rate of $30{ }^{\circ} \mathrm{C} \cdot \mathrm{min}^{-1}$. Ignition of each of the samples occurred in the region of $250-280{ }^{\circ} \mathrm{C}$ and burnout in all cases was $\sim 520^{\circ} \mathrm{C}$.

357 As with the studies discussed previously herein, the first order Coats-Redfern method was used to calculate the activation energies, although a poor linear correlation was observed. Three steps in the process were observed; drying, pyrolysis and char combustion. A two-stage reaction

360 kinetic model (for the pyrolysis and char combustion) was based on the experimental data and

361 then was used to model the global process using weighted averages. The kinetics of the overall

362 process were deemed to be very similar to the pyrolysis stage observed during the TGA. As this is the stage where the greatest mass loss was observed and so it is perhaps not surprising that this 
364 would be a rate-limiting step as is indicated in the $\sim 1 \%$ variation between the activation energies 365 of the global process and the pyrolysis.

366 Other kinetic analysis studies of biomass combustion also used TGA but have applied the Coats-

367 Redfern approach. Álvaro et al. determined that this was the most appropriate approach for the 368 kinetic analysis of biomass combustion from their studies on woody biomass such as apple tree, 369 eucalyptus tree and chestnut tree (along with other biomass) [84]. Importantly it was reported 370 that Flynn-Wall-Ozawa and KAS model-free methods were not suitable approaches to employ 371 to study the kinetics of biomass combustion since the assumptions of these two methods are not 372 applicable for the entire range of combustion conditions which are observed for biomass 373 combustion.

374 Yorulmaz et al. [85] have reported the combustion kinetics for pine, medium density fibre 375 (MDF), particle board and plywood. Applying TGA in the temperature range of $30-900{ }^{\circ} \mathrm{C}$, the 376 thermal kinetics of the samples were studied at three different heating rates; $10^{\circ} \mathrm{C} \cdot \mathrm{min}^{-1}$, $37720{ }^{\circ} \mathrm{C} \cdot \mathrm{min}^{-1}$ and $30{ }^{\circ} \mathrm{C} \cdot \mathrm{min}^{-1}$. The Coats Redfern approach for the determination of kinetic 378 parameters was used to calculate activation energies and pre-exponential constants. Results were 379 compared with similar studies in the literature [86-92].

380 In summarising, Yorulmaz et al. [85] identified three regions of thermal degradation that were 381 observed during the course of the experiments: moisture and highly volatiles removal, 2) 382 volatiles oxidised and removed 3) residual char oxidised. Given that three of the samples were 383 treated (MDF, plywood and particle board) that are typically used in construction, it is important

384 to note that the treatments resulted in the materials being less combustible than the untreated 385 wood (pine). Furthermore, it was observed that the oxidation mechanisms of the treated woods 386 were modified by the additives and glues. 
387 Wang et al. [93] studied combustion of sawdust (as well as cornstalk, rice straw, rice hull) using thermogravimetric analysis from ambient conditions up to $850{ }^{\circ} \mathrm{C}$ using various ramp rates $(10$, $\left.20,50{ }^{\circ} \mathrm{C} \cdot \mathrm{min}^{-1}\right)$, with weight loss plotted as a function of temperature and the kinetic parameters

390 for the volatile combustion stage and fixed carbon burning stage were obtained. Coats-Redfern 391 plots were also used to determine activation energies and frequency factors. Of all the samples 392 studied, the sawdust was found to have the lowest combustion reactivity. While combustion of this material could be considered a low-grade use, for this reason, it has been reported that when there is a significant amount of such material readily available, such as the sawmills in the Amazon, that there is a great potential for combustion for electrical production [94]. There is some advantage, therefore, in combustion of woody biomass to produce "bioenergy" as it has also been shown that compared to non-woody materials (e.g. fossil fuels), the greenhouse gas emissions can be lower when woods are used [18], while some industries, such as wine production, can become more profitable by using their own residual biomass as a fuel [95]. It should be noted that, in the spirit of the circular economy, that the residual char/ash left after combustion can also have further use as catalysts/filters/scrubbers [96-98].

402 Dhahak et al.[99] recently studied the thermochemical behaviour of three types of woody biomass (oak, fir and beech). They developed a kinetic model (Biomass Pyrolysis and Oxidation

404 (BioPOx)) which involved 710 species and included 5035 reactions. They also claimed that 405 BioPOx can predict results obtained from different experimental setup systems such as fluidized 406 bed, tubular, jet-stirred reactor and closed ampoule along with various operating conditions such as temperature and pressure. Kim et al.[100] applied the multi-Gaussian distributed activation energy model (DAEM) and Kissinger equation to obtain the kinetic parameters of wood pellets

409 thermal decomposition. The calculated Ea for each wood pellet component was 182, 191 and $410203 \mathrm{~kJ} \cdot \mathrm{mol}^{-1}$ for hemicellulose, cellulose and lignin, respectively. 


\subsection{Herbaceous biomass}

412 Herbaceous biomass usually contains components such as seeds, cones, leaves and stems that

413 require further size reduction (as described above in section 3.1) as a post-harvest handling

414 procedure to increase the bulk density of the biomass, thus facilitating its storage and

415 transportation alongside increasing the surface area, hence, increasing the chemical process

416 reaction rate [101]. As discussed previously, size reduction methods such as the grinding process

417 require energy. Naimi et al. [101], studied the required energy input for five herbaceous biomass

418 (miscanthus, wheat straw, switchgrass, corn stover and canola straw) and found out that it was

419 in the range of $22-35 \mathrm{kWh} \cdot \mathrm{t}^{-1}$ at a lab scale while using an industrial grinder showed a required 420 energy input of $59.4 \mathrm{kWh} \cdot \mathrm{t}^{-1}[102]$.

421 The torrefied biomass or biochar derived from the thermal conversion of biomass is not classified as biomass according to the current European regulations, thus it cannot replace biomass in the energy production from renewable feedstocks [103].

424 Herbaceous biomass such as miscanthus is typically characterised based on its silica and 425 inorganic contents. These components cause various problems during the thermal decomposition 426 via valorisation and melting of the low potassium silicates compounds. While in the case of woody biomass this problem is less noticeable due to the low alkali and Si content in the biomass [104]. Thus, herbaceous biomass is usually mixed with other other woody fuel or coal to harness the energy inherent in these types of biomass. Furthermore, the high ash content in the

430 herbaceous biomass is problematic as it catalyses the thermochemical reactions and affects the 431 yield of the pyrolysis products and their subsequent composition as well [105]. Forbes et al. studied the physicochemical characteristics of eight different biomass fuels such as pine, spruce, brash, Wr (riddled willow), Ws (open air dried chipped willow), miscanthus and commercially

434 available wood pellets. They reported that the standard wood pellet fuel showed the best 435 combustion performance while miscanthus showed the largest clinker formation due to the 
highest ash content [106]. Biomass-coal co-firing has been shown to diminish the dangerous

437 greenhouse gas emissions and particulates derived from the coal-fired power plants. However,

438 due to the low bulk, low energy density and wet nature of biomass along with the seasonal 439 availability, it makes it a more challenging process. Co-HTC (miscanthus-coal) showed

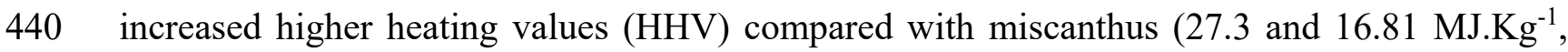
441 respectively). While it decreased regarding the pure coal, due to the low mass density with HHV 442 of $28.10 \mathrm{MJ} \cdot \mathrm{Kg}^{-1}[23]$

443 It is well known that the main drawbacks of utilising biomass in energy applications are the 444 moisture content along with low HHVs. Thus, different pretreatments could be applied to 445 decrease the moisture content and increase the HHV such as DT as well as the aforementioned 446 HTC. Recently, Wu et al. prepared charcoal briquettes from different types of biomass wastes 447 using HTC and DT in a temperature range of $200-260{ }^{\circ} \mathrm{C}$, followed by a carbonisation process at $400{ }^{\circ} \mathrm{C}$. The results showed that the mass density and the compressive strength of the charcoal briquette prepared by the HTC are better than that of the DT method [21].

450 It is worth noting that biomass waste materials can be considered as challenges and opportunities at the same time. For instance, byproduct of $\mathrm{AD}$ in the form of digestate is rich in nutrients and can be recycled into fertilizers and pelletized for energy applications (combustion). There is a need to regulate digestate since it generates chemical oxygen demand, pathogens and other hazardous materials that can pollute the water [107]. In general, raw digestate contains up to 80 wt.\% water content with a low bulk density which is problematic in storage, transportation and utilisation [108]. Thus size enlargement process (granulation) increases its bulk density, reduce the water content and enhance its flowability [108].

458 Emission control should be taken seriously in the case of using biomass in combustion engines as the gaseous and particulate emissions could be of potential risk to the environment and health.

460 Those emissions could travel deeply into the respiratory tract [109]. 
461 The thermal degradation and the kinetic parameters during the combustion of Arundo donax and

462 miscanthus giganthus was performed to quantify the gaseous and particulate emissions during

463 the combustion. The results revealed that the thermal degradation of miscanthus giganthus was

464 higher than that of Arundo donax, while the gaseous emissions along with the particulate matter

465 of both were comparable. The miscanthus giganthus particulate emissions showed a value of 1.8

$466 \times 10^{13}$ particles. $\mathrm{g}^{-1}$, while the dominant gaseous emissions were observed for $\mathrm{CO}_{2}, \mathrm{CO}$ and VOC

467 (volatile organic compound) with a value of $26.8 \mathrm{mmol} . \mathrm{g}^{-1}$ [109].

468

\subsection{Other types of biomass}

470 Species of seaweed are conventionally characterised by their physical colour. The contents of organic based constituents such as carbohydrates, fats and proteins vary considerably in different types and species of seaweeds [110]. For instance, brown seaweed is very rich in carbohydrates with its protein content is relatively low, whereas approximately $33 \mathrm{wt} . \%$ of red seaweed is protein [111]. This feature of brown seaweeds may be useful in carbonisation based processes since carbohydrates can produce volatile gaseous compounds, as well as some char in the pyrolysis/carbonisation processes.

477 Phaeophyta or "brown seaweed" as it is more commonly known, is the most common type of seaweed. Mannitol, fucoidan, laminarin and alginic acid are the main building blocks of this particular type of seaweed $[112,113]$. Conventionally, seaweed is classed as unsuitable for thermochemical conversions such as combustion and gasification unless pre-treatments are carried out or the application is carried out in conjunction with a co-existing feedstock. It is the 482 inorganic matter that is contained within the seaweed that gives rise to some problems. Typically, 483 this will lead to a higher variation in ash-forming elements, ash content and high levels of salts 484 (e.g. sodium chloride) compared to other fuel sources available such as coal or diesel. The 
combination of high $\mathrm{Na}$ and $\mathrm{Cl}$ concentrations promote the risk of alkali chloride-related operational problems [114]. There are several studies reporting on the complex ash composition that arises from seaweed-based feedstocks [115-117]. For example, compared to land-based biomass, the composition of seaweeds are heterogeneous with high concentrations of ash489 forming elements, higher ratios of $\mathrm{Na} / \mathrm{K}$ and $\mathrm{Mg} / \mathrm{Ca}$ and higher $\mathrm{Cl}$ contents. These higher 490 concentrations can be explained by the region and environment in which the biomass grows (i.e. sea water). Characterisation for this type of biomass and its ash content is extremely important because numerous problems (fouling, deposit formation or slagging) can arise when using as a fuel application. These problems will likely cause a financial and time burden in the form of

494 potential shutdowns of apparatus or there being substantial periodical maintenance required. In 495 most cases, seaweeds require a pre-treatment step prior to utilization, and washing/leaching with 496 water or weak acids are the most common practice to remove mineral matter and halogens [116].

497 Looking at the fuel fingerprints from Skoglund et al. [115] of both the raw and washed seaweed, 498 elemental composition of $\mathrm{K}, \mathrm{Na}, \mathrm{Mg}, \mathrm{P}, \mathrm{S}, \mathrm{Cl}$ all lowered when washed. $\mathrm{Cl}$ showed the most 499 significant loss out of all of these problematic elemental species, while the Ca composition nearly 500 doubled.

501 Skoglund et al., therefore, proposed a washing procedure of seaweed that was used to remove 502 alkali chlorides which enabled seaweed use in combustion [115]. This washing procedure 503 directly affected the fuel by reducing the ash content from 45.7 to 35.9 wt.\% and increasing the

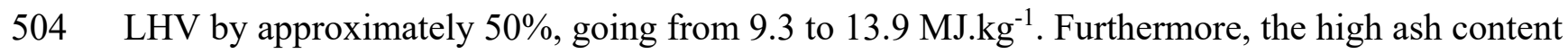
505 of washed seaweed (35.9 wt.\%) suggests that adding seaweed to a fuel blend (even at low blend 506 ratios) will have a large impact on the total ash composition.

507 Using a fuel design approach, a composition of seaweed with Ca-containing bryozoans was 508 combined with miscanthus to avoid issues related to alkali-silicate melt formation during 
combustion. In the combustion experiments, the $\mathrm{Ca}$ from the seaweed was found to be more

510 efficient than a mineral-based $\mathrm{CaCO}_{3}$ additive to prevent the ash melting problems. Besides the

511 synergetic co-combustion with miscanthus performed here, this approach opens the possibility

512 for system integration advantages such as a thermochemical step in future algal-based 513 biorefineries.

514 One prevalent advantage of utilising aquatic biomass such as seaweeds is that it has higher

515 photosynthetic efficiency and faster growth rate in comparison to terrestrial land-based biomass.

516 On average, the photosynthetic efficiency of aquatic biomass changes in the range of $6-8 \%$ while

517 that for terrestrial biomass varies between 1.8 and $2.2 \%$ [118].

518 Ross et al. have noted that the char yield from the slow pyrolysis/carbonisation of macro-algae

519 should not be neglected and should be utilised $[116,119]$. The abundance of alkali metals in the 520 biomass directly affects the char yield as it alters the pyrolysis mechanism as reported by Ross 521 et al. themselves elsewhere [111].

522 Such marine biomass accumulates considerable amounts of heavy metals since they act as a sink for such pollutants; the naturally occurring biosorption properties of seaweed contributes to this 524 accumulation [120].

Haykiri-Acma et al. published a study on the production of bio-briquettes from carbonised brown seaweed. The carbonisation process was conducted at temperatures up to $900{ }^{\circ} \mathrm{C}$, with a heating

527 rate of $10{ }^{\circ} \mathrm{C} \cdot \mathrm{min}^{-1}$ in a nitrogen-based atmosphere. The residue that was left over was then 528 pressed in a steel mould using a hydraulic press at a pressure of $187 \mathrm{MPa}$ with a mixture of 529 different binding agents. Thermal analysis of brown seaweed indicated that both carbonisation 530 and combustion are multi-step reactions in which different mechanisms occur and govern the 531 mass losses and heat flow properties because of the complex structure of this particular type of 532 biomass species. Carbonisation of seaweed eliminated the majority of the volatile matter, leading 
533 to subsequent increases in calorific value, fixed carbon and ash content. Furthermore, thermal

534 reactivity and exothermic characteristics during the combustion of seaweed were also affected

535 positively by the carbonisation process. Thus, the carbonisation technique improved the fuel

536 quality of the parent material. Briquetting of the carbonised sample with some binding agents

537 such as sulfide liquor, molasses, and Linobind yielded briquettes that are highly durable against

538 the impacts of compressibility. However, the falling stability of the briquettes was found to be

539 intimately dependent on the type of the binder. The addition of molasses provided very high

540 values of falling stability, while sulfide liquor was deemed to be an unsuitable binder for this

541 particular application. Additionally, the water resistance of the produced briquettes was not good

542 and so they should be prevented from any close interaction with water.

543 Bae et al. looked at bio-oil resulting from the pyrolysis of three species of seaweed: two brown

544 (Laminaria japonica and Undaraia pinnatifida) and one red (Porphyra tenera) in a temperature

545 range of $300-600^{\circ} \mathrm{C}$ with an unspecified heating rate and left for one hour [110]. An acid washing

546 pre-treatment phase was selected to reduce the ash content. The optimum temperature for

547 maximum production of bio-oil was at $500{ }^{\circ} \mathrm{C}$ with the yield varying from $37.5-47.4 \mathrm{wt} . \%$. The

548 Porphyra type produced the maximum amount of bio-oil. C1-C4 hydrocarbons were found to

549 increase after $400{ }^{\circ} \mathrm{C}$. The resultant bio-oil constituents were different for each type of seaweed

550 tested. Bae et al. have suggested that this bio-oil be used for fine chemical upgrading or as a

551 precursor, as the high nitrogen content does not look attractive for the prospects as a fuel.

552 Looking at the AD potential of brown seaweed, Tabassum et al. tested five different types and 553 concluded that the highest biomethane potential (BMP) was 286 L.CH4.Kg. VS ${ }^{-1}$ from L. digitate 554 and the lowest BMP of the five types was L. hyperborean with 118 L.CH4.Kg.VS ${ }^{-1}$. The specific 555 yield per net weight of the brown seaweed was found to be $10-32 \mathrm{~m}^{3}$ [121]. Of the different 556 selective regions of the seaweed strain, the frond was deemed to be the most significant and 557 suitable region for biogas production from brown seaweed. It should be noted that biogas 
production from seaweeds has been previously reported by Ross et al. to be more expensive than terrestrial biomass [111].

560 Cassava (Manihot esculenta) is extensively grown in countries such as Columbia and Indonesia as one of the major staple food resources and a multipurpose agro-industrial crop. Since cassava peel contains cyanogenic glucosides mainly linamarin and lotaustralin, the disposal and improper handling of this waste often create an environmental burden due to the release of hydrogen

564 cyanide (HCN) from cyanogenesis activity of endogenous linamarase enzyme [122, 123].

565 In order to further predict the yield of pyrolysis products from slow pyrolysis and compare with 566 that of fixed-bed reactor experiments, a mechanistic-based model was designed. This was an 567 adaption of a model originally developed by Van de Velden et al. [124]. The model was found 568 to give good accuracy at predicting the pyrolysis products over the temperature range of 400$600{ }^{\circ} \mathrm{C}$ producing a mean squared error of $0.49,16.34$ and 13.37 for gas, bio-oil and char, respectively. The overall bio-oil yield from the slow pyrolysis process of cassava peel was found to be $38.7-51.2 \mathrm{wt} . \%$, with the optimum yield of $51.2 \mathrm{wt.} \%$, corresponding to a temperature of

$572525{ }^{\circ} \mathrm{C}$. Above this temperature, the yield was found to decrease and this was attributed to 573 secondary thermal cracking. The resultant bio-oil properties satisfied all the ASTM D7544 standard requirements which suggest that bio-oil coming from the pyrolysis of cassava peel could be used as a resultant bio-fuel.

576 Alternatively, there is potential to produce activated carbon from cassava peel. The main 577 application of activated carbon adsorbents is to purify and separate gas/liquid mixtures [125, 578 126]. Sudaryanto et al. [127] conducted a study where high surface area activated carbon was 579 prepared from cassava peel by chemical activation using $\mathrm{KOH}$ as an activating agent. Different 580 impregnation ratios, carbonisation time and temperature were all studied to determine how this would affect the pore characteristics and surface chemistry of the cassava peel feedstock. It was 
582 found that carbonisation time had little effect in the yield or pore characteristics of activated 583 carbon, but, the carbonisation temperature had an important effect on the yield. Carbonisation 584 temperature of $450{ }^{\circ} \mathrm{C}$ produced the highest yield out of the four temperatures used (450, 550, 585650 and $750{ }^{\circ} \mathrm{C}$ ). Increasing the carbonisation temperature from $450-650{ }^{\circ} \mathrm{C}$, increased both the 586 micropore and total pore volume. Above $650{ }^{\circ} \mathrm{C}$, promotion of a higher total pore volume and a 587 lower micropore volume occurred [127]. This is due to the surface metal complex promoting 588 further carbon gasification leading to a widening of the micropores to increase in size to become 589 mesopores as described by Ganan et al. [128]. Furthermore, it was deduced that increasing the 590 impregnation ratio decreased the overall yield of activated carbon. At lower impregnation ratios, 591 the structure of the activated carbon consisted mainly of micropores and increasing this led to 592 the creation of mesopores due to widening [127].

593 Moreno-Piraján further extended this research by preparing activated carbon from cassava peel 594 and studying the adsorption of copper from aqueous solution. Instead, the activation was carried 595 out using zinc chloride. It was determined that it was possible to gain surface areas as high as $5961567 \mathrm{~m}^{2} \cdot \mathrm{g}^{-1}$ and pore volumes as large as $1.18 \mathrm{~cm}^{3} \cdot \mathrm{g}^{-1}$ [129]. The trend on impregnation ratio 597 was the same as Sudaryanto et al. in that as it increased, this promoted more mesopores [127]. 598 The sorption capacity of activated carbon of cassava peel to uptake copper ions was determined 599 to be $55 \mathrm{mg} \cdot \mathrm{g}^{-1}$ by using four different best-fit three parameter isotherms Vieth-Sladek, Toth, 600 Sips and Radke-Prausnitz [129]. This was found to be more than fives times the sorption capacity 601 for uptake of copper ions of activated charcoal [130]. It was also close to the sorption capacity 602 of Humic acids and bark pine pulp at 51.47 and $45.2 \mathrm{mg} \cdot \mathrm{g}^{-1}$, respectively [129, 131]. Interestingly, Kosasih et al. took a different approach and looked at the sequestering of $\mathrm{Cu}^{2+}$ 604 using cassava peel as a standard biosorbent. The biosorption process was carried out isothermally 605 at three separate temperatures $\left(30,45\right.$ and $\left.60{ }^{\circ} \mathrm{C}\right)$. The metal binding occurred between the 606 functional groups located on the cassava's surface and the $\mathrm{Cu}^{2+}$ ions. The biosorption process 
607 was found to be $\mathrm{pH}$ dependent, which is in agreement with what was reported by Ekmekyapar et

608 al. [132]. The optimum $\mathrm{pH}$ was determined to be 4.5 and the thermodynamic parameters suggest

609 that the biosorption process is completely irreversible, endothermic and spontaneous. The

610 maximum adsorption capacity was found to be $41.77 \mathrm{mg} \cdot \mathrm{g}^{-1}$ which was obtained at $60{ }^{\circ} \mathrm{C}$ [133].

611 Kurniawan et al. in a similar work studied the sequestering of $\mathrm{Ni}^{2+}$ using cassava peel as a

612 standard biosorbent. The biosorption process was carried out isothermally at three separate

613 temperatures $\left(30,45\right.$ and $\left.60{ }^{\circ} \mathrm{C}\right)$, respectively. Again, the optimum $\mathrm{pH}$ was determined to be 4.5

614 and the thermodynamic parameters suggest that the biosorption process is completely

615 irreversible, endothermic and spontaneous which is in agreement with work published by

616 Kosasih et al. [133]. The Sips model was found to demonstrate the best fitting with the maximum

617 uptake of $\mathrm{Ni}^{2+}$ ions with a maximum sorption capacity of $57 \mathrm{mg} \cdot \mathrm{g}^{-1}$ for $\mathrm{Ni}^{2+}$ ions [134]. This was

618 found to be approximately six times higher than the sorption capacity of orange peel (9.82 $\mathrm{mg} . \mathrm{g}^{-}$

$619^{1}$ ) as reported by Feng et al. [135]; subsequently, this was still lower than the sorption capacity

620 of pomegranate peel (69.4 mg. $\left.\mathrm{g}^{-1}\right)$ reported by Bhatnagar et al. [136].

621 Moshi et al. [137] looked at multiple scenarios as to what was the best way to harness the energy

622 inherent within the cassava peels. The pre-treatments used in their study were alkali, enzyme and

623 a combination of one another for the production of bioethanol or biogas, or both. The study

624 showcased that wild cassava peel can be upgraded into both biogas and ethanol concurrently.

625 This resulted in a higher fuel energy value compared to the option of separate processes. Alkali 626 combined with enzyme pre-treatment was proven to be the best method, indicating a $56 \%$

627 improvement in methane yield for the AD process compared to the untreated counterpart. The 628 combined methane and ethanol production resulted in 1.2-1.3 times the fuel energy yield 629 compared to the generation of sole methane and 3-4 times the fuel energy yield compared to 630 solely ethanol production [137]. Adekunle et al. reviewed ways in which to produce bio-ethanol 631 from cassava peels and provided a design conceptualisation. It was their suggestion that although 
632 some challenges occur to the industrialisation of any given process, the best case scenario would

633 be to integrate directly with the petrochemical industry to ensure proper blending of the bio-

634 ethanol into biofuel and ensure profitability [138]. They also suggested the potential co-

635 production of ethanol/biogas with the biogas part contributing to power generation, in agreement

636 with Moshi et. al. [137] had published earlier.

637 In the local western world demographic, coffee plays a majour role in the global economy. It has

638 been said to be the second most traded commodity in the world after oil [139]. Spent coffee

639 grounds (SCG) contain polysaccharides, oligosaccharides, lipids, aliphatic acids, amino acids,

640 proteins, alkaloids (e.g., caffeine, trigonelline) and phenolics, minerals, lignin, melanoidins and

641 volatile compounds [140-142].

642 One issue with utilising spent coffee grounds (SGC) as a fuel type is the energy or time required

643 to dry the feedstock as the raw form is approximately $65 \%$ moisture. Kang et al. conducted a

644 study using SCG as a fuel in a $6.5 \mathrm{~kW}$ combustion boiler after drying SGC for 2 days to lower

645 the moisture content to less than $15 \%$. The combustion process consumed $1.17 \mathrm{~kg}$. $\mathrm{hr}^{-1}$, was able

646 to heat up $40 \mathrm{Kg}$ of water from 9 to $78{ }^{\circ} \mathrm{C}$ in 146 minutes. The $\mathrm{O}_{2}, \mathrm{CO}$ and $\mathrm{NO}_{\mathrm{x}}$ concentrations

647 were measured to be $17.8 \%, 643$ and $163 \mathrm{ppm}$, respectively. Although the $\mathrm{O}_{2}$ concentration of

648 the flue gas was higher than a conventional domestic gas boiler, it was noted that these emissions

649 could be lowered with further optimisation of the fuel boiler design to suit this type of feedstock $650 \quad[143]$.

651 Looking at the activated carbon made from SCG, Jutakridsada et al. [144] produced activated 652 carbon with a fixed pyrolysis heating rate of $10^{\circ} \mathrm{C} \cdot \mathrm{min}^{-1}$ for $4 \mathrm{hrs}$. SCG was chemically activated 653 using $\mathrm{ZnCl}_{2}$ and there were three concentrations (5, 10 and 15 wt.\%), three impregnation times $654(8,12$ and $24 \mathrm{hrs})$ and three carbonisation temperatures $\left(400,450\right.$ and $\left.500{ }^{\circ} \mathrm{C}\right)$ tested in the 655 particular study. The optimum concentration, impregnation time and temperature were found to 
be $15 \mathrm{wt} . \%, 24 \mathrm{hrs}$ and $500{ }^{\circ} \mathrm{C}$, respectively. This led to an average specific surface area and average pore volume of $831 \mathrm{~m}^{2} \cdot \mathrm{g}^{-1}$ and $0.44 \mathrm{~cm}^{3} \cdot \mathrm{g}^{-1}$, respectively. The adsorption capacity of $\mathrm{Cu}^{2+}$ was $18 \%$ removal with 100 ppm of $\mathrm{CuSO}_{4}[144]$.

Babu et al. studied the removal of lead and fluoride from contaminated water sources using exhausted coffee grounds. The biomass was firstly acid activated by adding to $\mathrm{HCl}$ and boiled for 2 hours. They then created synthetic wastewater by adding lead nitrate and sodium fluoride.

662 The maximum adsorption capacity for the lead was found to be $61.6 \mathrm{mg} \cdot \mathrm{g}^{-1}$ at $\mathrm{pH}$, dosage $6630.15 \mathrm{~g} .100 \mathrm{~mL}^{-1}$, time of $75 \mathrm{~min}$., the temperature of $303 \mathrm{~K}$ for an initial concentration of 100 $\mathrm{mg} \cdot \mathrm{L}^{-1}$. The maximum adsorption capacity for fluoride was determined to be $9.05 \mathrm{mg} \cdot \mathrm{g}^{-1}$ at $\mathrm{pH}$ 4, dosage $0.2 \mathrm{~g} .100 \mathrm{~mL}^{-1}$, time of $105 \mathrm{~min}$., the temperature of $303 \mathrm{~K}$ for an initial concentration of $20 \mathrm{mg} . \mathrm{L}^{-1}$. The kinetics for removal of both these species follows the pseudo-second-order model and the adsorption behaviour follows the Langmuir isotherm model [145].

Liu et al. conducted a study in which SCG biochar was prepared by $\mathrm{CO}_{2}$ sequestration at $400{ }^{\circ} \mathrm{C}$ under a nitrogen flow rate of $100 \mathrm{~mL} \cdot \mathrm{min}^{-1}$. Three methods for the ammoxidation of the biochar was tested and then chemically activated using potassium hydroxide. The $\mathrm{CO}_{2}$ sorption capacities of the three sample were found to be $2.04-2.67 \mathrm{mmol} \mathrm{CO} 2 . \mathrm{g}^{-1}$ sorbent at $35{ }^{\circ} \mathrm{C}$ under atmospheric pressure using completely dry $\mathrm{CO}_{2}$. The most successful sample was one prepared using sonication, melamine and hydrothermal treatment. This was attributed to the unique properties of the adsorbent including a highly developed microporosity as the ratio of the micropores volume to the total pore volume was approximately $82 \%$.

676 Interestingly, Chen et al. [146] proposed a method of using SCG as a co-combustion material 677 alongside sewage sludge (SS). They tested mixing ratios of $60 / 40,70 / 30,80 / 20$ and $90 / 10 \%$ of 678 SS to SCG, respectively. It was suggested that there were chemical interactions between both the feedstocks and that the impacts were mostly positive. Adding SCG promoted the mass loss 
rate and the reactivity of SS to increase and the charring of both feedstocks subsequently decreased. The activation energies were determined using the KAS and Ozawa-Flynn-Wall methods and the average values were 166.8 and $168.8 \mathrm{KJ} \cdot \mathrm{mol}^{-1}$, respectively. The lowest activation was located at SCG content $=40 \%[146]$.

Primaz et al. [147] recently looked at the influence of temperature on the yield of bio-oil from the fast pyrolysis of SCG. They produced the bio-oil at five different temperatures $(400,450$, 500,550 and $600{ }^{\circ} \mathrm{C}$ ), using a heating rate of $100{ }^{\circ} \mathrm{C} \cdot \mathrm{min}^{-1}$, a flow rate of $150 \mathrm{~mL} \cdot \mathrm{min}^{-1}$ of nitrogen and a hold time of 15 min., once the temperature was reached. The gases and oil were passed through a condenser with circulation of ice water $\left(-5^{\circ} \mathrm{C}\right)$. The maximum bio-oil yield was found to be $30.51 \mathrm{wt} . \%$ at $500{ }^{\circ} \mathrm{C}$ with the major components in the bio-oil to be palmitic acid (19\%), oleic acid (11\%) and stearic acid (10\%) [147]. This is lower than the 56.09\% reported by Luz et al. and is likely due to their use of a screw-based reactor which can optimise vapour residence times [148]. After $500{ }^{\circ} \mathrm{C}$, the bio-oil decreases and climatizes around $27 \%$.

693 The decrease in yield with increasing temperature occurs usually due to secondary side reactions of the pyrolysis vapours which contributes to the increase in gaseous product and possible decrease of other products $[149,150]$.

Recently Kim et al. [151] conducted an anaerobic co-digestion study using SCG alongside other feedstocks such as ulva, food waste, waste activated sludge and whey. For each additive, they tested a pure SCG sample and mixing ratios of $75 / 25,50 / 50,25 / 75$ and $0 \%$ SCG/100\% co-

699 feedstock. The individual feedstock's composition was saw to have a significant effect on the 700 biomethanation performance. Every co-feedstock had comparable or higher methane production rates or yields except for the waste activated sludge feedstock which showed negative impacts. The co-digestion with whey, ulva or food waste increased the reaction rate of the AD process without losses in biomethane potential. A 75/25 mixing ratio of food waste to spent coffee grounds showed the most promising results. It produced the largest biomethane potential of all 
the 69 tests. The cumulative methane production at 28 days was $0.355 \mathrm{~L} . \mathrm{CH} 4 . \mathrm{g}^{-1} \cdot \mathrm{VS}_{\mathrm{in}}{ }^{-1}$ and the methane production potential was $0.344 \mathrm{~L} . \mathrm{CH}_{4} \cdot \mathrm{g}^{-1}$.VSin. The 50/50 mix of food waste to spent coffee grounds was ever so slightly lower than this result so both mixing ratios could be deemed suitable [151].

709 Similarly, Luz et al. studied AD under mesophilic conditions at $37{ }^{\circ} \mathrm{C}$ for 22 days of the liquid

710 fraction from spent coffee grounds (SCL) mixed with cow manure and compared this with a

711 reference of pure cow manure. An inoculum ratio of 1.5 was used (g volatile solids (VS) substrate

712 per g.VS). They found that the SCL reactors showed a $\mathrm{pH}$ reduction in the first days compared

713 with the pure cow manure samples. The addition of the SCL produced more stable values for the

714 lower heating value (28.24MJ. $\mathrm{Kg}^{-1}$, as opposed to $26.30 \mathrm{MJ} . \mathrm{Kg}^{-1}$ for the pure cow manure

715 sample), biogas composition (peaks of $60 \%$ methane when SCL is used; $9 \%$ higher than the pure

716 cow manure sample) and carbon conversion efficiency (38\% higher than the pure cow manure

717 sample). SCG was indicated to have an individual contribution up to $254 \mathrm{ml} \mathrm{CH} 4 . \mathrm{g}^{-1} \mathrm{VS}^{-1}$ [152].

718 Hazelnut is Turkey's most important agricultural drop as they are one of the main producers of

719 hazelnuts in the world. Although mainly used for its fruit the shells have significant importance

720 in being a potential source of energy. The main way the shell is utilised in the Black Sea region

721 of Turkey is direct combustion for domestic purposes [153].

722 Hazelnut shells are a unique type of biomass in that they have above $40 \%$ cellulose content [154],

723 abundant hydrocarbon, low moisture and high carbon content which are appropriate to the 724 thermochemical conversion method of pyrolysis [155]. 
Table 1: The ultimate and proximate analysis of different types of biomass.

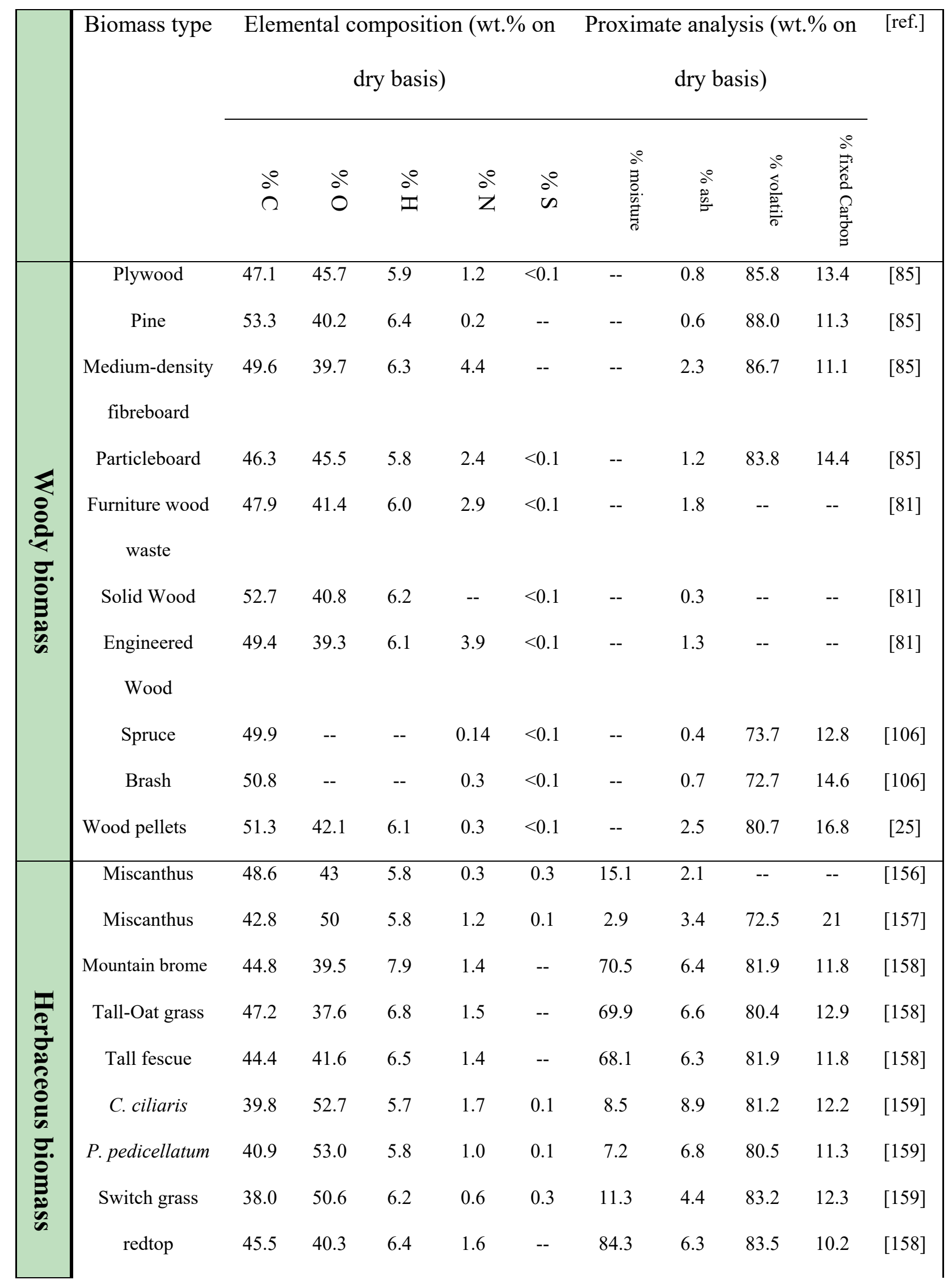




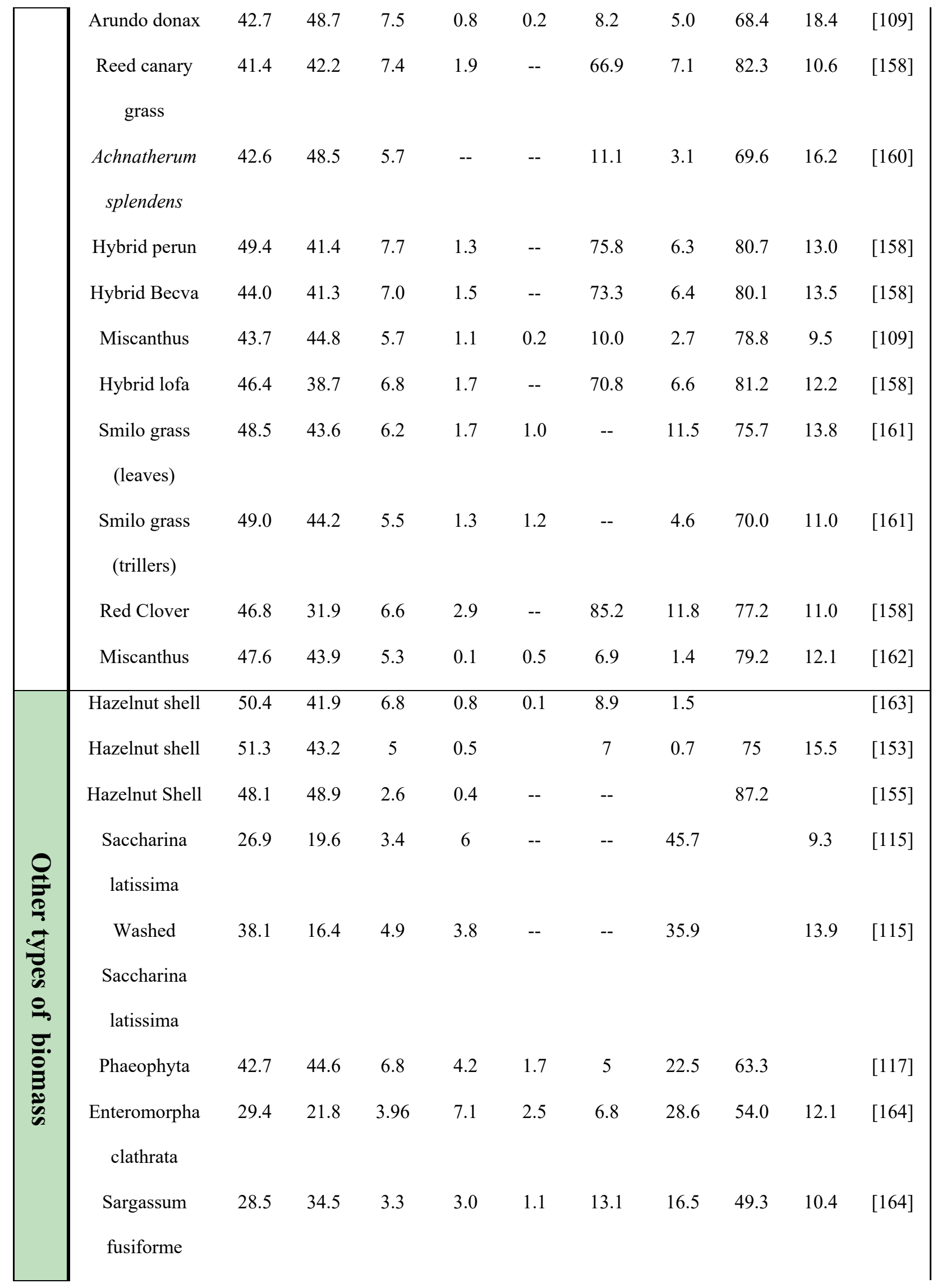




\begin{tabular}{|cccccccccccc}
\hline Cassava Peel & 53.7 & 37.9 & 7.1 & 1.2 & 0.1 & 1.8 & 2.3 & 74.5 & 17.9 & {$[123]$} \\
& & & & & & & & & & \\
Rice husk & 38.8 & 35.5 & 4.75 & 0.52 & $<0.1$ & --- & 20.3 & 63.5 & 16.2 & {$[165]$} \\
Rice husk & 37.6 & 32.6 & 4.9 & 1.9 & $<0.1$ & --- & 16.9 & 51.9 & 25.1 & {$[166]$} \\
Rice husk & 39.5 & 39.3 & 5.7 & 0.7 & 0.1 & --- & 14.8 & 68.3 & 16.9 & {$[166]$} \\
Rice husk & 38 & 32.4 & 4.6 & 0.7 & $<0.1$ & 10.3 & 14 & 55.6 & 20.1 & {$[167]$} \\
Rice husk & 53.9 & 38.8 & 6.3 & 0.98 & $<0.1$ & 9.8 & 9.9 & 64.9 & 15.4 & {$[168]$} \\
Rice husk & 38.5 & 36.6 & 5.5 & 0.4 & 0.2 & 3.6 & 16.3 & 60 & 20.1 & {$[169]$} \\
Olive solid & 57.8 & 34.4 & 7.1 & 0.7 & 0.1 & -- & 5.3 & 76.6 & 12.3 & {$[170]$} \\
waste & & & & & & & & & & \\
Goat manure & 42.1 & 39.9 & 5.6 & 1.5 & 0.1 & 8.9 & 16.8 & 70.1 & 4.18 & {$[171]$} \\
Horse manure & 43.3 & 49.2 & 5.9 & 0.9 & 0.8 & 8.2 & 10.5 & 70.4 & 11 & {$[172]$} \\
Swine manure & 33.5 & 56.7 & 6.2 & 2.8 & 0.8 & --- & 7.13 & 77.7 & 15.2 & {$[173]$} \\
\end{tabular}

729

730 Rice represents one of the most essential and important agricultural products in our life 731 nowadays and it is commercially grown in 112 countries [165]. With the increased global 732 population, the global production of rice is also expected to increase. During the harvesting of 733 rice in the fields leaves, stems and roots are obtained, leaving rice with husk (paddy). The global 734 annual production of rice reaches about 670 million tones of paddy, of which Asia produced 735 about $90 \%[174,175]$. When processing paddy in the mills, grains of rice husk, which is the 736 natural sheath surrounding the rice, are generated. The estimated annual amount of rice husk 737 worldwide is $\sim 150$ million metric tons which is approximately 20 to $33 \%$ by weight of the paddy 738 rice [176]. More than $80 \%$ of this amount of rice husk is discarded as waste, causing pollution 739 to water and soil [175]. The rice husk consists of $70-80 \%$ organic substances which includes 740 three polymer components: cellulose, hemicellulose and lignin. The remaining $20-30 \%$ of the 741 rice husk mass consists of mineralogical components such as silica, alkalis and trace elements 
742 [166]. The variations in the ratios of the rice husk's three constituents depend on different factors

743 including weather conditions, agronomic handling and type of soil [166]. Due to its low

744 nutritional value, rice husk is not suitable for feeding animals. In addition, the irregular abrasive

745 surface and the high siliceous composition of rice restricts its natural degradation; this increases

746 its potential candidate for environmental pollution through combustion and other polluting

747 processes.

748 Considering the reusing and recycling approaches of rice husk, rice husk and its char are used mainly as an energy source. In addition, ashes and char produced as a byproduct of rice husk combustion and pyrolysis can be used for the removal of heavy metals from wastewaters. Furthermore, rice husk ash has additional uses such as the use in the production of highperformance concrete. The thermochemical conversion of rice husk represents the main route for the production of energy from rice husk and can be achieved by four different technologies [28]: combustion, gasification, pyrolysis and liquefaction processes.

Pyrolysis of rice husk using solar energy was studied by Weldekidan et al. [177] to produce fuels and chemicals. A parabolic dish was used with maximum heat flux concentrating capacity of 70 $\mathrm{kW} \cdot \mathrm{m}^{-2}$ to generate pyrolysis temperatures from 500 to $800^{\circ} \mathrm{C}$ on a reactor loaded with biomass. The highest gas, bio-oil and biochar yields obtained were found to be 25.48 wt. $\%$ at $800{ }^{\circ} \mathrm{C}$, 43.13 wt. $\%$ at $700{ }^{\circ} \mathrm{C}$ and 43 wt. $\%$ at $500{ }^{\circ} \mathrm{C}$, respectively. Lim et al.[178] studied the pyrolysis

760 of rice husk using thermogravimetry and by applying the KAS method for the kinetic analysis 761 of the pyrolysis process. The results indicated that the maximum degradation rate of rice husk 762 increases from 4.42 to $21.87 \mathrm{wt} . \% \cdot \mathrm{min}^{-1}$ by increasing the heating rate of 10 to $50 \mathrm{~K} \cdot \mathrm{min}^{-1}$. 763 Furthermore, in the range of heating rates studied, the predicted values of the activation energy 764 ranged from 48.64 to $54.21{\mathrm{~kJ} . \mathrm{mol}^{-1}}^{-}$and the average value of activation energy is $51.19 \mathrm{~kJ}^{\mathrm{mol}}{ }^{-}$ 765 
766 Yoon et al. [169] studied the gasification and power generation characteristics of rice husk and 767 rice husk pellet by using a downdraft fixed-bed gasifier in a temperature range of $600-850{ }^{\circ} \mathrm{C}$, 768 fuel feeding rate of $40-60 \mathrm{~kg} \cdot \mathrm{hr}^{-1}$ and gasification agent feeding rate of $50-75 \mathrm{Nm}^{3} \cdot \mathrm{hr}^{-1}$. 769 According to the results, the gasification of rice husk pellet produces a higher heating value of 770 synthetic gas and higher cold gas efficiency than that in the case of rice husk gasification. 771 Kinetics of rice husk tar cracking was studied in a two-stage gasifier by Khonde et al. [179] at different temperatures and residence times. They found that nitrogen and air were the best as gasification media for secondary gaseous yield than other gases. In addition, hydrogen-rich syngas was produced by increasing residence time and the temperature of gasification.

The thermochemical treatment processes of rice husk have attracted considerable interest in the literature as a way for recycling, reuse and up-cycling of rice husk biomass. Madhiyanon et al. [167] studied the combustion characteristics of rice husk in a short combustion chamber fluidized bed combustor (SFBC) and successfully obtained high combustion efficiency and high heat rate intensity without the use of a secondary solid to promote fluidization. Ninduangdee et al. [168] studied the effects of co-combustion methods on gaseous emissions during the combustion of rice husk. They investigated the effects of co-firing methods and operating parameters on the emissions and combustion efficiency. They found that the proposed co-combustion methods and the operating parameters have noticeable effects on the major gaseous emissions and combustion efficiency of the combustor. In addition, the oxidation kinetics of rice husks combustion were investigated by Alias et al. [180] by using an evolved gas analysis technique. They heated rice husk samples inside a small pressurised reactor from $100-500{ }^{\circ} \mathrm{C}$ at a constant rate. A controlled flow of oxygen-containing gas was passed through the reactor where the moisture had been removed and the content of oxygen, carbon monoxide and carbon dioxide in the evolved gas was continually analysed. According to the results obtained, they proposed a model for the oxidation of the rice husks samples represented the simultaneous and competing for oxidation reactions by 
three overlapping and competing reaction regimes in which the only reaction products are $\mathrm{CO}_{2}$, $\mathrm{CO}$ and $\mathrm{H}_{2} \mathrm{O}$.

793 García et al. [170] studied the pyrolysis of the two-phase olive mill solid waste. They characterised the olive mill solid waste in terms of its physical-chemical properties. In addition, they studied the solid waste behaviour on pyrolysis processes by dynamic thermogravimetry and derivate thermogravimetry. The particle size analysis indicated that the two-phase olive mill solid waste can be used directly as solid fuel in some of the available technologies. In addition, the results indicated that calcium and potassium carbonates are the main inorganic material in the solid waste and the sulfur content is low which is important environmentally. Furthermore, the results of the proximate analysis and the gross calorific value indicated that the energy content

801 of the two-phase olive mill solid waste is sufficient to introduce it as a possible promising solid 802 fuel.

803 In a technical and economic evaluation study by Christoforou et al. [181], the competitiveness

804 of olive mill solid waste pellets against wood pellets as an energy source was examined in Cyprus 805 as an olive oil producing country. The technical analysis results indicated that olive mills solid 806 waste has a significant potential to contribute to the country's energy mix. The feasibility analysis 807 presents the competitiveness of olive mills solid waste over other commercially available pellets. 808 In addition, according to this study, the olive mills solid waste pellets could enter the energy 809 market with relatively low price and could contribute effectively in the households, industrial 810 and agricultural sectors.

811 Abdelhadi et al. [182] studied the production of biochar from olive mill solid waste for heavy

812 metal removal from water. They studied the production of biochar from olive solid waste from 813 two olive cultivars and two oil production process (two- or three-phase) at two temperatures (350 and $\left.450^{\circ} \mathrm{C}\right)$. The yield of biochar was $24-35 \mathrm{wt} . \%$ of the biomass, with a low surface area $(1.65-$ 
$\left.8158.12 \mathrm{~m}^{2} \cdot \mathrm{g}^{-1}\right)$ compared to that of commercial activated carbon $\left(1100 \mathrm{~m}^{2} \cdot \mathrm{g}^{-1}\right)$. However, the

816 biochar from olive mill solid waste shows a better performance for the removal of heavy metal

$817\left(\mathrm{Cu}^{+2}, \mathrm{~Pb}^{+2}, \mathrm{Cd}^{+2}, \mathrm{Ni}^{+2}\right.$ and $\left.\mathrm{Zn}^{+2}\right)$ with more than $85 \%$ compared to commercial activated carbon.

818 According to the results obtained, Abdelhadi et al. suggested that the surface area cannot be used

819 as a sole predictor of heavy metal removal capacity.

820 Elkhouly et al. [183] studied the feasibility of using waste date palm seeds as filler material 821 in glass-epoxy composites. The effects date seeds had as filler on the wear rate and impact energy

822 at different conditions were studied. A comparison between date seeds, silicon carbide and 823 alumina as filler was carried out from both the technical and economic perspective. The results 824 of the study indicated that the date seeds, as a filler, are less effective than silicon carbide and 825 more effective than alumina and the unfilled composite. According to the results obtained in this 826 study, the addition of $10 \%$ date seeds reinforcement to the glass fibre had improved the wear 827 resistance rate and the toughness by about 71 and $80 \%$, respectively. In a recent study by Sirry 828 et al.[184], the chemically treated date seeds were used as an adsorbent for the extraction of 829 uranium ions from wastewater, providing a good substitution for current, expensive removal 830 procedures of such pollutants. In order to improve the adsorption capacity of the date seeds, it 831 was treated with petroleum ether, hydrochloric acid, sodium carbonate, a combination of 832 petroleum ether and hydrochloric acid and a combination of petroleum ether and sodium 833 carbonate. The characteristics of the treated date seeds as adsorbents was examined at different contact times and different initial concentrations of uranium ions. According to the results of this study, Sirry et al. concluded that the date seeds treated with hydrochloric acid and the 836 combination of petroleum ether and hydrochloric acid exhibit higher adsorption capacity 837 compared to the other treated date seeds and compared to other bio-adsorbents reported in the 838 literature. El Messaoudi et al. [185] studied the removal of cationic dyes (methylene blue and 839 crystal violet) from aqueous solutions using date stones treated with sulfuric acid and sodium 
bicarbonate. The study investigated the effect of different parameters including contact time,

841 initial dye $\mathrm{pH}$, temperature and initial dye concentration on the efficiency of the adsorption

842 process of dyes by the chemically treated date seeds. The results indicated a high efficiency of

843 the chemically treated date seeds in the adsorption of the two dyes with adsorption capacities of

844515.46 and $543.47 \mathrm{mg} / \mathrm{g}$ for methylene blue and crystal violet at $50{ }^{\circ} \mathrm{C}$, respectively, and with

845 the pseudo-second-order as the suitable adsorption kinetic model. In addition, the used

846 chemically treated date stones were regenerated using nitric acid solution and performed well in

847 four repeated cycles with high efficiency in the removal of both dyes.

848 Al-Omari [186] has investigated the potential of date seeds as an energy source for furnaces

849 compared with coal. The comparison between date seeds and coal as fuels was carried out

850 according to the combustion and heat transfer characteristics obtained in a furnace fueled with

851 both fuels. According to the results obtained, the combustion and heat transfer rates per unit mass

852 of the fuel were higher in the case of date stones compared with the coal used. According to Al-

853 Omari, the higher combustion and heat transfer rates in the case of date seeds is due to its higher

854 volatile matter content and the very low ash content compared with the coal.

855 Sekirifa et al. [187] succeeded in producing activated carbon with high surface area $\left(604 \mathrm{~m}^{2} . \mathrm{g}^{-}\right.$

$85 \mathrm{r}^{1}$ ) from date seeds. The produced activated carbon was used as an adsorbent of a potent phenolic

857 derivative compound 4-chlorophenol and showed high efficiency in the adsorption process with

858 adsorption capacity of 23.25 and $28.57 \mathrm{mg} \cdot \mathrm{g}^{-1}$. Rezma et al. [188] have prepared microporous

859 activated carbon electrode from date seeds for capacitive deionisation application without the

860 use of a binder. The process involved the pyrolysis of the date seeds at a temperature of $1000{ }^{\circ} \mathrm{C}$

861 under nitrogen flow followed by physical activation of the obtained carbon monoliths at $900{ }^{\circ} \mathrm{C}$

862 under $\mathrm{CO}_{2}$ flow. The prepared activated carbon exhibited a high surface area and well-developed

863 microporosity and a good efficiency as a capacitive deionisation electrode in water treatment

864 was observed. In a study by Abbas et al.[189], mesoporous activated carbon with surface area, 
865 total pore volume and average pore diameter of $1144.25 \mathrm{~m}^{2} \cdot \mathrm{g}^{-1}, 0.656 \mathrm{~m}^{3} \cdot \mathrm{g}^{-1}$ and $3.004 \mathrm{~nm}$, 866 respectively, were prepared from date stones by one-step microwave assisted $\mathrm{K}_{2} \mathrm{CO}_{3}$ pyrolysis.

867 The efficiency of the prepared activated carbon compared to raw date stones as adsorbents for 868 the extraction of methylene blue dye was investigated. The effects of different parameters 869 including radiation time, radiation power and impregnation ratio on the yield and dye uptake of 870 the prepared activated carbon were investigated. The activated carbon prepared from date stones 871 showed high efficiency in the removal of methylene blue dye with maximum adsorption capacity 872 of $504.79 \mathrm{mg} . \mathrm{g}^{-1}$ compared to that of raw date stones $\left(256.15 \mathrm{mg} . \mathrm{g}^{-1}\right)$. The kinetic data obtained 873 in this study were fitted well with a pseudo-second-order model at different initial concentrations.

874 Animal manure is one of the most important biomass wastes produced every day all over the 875 world in staggering amounts. Animal manure consists mainly of urine and faeces in addition to 876 other constituents that may be found in manure such as bedding materials, dropped feed, scurf, 877 and other farming wastes [190]. The amount of animal manure produced annually in the 878 European Union is about 1400 million tons [191]. Disposing of manure as a biodegradable 879 product containing high levels of nutrients and pathogens will contaminate soil, air and water 880 [192]. Consequently, it is necessary to find an effective and appropriate way to benefit from these 881 huge amounts of waste without damaging the environment. The traditional use of manure is as a 882 valuable fertilizer to provide the crops with the required nutrients for growth [192]. In addition 883 to the use of animal manure as fertilizer in farming, it can be used as combustive material to 884 produce heat and electricity (recycling) or can be used as a source of biogas and bio-oil (up885 cycling) through digestion processes [193].

886 In a study by Hadin et al. [194] the feasibility and potential to produce biogas and bio-fertilizer 887 from horse manure by anaerobic digestion were analysed via a thorough literature review in 888 combination with mathematical modelling and simulations. AD represents one of the best 889 manure management methods by which both waste treatment and bio-energy production goals 
could be achieved [195]. In addition, AD has a high degree of resource conservation, both in

891 terms of energy and nutrients [194]. Due to the low carbon to nitrogen $(\mathrm{C} / \mathrm{N})$ ratio in animal

892 manures, the co-digestion of another carbon-rich substrate with the animal manures is required

893 to improve its characteristics for anaerobic digestion by increasing the $(\mathrm{C} / \mathrm{N})$ ratio [192].

894 According to Hadin et al. the characteristics of the feedstock and the type of digestion method used are strongly affected by the type and amount of bedding material used. Burg et al. [54] studied the energy and greenhouse gas emissions benefits of using animal manure in Switzerland to produce biogas by anaerobic digestion. The study concluded that considerable quantities of energy can be recovered from animal manure which will reduce the greenhouse gases emissions.

899 In addition, according to Burg et al., suitable and effective techniques are required to remove 900 water from the manure which will improve the energy extraction efficiency. Furthermore, the study recommended the increase in local availability by pooling the manure from multiple farms into a single AD facility. This will reduce the pre-storage losses which will increase the available bioenergy while decreasing greenhouse gases emissions. A spatial analysis of biogas potential

904 from manure in Europe was carried out by Scarlat et al. [196]. They carried out a study to 905 estimate the biogas potential of farm manure for the whole of Europe based on regional statistical 906 data and spatial distribution of livestock and poultry population. According to this study, the

907 amount of manure produced (wet weight) every year is about 1347 million tones throughout

908 Europe and about 1200 million tonnes in the European Union. Despite the huge amount of 909 manure produced in Europe and the European Union, only about 942 million tonnes could be 910 collected in Europe and around 861 million tonnes in the European Union [196]. The study

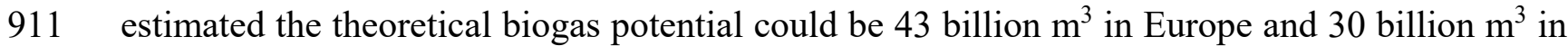
912 the European Union in comparison to 30 billion $\mathrm{m}^{3}$ in Europe and 27 billion $\mathrm{m}^{3}$ in the European

913 Union as realistic biogas potential. In addition, the study estimated the primary energy potential 914 of biogas from farm manure to be about 924 PJ in Europe of which about 639.3 PJ would be 
915 exploitable. The study developed a Geographic Information System (GIS)-based methodology

916 that can be used as decision support tool on basis of the dataset of manure and biogas potential

917 to analyse suitable locations and number of biogas plants and their capacities depending on

918 resources. The study showed the capacity of biogas plants for both constant and variable

919 collection radiuses [196].

920 In addition to anaerobic digestion, the thermochemical techniques (pyrolysis, combustion, 921 gasification and liquefaction) are of great importance as waste-to-energy techniques used for the 922 valorisation of animal manure $[19,171-173,197-206]$. The enhancement of energy production, as a form of syngas $\left(\mathrm{CO}\right.$ and $\left.\mathrm{H}_{2}\right)$, from chicken manure by pyrolysis in carbon dioxide was studied by Lee et al. [56]. The syngas $\left(\mathrm{CO}\right.$ and $\left.\mathrm{H}_{2}\right)$ is known to be used as a fuel for internal combustion engines. Lee et al. found that the $\mathrm{CO}$ production in the case of using $\mathrm{CO}_{2}$ as pyrolysis atmosphere is higher than that in the case of using $\mathrm{N}_{2}$. In addition, the CO production was also increased by the existence of $\mathrm{CaCO}_{3}$ in both in $\mathrm{N}_{2}$ and $\mathrm{CO}_{2}$ atmospheres which means that the catalytic effects of $\mathrm{CaCO}_{3}$ on the pyrolysis could act together with the influence of $\mathrm{CO}_{2}$ in enhancing the $\mathrm{CO}$ production.

The results of this study showed the feasibility of pyrolysis as an effective waste-to-energy process that recovers energy from chicken manure. In addition, this study represents an approach for utilising $\mathrm{CO}_{2}$ gas as a potent greenhouse gas. Pyrolysis of goat manure to produce bio-oil was studied by Erdogdu et al. [171] within the temperatures range $300-600{ }^{\circ} \mathrm{C}$ to investigate the

934 feasibility of using goat manure as a source of energy or as a raw material for chemical 935 production. The effect of changing the pyrolysis temperature within the $300-600{ }^{\circ} \mathrm{C}$ on the solid, 936 liquid and gas product distributions was studied. According to the obtained results, the maximum non-condensable gas yield (33\%) was obtained at $600{ }^{\circ} \mathrm{C}$ and the maximum bio-char yield (48.6\%) was obtained at $300{ }^{\circ} \mathrm{C}$. In addition, the maximum bio-oil yield (26.1\%) was obtained at $500{ }^{\circ} \mathrm{C}$. Fernandez-Lopez et al. [202] carried out a kinetic analysis study of manure pyrolysis 
940 and combustion processes. They conducted a thermogravimetric analysis of the pyrolysis and

941 combustion of three different biomass waste samples; two dairy manure samples (before and

942 after anaerobic digestion) and one swine manure sample. Three iso-conversional methods

943 (Friedman, Flynn-Wall-Ozawa and KAS) were used by Fernandez-Lopez et al. and were

944 compared with the Coats-Redfern method. According to the kinetic analysis results, the

945 activation energy values of pyrolysis devolatilisation stages were in the range of $152-170 \mathrm{~kJ}^{\mathrm{mol}}{ }^{-}$

$946{ }^{1}$ for dairy manure before anaerobic digestion, $148-178 \mathrm{~kJ} \mathrm{~mol}^{-1}$ for dairy manure after anaerobic

947 digestion and 156-209 kJ.mol ${ }^{-1}$ for swine manure. Regarding the combustion process, the

948 activation energy values of combustion devolatilisation stages were in the range of 140-175

$949 \mathrm{~kJ} . \mathrm{mol}^{-1}$ for dairy manure before anaerobic digestion, $178-199 \mathrm{~kJ} . \mathrm{mol}^{-1}$ for dairy manure after

950 anaerobic digestion and $122-144 \mathrm{~kJ} \cdot \mathrm{mol}^{-1}$ for swine manure. It was also found that the anaerobic

951 digestion process has no effect on the kinetics of the thermochemical processes as the activation

952 energy values were practically the same for samples before and after the anaerobic digestion.

953 The distributed activation energy model was the best fitting model with the experimental data in

954 both pyrolysis and combustion processes.

955

956

957

958

959

960

961 
962 Table 2: The combustion conditions along with the associated calorific values of different types

963 of biomass.

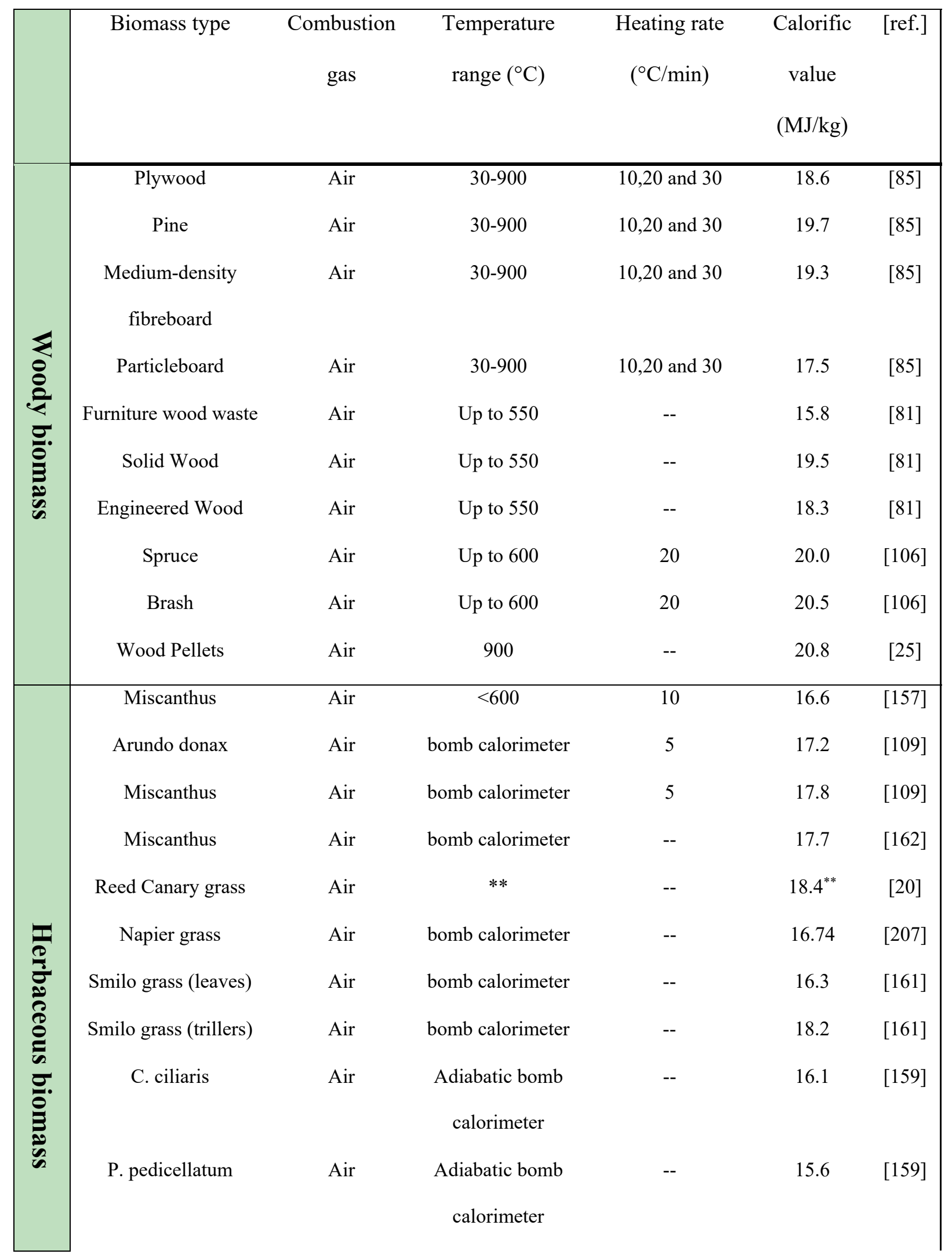




\begin{tabular}{|c|c|c|c|c|c|c|}
\hline & Switch grass & Air & $\begin{array}{l}\text { Adiabatic bomb } \\
\text { calorimeter }\end{array}$ & -- & 19.7 & [159] \\
\hline \multirow{13}{*}{ 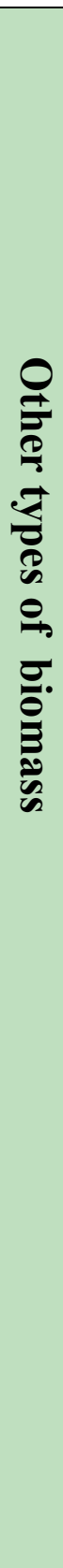 } & $\begin{array}{c}\text { Carbonized Seaweed } \\
\text { (Phaeophyta) }\end{array}$ & Air & $20-900$ & 10 & $\begin{array}{c}14.3 \\
(\mathrm{HHV})\end{array}$ & {$[117]$} \\
\hline & $\begin{array}{c}\text { Posidonea Oceanic } \\
\text { seaweed }\end{array}$ & $\mathrm{He} / \mathrm{O}_{2}=4: 1$ & $25-650$ & $5,10,20$ & undefined & [208] \\
\hline & $\begin{array}{c}\text { Agal HRD } \\
\text { (Hydroprocessed } \\
\text { renewable diesel fuel }\end{array}$ & Air & 280 & 25 & $44 * *$ & [209] \\
\hline & $\begin{array}{c}\text { Washed Saccharina } \\
\text { latissima }\end{array}$ & Air & 700 & (undefined) & 13.9 & {$[115]$} \\
\hline & $\begin{array}{l}\text { Sodium free, } \\
\text { pyroltyic char of } \\
\text { Hazelnut Shell }\end{array}$ & Air & 900 & $\begin{array}{c}5,10,20,30,40, \\
50\end{array}$ & 18.3 & {$[155]$} \\
\hline & Hazelnut shells & Air & 900 & 40 & 17.9 & {$[210]$} \\
\hline & Cassava peel bio-oil & air & Ambient - 800 & 10 & 27.43 & {$[123]$} \\
\hline & $\begin{array}{c}\text { Spent coffee grounds } \\
\text { based biodiesel }\end{array}$ & air & Ambient- 800 & 20 & -- & [211] \\
\hline & Rice husk & Air & 450 & 5 & 14.98 & [167] \\
\hline & Dairy manure & oxygen & bomb calorimeter & - & 18.4 & [203] \\
\hline & Dairy manure * & oxygen & bomb calorimeter & - & 16.9 & [204] \\
\hline & Swine manure & oxygen & bomb calorimeter & - & 16.1 & {$[204]$} \\
\hline & Horse manure & Air & 985 & --- & 19.4 & [204] \\
\hline
\end{tabular}




\section{Up-cycling approach}

969 Recently, the production of bio-oil from biomass has gained great attention as an alternative to 970 the fossil fuel. Usually, bio-oil, which is typically dark-brown, is composed of different

971 chemicals such as esters, acids, alcohols, ketones, aldehydes, phenols and lignin-derived

972 oligomers. Bio-oil is thus characterised by its high acidity $(\mathrm{pH} 2-3)$, high moisture and viscosity 973 [212]. Bio-oil typically has low heating value compared with fossil fuel with HHV of 974 approximately 20 and $40 \mathrm{MJ} \mathrm{kg}^{-1}$, respectively. In general, the pyrolysis of hemicellulose and cellulose occurred faster than that of lignin with weight loss in the range of $220-315{ }^{\circ} \mathrm{C}, 315$ $400{ }^{\circ} \mathrm{C}$ and $160-900{ }^{\circ} \mathrm{C}$, respectively [213]. The pyrolysis of cellulose is endothermic while pyrolysis of hemicellulose and lignin is exothermic [213]. Previous studies reported four stages

978 during the pyrolysis; water desorption followed by three decomposition stages for cellulose,

979 hemicellulose and lignin. The product distribution depends upon the feedstock chemical and 980 biochemical composition, the biomass taxonomy and the secondary interaction between liquid and char [158]. In general, the highest yield of liquid ( mostly anhydrosugars) is produced by the decomposition of cellulose along with the lowest char yield. While hemicellulose decomposes to the highest yield of gas and liquid ( mainly water, ketones and phenols), lignin produces the

984 phenols in the liquid form along with the highest yield in char [158]. Woody biomass decomposes slower than that of the herbaceous biomass with less evolution of volatile matters due to the larger contents of cellulose and hemicellulose within the herbaceous biomass [158].

987 The produced biochar is characterised with higher calorific value than the raw biomass with 988 values in the range of $25-26 \mathrm{MJ} \mathrm{kg}^{-1}$ which is due to the increase in the fixed carbon content $989[214]$ 
Table 3: The pyrolysis conditions along with the produced bio-oil yield of different types of 991 biomass.

\begin{tabular}{|c|c|c|c|c|c|c|}
\hline & Biomass type & $\begin{array}{c}\text { Pyrolysis } \\
\text { gas }\end{array}$ & $\begin{array}{c}\text { Temperature } \\
\text { range }\left({ }^{\circ} \mathrm{C}\right)\end{array}$ & $\begin{array}{l}\text { Heating } \\
\text { rate } \\
\left({ }^{\circ} \mathrm{C} / \mathrm{min}\right)\end{array}$ & $\begin{array}{l}\text { \% bio- } \\
\text { oil } \\
\text { yield }\end{array}$ & [ref.] \\
\hline \multirow{5}{*}{ 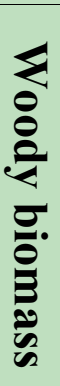 } & Birch & Nitrogen & Up to 500 & 3000 & 37 & [215] \\
\hline & Spruce (without bark) & Nitrogen & Up to 500 & 3000 & 36 & [215] \\
\hline & Pine Bark & -- & $400-625$ & -- & 43 & [216] \\
\hline & Maple & -- & $400-625$ & -- & 63 & [216] \\
\hline & Poplar Aspen & -- & $400-625$ & -- & 65 & [216] \\
\hline \multirow{13}{*}{ 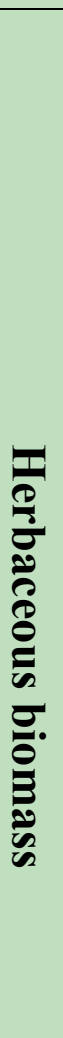 } & Mountain brome & Nitrogen & 700 & 10 & 58.6 & [158] \\
\hline & Tall-Oat grass & Nitrogen & 700 & 10 & 55.5 & {$[158]$} \\
\hline & Napier grass & Nitrogen & $500-600$ & -- & $55 \pm 2.6$ & {$[217]$} \\
\hline & Tall fescue & Nitrogen & 700 & 10 & 51.5 & [158] \\
\hline & redtop & Nitrogen & 700 & 10 & 48.7 & [158] \\
\hline & Napier grass & Nitrogen & 600 & 50 & 51.6 & [218] \\
\hline & Reed canary grass & Nitrogen & 700 & 10 & 56.0 & {$[158]$} \\
\hline & Hybrid perun & Nitrogen & 700 & 10 & 55.7 & {$[158]$} \\
\hline & Hybrid Becva & Nitrogen & 700 & 10 & 56.5 & [158] \\
\hline & Achnatherum splendens & -- & $300-450$ & 10 & $39-44$ & {$[160]$} \\
\hline & Achnatherum splendens & -- & $300-450$ & 30 & $42-45$ & {$[160]$} \\
\hline & Hybrid lofa & Nitrogen & 700 & 10 & 55.7 & {$[158]$} \\
\hline & Red Clover & Nitrogen & 700 & 10 & 48.1 & {$[158]$} \\
\hline \multirow{5}{*}{ 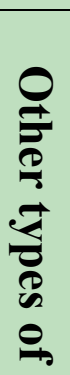 } & Hazelnut shells & Nitrogen & $400-700$ & 7 & 23.1 & {$[153]$} \\
\hline & Spent Coffee Grounds & Nitrogen & $450-550$ & $6000-30000$ & 56.1 & {$[148]$} \\
\hline & Hazelnut shells & Nitrogen & 550 & 20 & 41.95 & [219] \\
\hline & Spent coffee grounds & Nitrogen & $400-600$ & 100 & 30.51 & {$[147]$} \\
\hline & Cassava Peel & Nitrogen & $400-600$ & 20 & 51.2 & [123] \\
\hline
\end{tabular}




\begin{tabular}{|c|c|c|c|c|c|c|}
\hline \multirow{11}{*}{ 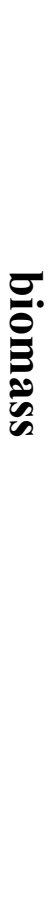 } & Ulva lactuca & Nitrogen & 550 & $200-2000$ & 65 & [220] \\
\hline & Chlamydomonas reinhardtii & Nitrogen & $400-550$ & 30000 & 60.2 & [221] \\
\hline & Rice husk & Argon & $500-800$ & 160 & 43.13 & [177] \\
\hline & Rice husk & Nitrogen & $150-900$ & 50 & 21.9 & [178] \\
\hline & Rice husk & Nitrogen & $400-550$ & -- & 46.9 & [222] \\
\hline & Rice husk & Nitrogen & 450 & -- & 52 & [223] \\
\hline & Rice husk & Nitrogen & $450-650$ & -- & 53.8 & [224] \\
\hline & goat manure & Nitrogen & $300-600$ & 15 & 26.1 & [171] \\
\hline & Swine manure & Nitrogen & $80-800$ & $10,20,30$ & 40 & {$[173]$} \\
\hline & & & & $\& 40$ & & \\
\hline & Swine manure & Nitrogen & $260-340$ & --- & 24.2 & [198] \\
\hline
\end{tabular}

992

993 The bio-oil composition and yield are unfavourably affected by the amount of the ash content in

994 the biomass feedstock, therefore washing it with water, surfactant or either acid improves both

995 the yield and the composition of the bio-oil. For instance, washing the biomass with water

996 showed an effective way to reduce the inorganic materials such as ( $\mathrm{K}, \mathrm{P}$ and $\mathrm{Cl})$ [225] and it is

997 an ideal pretreatment choice for woody biomass (low ash content) [226]. Again, washing with a

998 surfactant such as Triton X-100 can effectively reduce the ash content in comparison to the 999 untreated biomass [226]. Washing the raw biomass with $\mathrm{HCl}$ reduced the metal content and 1000 consequently increased the volatile materials during the pyrolysis which in turn increased the 1001 bio-oil yield [227] and also reduced the hemicellulose present in the polymer structure of the 1002 biomass [228]. Banks et al. [226] reported that using stronger acid could lead to hydrolyse both 1003 cellulose and hemicellulose completely that eventually decreased the bio-oil yield.

1004 Controlling the temperature is crucial in optimising the bio-oil yield. For example, Ozbay et al. 1005 [229] reported that the optimum temperature was $550{ }^{\circ} \mathrm{C}$ to get the maximum yield of bio-oil 1006 with $7^{\circ} \mathrm{C} \cdot \mathrm{min}^{-1}$ in a $\mathrm{N}_{2}$ atmosphere in a tubular reactor (\% yield was $\left.25 \%\right)$. On a further increase 
1007 in the temperature beyond $550{ }^{\circ} \mathrm{C}$, the yield decreased to approximately $21 \%$. However, Putun 1008 et al. [230] reported a slightly lower temperature than that of Ozbay et al., for the maximum bio-

1009 oil yield of $500{ }^{\circ} \mathrm{C}$. Encinar et al. [231] agreed with the results of Putun et al., as the maximum 1010 bio-oil yield at $500^{\circ} \mathrm{C}$. Again, Lu et al. [232] and Park et al. [233] stated even lower temperatures 1011 of 475 and $450{ }^{\circ} \mathrm{C}$, respectively, for maximum bio-oil yield. However, this may be attributed to 1012 using different biomass types.

1013 There is a debate in the literature regarding the relationship between the biomass particle size 1014 and the bio-oil yield as Brosse et al. [234] reported that the bio-oil yield was not significantly 1015 affected by the change in the particle size. While Demiral and Sensoz [235] found out that there 1016 is a decrease in the bio-oil yield with increasing the particle size of the biomass feedstock. In 1017 contrast, Demirbas [236] observed an increase in the bio-oil yield with increasing the biomass 1018 particle size.

1019 Interestingly, for bio-oil production, the selectivity and its composition significantly vary with 1020 the addition of a catalyst, with zeolite the most commonly used. For instance, it was observed 1021 that the wt.\% of water in the bio-oil increased upon using a catalyst compared with the uncatalysed condition [237]. It was reported that the bio-oil yield decreased in the presence of the catalyst, but also the oxygen content of the bio-oil decreased i.e. the catalyst promoted the 1024 production of valuable products such as the aromatic compounds within the bio-oil [237, 238]. 1025 The effect of the wt.\% of catalyst (ZSM-5) on the bio-oil production showed that the char yield 1026 along with the bio-oil decreased with increasing the ZSM-5: biomass ratio [239]. The quality of 1027 the bio-oil increased by producing more benzene, xylene, toluene, polycyclic aromatic 1028 hydrocarbons (PAHs) along with naphthalenes while phenol yield decreased. This is attributed 1029 to the fact that catalyst promoted the deoxygenation reaction. Du et al. [239] found out that at the 1030 ZSM-5: biomass ratio of 5, naphthalenes were the most abundant product within the produced 1031 bio-oil. Further research is needed to optimize the bio-oil yield in the presence of the catalyst 
along with using different pore size catalyst type on the distribution of the aromatic compounds within the bio-oil.

1034 The effect of the heating rate along with the residence time during the pyrolysis is crucial for the production of the bio-oil, char and the gaseous products. In general, such high heating rate with residence time less than ten seconds is considered as fast pyrolysis with the possibility of a heating rate of $1000^{\circ} \mathrm{C} . \mathrm{s}^{-1}$. A residence time of less than a second is referred to as flash pyrolysis.

1038 Conventional pyrolysis takes place with slower heating rates with a residence time as high as 30 1039 minutes. Thus, changing the heating rate could significantly change the bio-oil yield. Slow 1040 pyrolysis with a residence time of 24 hours was reported as the optimum condition for the char 1041 production, while fast pyrolysis was used for the production of a valuable bio-oil [240, 241].

1042 Duman et al.[242] showed that the bio-oil yield increased two-fold with fast pyrolysis compared 1043 to that of the slow pyrolysis. Furthermore, the light and heavy bio-oil fraction vary with heating 1044 rate during the pyrolysis. It was reported that during the slow pyrolysis, the light bio-oil yield increased then remained constant in the temperature ranges of $400-500{ }^{\circ} \mathrm{C}$ and $500-600{ }^{\circ} \mathrm{C}$, respectively, while the heavy bio-oil yield remained constant throughout the whole temperature range of $400-600{ }^{\circ} \mathrm{C}$. Both light and heavy bio-oil yield increased in the temperature range of $1048400-500{ }^{\circ} \mathrm{C}$ then decreased in the temperature range of $500-600{ }^{\circ} \mathrm{C}$, respectively [243]. A 1049 detailed comparison between different type of pyrolysis on the bio-oil production showed that the yield of bio-oil showed the following series; fast pyrolysis $>$ intermediate pyrolysis $>$ carbonisation $>$ gasification $>$ torrefaction processes. It is not surprising that torrefaction obtained the lowest bio-oil yield as it is designed generally for the production of char and takes 1053 place at considerably lower temperature range than that of the desired temperature range for the 1054 bio-oil production. Also, gasification is generally used for the production of gaseous species and 1055 is conducted at higher temperature ranges than that required for the bio-oil production. Interestingly, fast pyrolysis showed twice as bio-oil yield as that of the intermediate pyrolysis 
with gas and char selectivity higher in the case of the carbonisation process [216]. In summary, fast pyrolysis showed the most suitable process for the maximum bio-oil yield.

1059 As stated earlier, the bio-oil yield in catalytic systems should be lower than that of the 1060 corresponding uncatalyzed system due to an increase in the wt.\% of water caused by the 1061 promotion of the deoxygenation route in the presence of the catalyst. One of the highest reported 1062 bio-oil yields (75\%)for an uncatalyzed system was for fast pyrolysis of wood which included 1063 water in the liquid product. This fast pyrolysis used high heating rate $\left(25^{\circ} \mathrm{C} \cdot \mathrm{min}^{-1}\right)$ with short 1064 residence time and fast quenching to prevent the reverse reaction of liquid to gas phase [34]. 1065 Using intermediate pyrolysis for hazelnut bagasse with a heating rate of $10^{\circ} \mathrm{C} \cdot \mathrm{min}^{-1}$ showed a lower bio-oil yield of $54.7 \%$ including water in the liquid product $(17.1 \%)$. The lower bio-oil

1067 yield could be due to a combination of reasons; the change in the biomass type along with using 1068 lower heating rates [244]. Using different biomass feedstock such as miscanthus while keeping 1069 the heating rate the same as in the previous study i.e. $\left(10^{\circ} \mathrm{C} \cdot \mathrm{min}^{-1}\right)$ showed 55.2 and $57.3 \%$ bio1070 oil yield in different studies [226, 233]. This implies that the heating rate could be of great 1071 influence on the bio-oil yield. A lower bio-oil yield was reported of $40 \%$ at $500{ }^{\circ} \mathrm{C}$ with a heating 1072 rate of $200{ }^{\circ} \mathrm{C} \cdot \mathrm{min}^{-1}$ and decreased to $30 \%$ with increasing the final temperature to $600{ }^{\circ} \mathrm{C}$. To 1073 sum up, the expected bio-oil yield in the uncatalysed system could be in the range of $40-75 \%$ 1074 (including water in the liquid products) while the common yield reported in the literature of 1075 approximately 55\%. The catalysed system improves the selectivity and produces a higher quality 1076 bio-oil, albeit with a lower yield than that of the corresponding uncatalysed system which 1077 produces a lower quality bio-oil. One bio-oil yield in the presence of the catalyst which was 1078 closest to the yield of uncatalysed system reported were $51 \%$, however, the wt.\% of water 1079 increased by around $10 \mathrm{wt.} \%$ (35\% - 45\%) [233]. Using waste biomass such as olive oil waste 1080 feedstock showed a lower bio-oil yield of around 30\%. This is perhaps in part due to the type of 1081 biomass or the long residence time along with the absence of a quenching process. The effect of 
the catalyst: biomass ratio on the yield of the bio-oil yield showed $33 \%$ when the ratio was 1 , while the yield decreased to $27 \%$ by increasing the ratio to 5 [239]. The bio-oil yield in case of catalysed cellulose pyrolysis was reported to be higher than that of pine using the same pyrolysis condition of 33.4 and $24.4 \%$, respectively [245]. To sum up, the expected bio-oil yield in the catalysed system based on the literature is the range of $\sim 30-35 \%$.

The produced bio-oil can be upgraded into high value-added chemicals or transportation fuels, while the char can be used in carbon sequestration, fertilizer, activated carbon or heavy metal removals and others [20]. Catalytic fast pyrolysis (CFP) is a distinguished thermochemical process for the production of high-quality bio-oil with zeolite catalyst again being the most common catalyst used [212].

Fermoso et al. [246] studied the effect of the indigenous and external catalysts (HZSM-5) on the fast pyrolysis of lignocellulose. They found out that in case of non-catalytic, mineral components and zeolite type catalyst showing different prominent route such as dehydration, dehydroxylation and decarbonylations, respectively as the main route of deoxygenation in the

1098 pyrolysis process. ZSM-5 decreased the bio-oil production, however, increased the production 1099 of aromatic compounds in the bio-oil, thus the produced bio-oil composition can vary according 1100 to the catalyst type, pyrolysis condition and the biomass type [246]. Other than aromatization, a 1101 series of complex reactions occur inside the pores of the catalyst such as cracking, 1102 oligomerization, ketonization, isomerization and aldol condensation of the produced pyrolysis 1103 vapour. Thus, catalysts with meso- and macroporous structure are preferred, otherwise coke 1104 deposition occurs and eventually, the catalyst deactivates.

1105 Liang and McDonald studied the possibility of using potato peel waste (PPW) as a potential 1106 resource for biofuel and bioproducts production [247]. During the PPW fermentation, starch 
1107 was mainly consumed for the production of alcohol (ethanol) and organic acids (acetic and lactic 1108 acid), while under the pyrolysis conditions, a total of 51 products were detected; the main five

1109 products were $\mathrm{CO}_{2}$, acetic acid, acetic anhydride, hexadecenoic acid and phenol [247]. In another

1110 study, orange peel waste showed calorific values in the range of 10.9-19.3 $\mathrm{MJ}^{\mathrm{kg}} \mathrm{kg}^{-1}$ with a high 1111 absorption capacity for heavy metals such as lead [248].

\subsection{Woody biomass}

1113 Woody biomass can be upcycled/valorised via torrefaction, gasification, hydrothermal

1114 carbonisation, biological treatments, pyrolysis, anaerobic digestion, fermentation and

1115 transesterification. Many of these processes have been described herein previously for recycling/

1116 reusing and/or applied to other types of biomass.

1117 Primarily in this section, the focus will be on the bio-refinery and the extraction of platform and

1118 value-added chemicals from woody biomass. Woody biomass can be fed into anaerobic digesters

1119 for the conversion of solid/liquid heterogeneous biomass mixtures to biogas, though would

1120 typically require a higher residence time compared to some other types of biomass. Pyrolysis

1121 and hydrothermal liquefaction result in bio-oil which can then be upgraded to the value added

1122 chemicals or fuels $[215,249-253]$. Pyrolysis is conducted between 450 and $500{ }^{\circ} \mathrm{C}$ for short

1123 residence times at atmospheric conditions and requires drying whereas the hydrothermal

1124 liquefaction is at lower temperatures $\left(300-400^{\circ} \mathrm{C}\right.$ ) at higher pressure (up to $25 \mathrm{MPa}$ ) and for

1125 longer times (up to $1 \mathrm{~h}$ ) with the advantage of no drying step being required.

1126 Ranzi et al. have conducted a kinetic study of the pyrolysis of reference components of woody

1127 biomass such as cellulose, hemicellulose and lignin [254]. Applying a particle scale mechanistic

1128 kinetic model, the relative contributions of transport processes and reaction kinetics was

1129 assessed. Using TGA of the devolatisation stages of the biomass reference components,

1130 predictions were reported regarding the rate of weight loss as well as the evolution of gaseous 
1131 and vapour species. It was found that these predictions could be validated with the experimental

1132 results. In summary, this simple kinetic approach could accurately model degradation stages,

1133 durations and product evolution and the model has the potential to be applied to a wide range of

1134 gasifiers. The reality of course, as acknowledged by the authors, that the model is only in its

1135 early stages of application since it has been used so far for only for the main constituent parts of

1136 wood which were treated as references by Ranzi et al. [254]. There are reports of applying

1137 mathematical modelling to analyse both the reference components and wood samples, such as

1138 pine [255], though in this case, the model was only accurate for larger particles. For the first time

1139 in literature, an autocatalytic model was developed therein so as to better describe secondary

1140 degradation processes which were observed during the pyrolysis studies of the pine and the

1141 constituent components (except for lignin). Good agreement between experimental data and the

1142 kinetic modelling was reported as so it was reported that, in theory, this method could be applied

1143 for other biomasses.

1144 A fluidized bed was used by di Celso et al. to conduct a kinetic analysis of the pyrolysis of 1145 spherical particles of wood from the Ostrya carpinifolia tree at 700, 800 and $900{ }^{\circ} \mathrm{C}[256]$. Infra-

1146 Red (IR) and thermal conductivity detector (TCD) were employed to analyse the effluent of the 1147 pyrolysis $\mathrm{CO}, \mathrm{CO}_{2}, \mathrm{CH}_{4}$ and $\mathrm{H}_{2}$ specifically monitored. Separate semi-empirical models have 1148 been proposed for the two mechanistic stages of wood gasification, i.e. pyrolysis followed by

1149 char/tar combustion. For the most part, these models were found to be capable of reproducing

1150 the evolution of the experimentally monitored gas concentrations. The pyrolysis model was able

1151 to closely match the interaction of wood particle size on the gas yield (smaller particles meant

1152 faster pyrolysis), though the model could not adequately predict the impact of changing the 1153 temperature on these yields. 
1154 Bioethanol, which can be used as both a fuel and as a chemical feedstock, can be extracted from

1155 woody biomass, such as eucalyptus wood via uncatalyzed steam explosion [72]. The time and

1156 temperature dependencies were monitored during this study, and the data could be fitted with an

1157 empirical equation, with the linear regressions being derived by the least squares method. There

1158 have also been reports in the literature of boosting the bioethanol yields by adding other biomass,

1159 such as cheese whey powder [257].

1160 Sheldon has provided a comprehensive review on the opportunities to apply catalysis to utilise

1161 biomass to support green chemistry and the circular economy by producing fuels, commodity

1162 chemicals and other products such as bio-plastics [258]. Cork, for example, is a potentially

1163 significant chemical feedstock, given the volumes produced (201 ktonnes per year [16, 259]) and

1164 the fact that due to a high suberin content it does not biodegrade. $40 \%$ of this cork is used as

1165 wine stoppers and there is only limited recycling of used wine corks, with $66 \%$ of these estimated

1166 to go to landfill. Aroso et al. [259] have provided an extensive discussion on possible uses of

1167 cork as a sustainable material, though the methods discussed could be applied to other types of

1168 woody biomass. Depolymerisation methods to extract value-added chemicals such as waxes and

1169 phenolic compounds from cork include chemical (acid/base [260] and catalytic [261],

1170 oxypropylation [262], liquefaction [263] and pyrolysis [264].

1171 As an example, Cordeiro et al. [260] have reported a kinetic study on the extraction of urethanes

1172 and polyurethanes from suberin derived from reproduction cork. The hydroxy index was

1173 determined and validated using FTIR (by monitoring decreasing $\mathrm{OH}$ peak and the increasing

1174 NCO peak). It was reported that a second-order kinetic model was the most accurate in fitting

1175 the experimental data.

1176 Evtigouguina et al. [265] conducted a kinetic study of the oxypropylation of cork powder, also

1177 for the extraction of urethanes and polyurethanes by exposing the cork to propylene oxide at high 
1178 pressure. In this case, a second-order kinetic process was observed and rate constants were

1179 determined. In summary, the authors state that their findings have demonstrated that

1180 oxypropylation is a reasonable and feasible process to extract valuable products from biomass

\section{$1181 \quad 4.4$ Other types of Biomass sources upcycling}

1182 Ross et al. have noted that the char yield from the slow pyrolysis/carbonisation of macro-algae

1183 should not be neglected and should be utilized $[116,119]$. The abundance of alkali metals in the

1184 biomass directly affects the char yield as it alters the pyrolysis mechanism as reported by Ross 1185 et al. themselves elsewhere [111].

1186 Looking at the AD potential of brown seaweed, Tabassum et al. tested five different types and

1187 concluded that the highest biomethane potential (BMP) was $286 \mathrm{~L} . \mathrm{CH} 4 . \mathrm{Kg}_{\text {.VS }}{ }^{-1}$ from L. digitate

1188 and the lowest BMP of the five types was L. hyperborean with 118 L.CH4.Kg.VS ${ }^{-1}$. The specific 1189 yield per net weight of the brown seaweed was found to be $10-32 \mathrm{~m}^{3}$ [121]. Of the different

1190 selective regions of the seaweed strain, the frond was deemed to be the most significant and

1191 suitable region for biogas production from brown seaweed. It should be noted that biogas

1192 production from seaweeds has been previously reported by Ross et al. to be more expensive than 1193 terrestrial biomass [111].

1194 In order to further predict the yield of pyrolysis products from slow pyrolysis and compare with

1195 that of fixed-bed reactor experiments, a mechanistic-based model was designed. This was an 1196 adaption of a model originally developed by Van de Velden et al. [124]. The model was found

1197 to give good accuracy at predicting the pyrolysis products over the temperature range of 400$1198600{ }^{\circ} \mathrm{C}$ producing a mean squared error of $0.49,16.34$ and 13.37 for gas, bio-oil and char, 1199 respectively. The overall bio-oil yield from the slow pyrolysis process of cassava peel was found 1200 to be 38.7-51.2 wt.\%, with the optimum yield of $51.2 \mathrm{wt} . \%$, corresponding to a temperature of $1201525{ }^{\circ} \mathrm{C}$. Above this temperature, the yield was found to decrease and this was attributed to 
secondary thermal cracking. The resultant bio-oil properties satisfied all the ASTM D7544

1203 standard requirements which suggest that bio-oil coming from the pyrolysis of cassava peel could

1204 be used as a resultant bio-fuel.

1205 Alternatively, there is potential to produce activated carbon from cassava peel. The main 1206 application of activated carbon adsorbents is to purify and separate gas/liquid mixtures [125, 1207 126]. Sudaryanto et al. [127] conducted a study where high surface area activated carbon was 1208 prepared from cassava peel by chemical activation using $\mathrm{KOH}$ as an activating agent. Different 1209 impregnation ratios, carbonisation time and temperature were all studied to determine how this 1210 would affect the pore characteristics and surface chemistry of the cassava peel feedstock. It was 1211 found that carbonisation time had little effect in the yield or pore characteristics of activated 1212 carbon, but, the carbonisation temperature had an important effect on the yield. Carbonisation 1213 temperature of $450{ }^{\circ} \mathrm{C}$ produced the highest yield out of the four temperatures used $(450,550$, 1214650 and $750{ }^{\circ} \mathrm{C}$ ). Increasing the carbonisation temperature from $450-650{ }^{\circ} \mathrm{C}$, increased both the 1215 micropore and total pore volume. Above $650{ }^{\circ} \mathrm{C}$, promotion of a higher total pore volume and a 1216 lower micropore volume occurred [127]. This is due to the surface metal complex promoting 1217 further carbon gasification leading to a widening of the micropores to increase in size to become 1218 mesopores as described by Ganan et al. [128]. Furthermore, it was deduced that increasing the 1219 impregnation ratio decreased the overall yield of activated carbon. At lower impregnation ratios, 1220 the structure of the activated carbon consisted mainly of micropores and increasing this led to 1221 the creation of mesopores due to widening [127].

1222 Moreno-Piraján further extended this research by preparing activated carbon from cassava peel 1223 and studying the adsorption of copper from aqueous solution. Instead, the activation was carried 1224 out using chloride zinc. It was determined that it was possible to gain surface areas as high as $12251567 \mathrm{~m}^{2} \cdot \mathrm{g}^{-1}$ and pore volumes as large as $1.18 \mathrm{~cm}^{3} \cdot \mathrm{g}^{-1}$ [129]. The trend on impregnation ratio 1226 was the same as Sudaryanto et al. in that as it increased, this promoted more mesopores [127]. 
1227 The sorption capacity of activated carbon of cassava peel to uptake copper ions was determined 1228 to be $55 \mathrm{mg} \cdot \mathrm{g}^{-1}$ by using four different best-fit three parameter isotherms Vieth-Sladek, Toth, Sips 1229 and Radke-Prausnitz [129]. This was found to be more than fives times the sorption capacity for 1230 uptake of copper ions of activated charcoal [130]. It was also close to the sorption capacity of 1231 Humic acids and bark pine pulp at 51.47 and $45.2 \mathrm{mg} \cdot \mathrm{g}^{-1}$, respectively $[129,131]$.

1232 Moshi et al. [137] looked at multiple scenarios as to what was the best way to harness the energy 1233 inherent within the cassava peels. The pre-treatments used in their study were alkali, enzyme and 1234 a combination of one another for the production of bioethanol or biogas, or both. The study 1235 showcased that wild cassava peel can be upgraded into both biogas and ethanol concurrently. 1236 This resulted in a higher fuel energy value compared to the option of separate processes. Alkali 1237 combined with enzyme pre-treatment was proven to be the best method, indicating a $56 \%$ 1238 improvement in methane yield for the AD process compared to the untreated counterpart. The 1239 combined methane and ethanol production resulted in 1.2-1.3 times the fuel energy yield 1240 compared to the generation of solely methane and 3-4 times the fuel energy yield compared to 1241 solely ethanol production [137]. Adekunle et al. reviewed ways in which to produce bio-ethanol 1242 from cassava peels and provided a design conceptualization. It was their suggestion that although 1243 some challenges occur to the industrialization of any given process, the best case scenario would 1244 be to integrate directly with the petrochemical industry to ensure proper blending of the bio1245 ethanol into biofuel and ensure profitability [138]. They also suggested the potential co1246 production of ethanol/biogas with the biogas part contributing to power generation, in agreement 1247 with Moshi et. al. [137] had published earlier.

1248 Looking at the activated carbon made from SCG, Jutakridsada et al. [144] produced activated 1249 carbon with a fixed pyrolysis heating rate of $10^{\circ} \mathrm{C} \cdot \mathrm{min}^{-1}$ for four hours. SCG was chemically 1250 activated using $\mathrm{ZnCl}_{2}$ and there were three concentrations (5, 10 and 15 wt.\%), three 1251 impregnation times (8, 12 and $24 \mathrm{hrs})$ and three carbonisation temperatures $(400,450$ and 
$500{ }^{\circ} \mathrm{C}$ ) tested in the particular study. The optimum concentration, impregnation time and temperature were found to be $15 \mathrm{wt} . \%, 24 \mathrm{hrs}$ and $500{ }^{\circ} \mathrm{C}$, respectively. This led to an average specific surface area and average pore volume of $831 \mathrm{~m}^{2} \cdot \mathrm{g}^{-1}$ and $0.44 \mathrm{~cm}^{3} \cdot \mathrm{g}^{-1}$, respectively. The adsorption capacity of $\mathrm{Cu}^{2+}$ was $18 \%$ removal with 100 ppm of $\mathrm{CuSO}_{4}[144]$.

Babu et al. studied the removal of lead and fluoride from contaminated water sources using exhausted coffee grounds. The biomass was firstly acid activated by adding to $\mathrm{HCl}$ and boiled for 2 hours. They then created synthetic wastewater by adding lead nitrate and sodium fluoride. The maximum adsorption capacity for the lead was found to be $61.6 \mathrm{mg} \cdot \mathrm{g}^{-1}$ at $\mathrm{pH} 6$, dosage $0.15 \mathrm{~g} .100 \mathrm{~mL}^{-1}$, time of 75 minutes, the temperature of $303 \mathrm{~K}$ for an initial concentration of 1261 100mg.L $\mathrm{L}^{-1}$. The maximum adsorption capacity for fluoride was determined to be $9.05 \mathrm{mg} \cdot \mathrm{g}^{-1}$ at $1262 \mathrm{pH} \mathrm{4}$, dosage $0.2 \mathrm{~g} \cdot 100 \mathrm{~mL}^{-1}$, time of 105 minutes, the temperature of $303 \mathrm{~K}$ for an initial 1263 concentration of $20 \mathrm{mg} . \mathrm{L}^{-1}$. The kinetics for removal of both these species follows the pseudo1264 second-order model and the adsorption behaviour follows the Langmuir isotherm mode [145].

1265 Liu et al. conducted a study in which SCG biochar was prepared by $\mathrm{CO}_{2}$ sequestration at $400{ }^{\circ} \mathrm{C}$ 1266 under a nitrogen flow rate of $100 \mathrm{~mL} \cdot \mathrm{min}^{-1}$. Three methods for the ammoxidation of the biochar 1267 was tested and then chemically activated using potassium hydroxide. The $\mathrm{CO}_{2}$ sorption 1268 capacities of the three sample were found to be $2.04-2.67 \mathrm{mmol} \mathrm{CO} 2 . \mathrm{g}^{-1}$ sorbent at $35{ }^{\circ} \mathrm{C}$ under 1269 atmospheric pressure using completely dry $\mathrm{CO}_{2}$. The most successful sample was one prepared 1270 using sonication, melamine and hydrothermal treatment. This was attributed to the unique 1271 properties of the adsorbent including a highly developed microporosity as the ratio of the 1272 micropores volume to the total pore volume was approximately $82 \%$.

1273 Primaz et al. [147] recently looked at the influence of temperature on the yield of bio-oil from 1274 the fast pyrolysis of SCG. They produced the bio-oil at five different temperatures $(400,450$, 1275500,550 and $600{ }^{\circ} \mathrm{C}$ ), using a heating rate of $100 \mathrm{C} \cdot \mathrm{min}^{-1}$, a flow rate of $150 \mathrm{~mL} \cdot \mathrm{min}^{-1}$ of nitrogen 
and a hold time of 15 minutes once the temperature was reached. The gases and oil were passed

1277 through a condenser with circulation of ice water $\left(-5^{\circ} \mathrm{C}\right)$. The maximum bio-oil yield was found to be 30.51 wt. $\%$ at $500{ }^{\circ} \mathrm{C}$ with the major components in the bio-oil to be palmitic acid (19\%), oleic acid (11\%) and stearic acid (10\%) [147]. This is lower than the $56.09 \%$ reported by Luz et

$1280 a l$ and is likely due to their use of a screw-based reactor which can optimize vapour residence 1281 times [148]. After $500{ }^{\circ} \mathrm{C}$, the bio-oil decreases and climatizes around $27 \%$. The decrease in 1282 yield with increasing temperature occurs usually due to secondary side reactions of the pyrolysis 1283 vapours which contributes to the increase in gaseous product and possible decrease of other 1284 products $[149,150]$.

1285 Recently Kim et al. [151] conducted an anaerobic co-digestion study using SCG alongside other 1286 feedstocks such as ulva, food waste, waste activated sludge and whey. For each additive, they 1287 tested a pure SCG sample and mixing ratios of $75 / 25,50 / 50,25 / 75$ and $0 \%$ SCG/100\% co1288 feedstock. The individual feedstock's composition was saw to have a significant effect on the 1289 biomethanation performance. Every co-feedstock had comparable or higher methane production rates or yields except for the waste activated sludge feedstock which showed negative impacts.

1291 The co-digestion with whey, ulva or food waste increased the reaction rate of the AD process 1292 without losses in biomethane potential. A 75/25 mixing ratio of food waste to spent coffee 1293 grounds showed the most promising results. It produced the largest biomethane potential of all 1294 the 69 tests. The cumulative methane production at 28 days was $0.355 \mathrm{~L} . \mathrm{CH}_{4} \cdot \mathrm{g}^{-1} \cdot \mathrm{VS}_{\mathrm{in}}{ }^{-1}$ and the 1295 methane production potential was $0.344 \mathrm{~L} \cdot \mathrm{CH}_{4} \cdot \mathrm{g}^{-1}$.VS in. The $50 / 50 \mathrm{mix}$ of food waste to spent 1296 coffee grounds was ever so slightly lower than this result so both mixing ratios could be deemed 1297 suitable [151].

1298 Similarly, Luz et al. studied AD under mesophilic conditions at $37{ }^{\circ} \mathrm{C}$ for 22 days of the liquid 1299 fraction from spent coffee grounds (SCL) mixed with cow manure and compared this with a 1300 reference of pure cow manure. An inoculum ratio of 1.5 was used (g volatile solids (VS) substrate 
per g.VS). They found that the SCL reactors showed a $\mathrm{pH}$ reduction in the first days compared with the pure cow manure samples. The addition of the SCL produced more stable values for the 1303 lower heating value (28.24MJ.Kg-1 as opposed to $26.30 \mathrm{MJ} . \mathrm{Kg}^{-1}$ for the pure cow manure 1304 sample), biogas composition (peaks of $60 \%$ methane when SCL is used; $9 \%$ higher than the pure 1305 cow manure sample) and carbon conversion efficiency (38\% higher than the pure cow manure 1306 sample). SCG was indicated to have an individual contribution up to $254 \mathrm{ml} \mathrm{CH}_{4} \cdot \mathrm{g}^{-1} \mathrm{VS}^{-1}$ [152].

1307 Pütün et al. conducted a study on the formation of bio-oil from hazelnut shells and its subsequent 1308 structure and yield using a standard fixed bed reactor. It was deduced that the optimum bio-oil 1309 yield was $23.1 \mathrm{wt} . \%$ at $500{ }^{\circ} \mathrm{C}$ with a heating rate of $7 \mathrm{~K} \cdot \mathrm{min}^{-1}$ and a nitrogen flow rate of $1310100 \mathrm{~cm}^{3} \cdot \mathrm{min}^{-1}$. They tested the yields at different purging rates of nitrogen and deduced above 1311 and below $100 \mathrm{~cm}^{3} \cdot \mathrm{min}^{-1}$ the yield would be approximately $20 \%$ and the $100 \mathrm{~cm}^{3} \cdot \mathrm{min}^{-1}$ flow rate 1312 of nitrogen accounts for the additional 3\% yield. The analysis of the pentane soluble fraction of 1313 the bio-oil showed that it was a mixture of alkanes, alkenes and branched hydrocarbons and the $1314 \mathrm{C} / \mathrm{H}$ ratio in comparison to other fuels indicates that this oil lies between the light and heavy 1315 petroleum products [153].

1316 Looking at the co-pyrolysis behaviour of hazelnut shells alongside another biomass-based feed,

1317 Zhao et al. [266] published a study looking at mixing municipal sewage sludge with hazelnut 1318 shells at four different heating rates $\left(5,10,15,30 \mathrm{~K} \cdot \mathrm{min}^{-1}\right)$ using TGA-DTG-MS under a nitrogen 1319 atmosphere.

1320 It was determined that adding the additional feedstock changed the number of thermal 1321 decomposition steps. In the co-pyrolysis case, it was found to be four stages. At the second and 1322 third stages, it was found that the biomass cracked into $\mathrm{H}_{2}, \mathrm{H}_{2} \mathrm{O}, \mathrm{CO}_{2}$, aromatic hydrocarbons 1323 and alkanes. The kinetics were evaluated using three different iso-conversional methods: Starink method, KAS method and the Flynn-Wall-Ozawa method. The apparent activation energy 
increased from 123.99 to $608.15 \mathrm{KJ} \cdot \mathrm{mol}^{-1}$ as the extent of conversion increased along the given reaction pathway [266].

Another use case for waste hazelnut shells is the production of levuinic acid as a precursor to biofuel production such as ethyl levulinate. Licursi et al. studied the hydrochar coming from the hydrothermal conversion of hazelnut shells to levulinic acid (LA). The hydrothermal conversion process was tested both using microwave-based technique and an autoclave technique. They found a maximum yield of LA to be $9-12 \mathrm{wt} . \%$ and the recovery yield of the hydrochar was found to be quite high at 43-47 wt.\%. The hydrochar that was formed showed a behaviour similar to lignite and was found to be suitable for energy production [267].

Another study on the valorization of hazelnut shells using the hydrothermal treatment was published by Gozaydin et al. [163]. They tested the product composition of value-added chemicals without the use of a heterogeneous catalyst and clarified the effects of reaction time, temperature, acid kind and concentration in a high temperature and pressure autoclave. The reactions were carried out between $150-280^{\circ} \mathrm{C}$ for $15-120$ minutes with varying concentrations of $\mathrm{H}_{2} \mathrm{SO}_{4}$ and $\mathrm{H}_{3} \mathrm{PO}_{4}$ of $0-125 \mathrm{mM}$. It was determined that the main products were levulinic acid (LA), furfural and acetic acid whilst $\mathrm{CO}$ and $\mathrm{CO}_{2}$ were the main gaseous products. An increase in temperature and reaction time resulted in a significant increase in yield of LA $(13.05 \%)$ and the overall conversion (65.4\%). LA production was enriched with the addition of $\mathrm{H}_{2} \mathrm{SO}_{4}$, whereas the other acid type $\mathrm{H}_{3} \mathrm{PO}_{4}$ promoted an increase in amounts of furfural [163].

Looking at the bio-oils and biochar that are made from the pyrolysis of hazelnut shells, Özçimen et al. published a collection of results for multiple feedstocks. The optimum conditions for producing biochar from the hazelnut shells was a heating rate of $5 \mathrm{~K} \cdot \mathrm{min}^{-1}$, a temperature of $750 \mathrm{~K}$ and a particle diameter between 1 and $1.4 \mathrm{~mm}$ in size. The optimum conditions for producing 
1349 bio-oil from the hazelnut shells was a heating rate of $20 \mathrm{~K} \cdot \mathrm{min}^{-1}$, a temperature of $823 \mathrm{~K}$, a particle 1350 diameter between 0.25 and $0.355 \mathrm{~mm}$ and a purging flowrate of $1000 \mathrm{~cm}^{3} \cdot \mathrm{min}^{-1}$. The gross

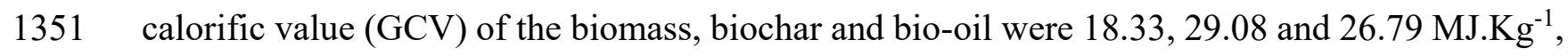
1352 respectively. The volatile matter, fixed carbon and ash percentage of the biomass and biochar 1353 were found to be:

1354 Hazelnut Shell: $(71.67,26.51$ and $1.83 \%$, respectively.)

1355 Hazelnut shell biochar: (30.26, 63.16 and 6.58\%, respectively.)

1356 The porosity, total pore volume and BET surface area of the biomass and biochar were found to 1357 be:

1358 Hazelnut shell: 0.0463\%, $0.0434 \mathrm{ml} . \mathrm{g}^{-1}$ and $5.8421 \mathrm{~m}^{2} \cdot \mathrm{g}^{-1}$

1359 Hazelnut shell biochar: $0.1130 \%, 0.1250 \mathrm{ml} . \mathrm{g}^{-1}$ and $14.6836 \mathrm{~m}^{2} . \mathrm{g}^{-1}$

1360 This signifies that the solid products could replace conventional fossil fuels due to the high fixed

1361 carbon percentage and the high GCV. These values are compared with those of other types of 1362 biomass in Table 1 and 2. The biochars have significant potential for other carbon materials such 1363 as carbon nanotubes or activated carbon to help sequester heavy metals [219].

1366 In general, the energy in rice husk as biomass can be obtained by two processes which are 1367 thermo-chemical and biochemical processes. The biochemical processes represent a route for the 1368 conversion of biomass into value-added products such as ethanol, hydrogen and methane which 1369 represent energy storage material. In addition, these products (i.e. ethanol, hydrogen and 1370 methane) are raw materials for other important chemical compounds which represent the up1371 cycling route of rice husk biomass. According to Abbas et al. [268], the estimated world output 
1372 of bioethanol recovered from rice husk is in the range of 20.9 to 24.3 billion litres per year which

1373 is equivalent to around $37 \%$ of the global demand. In a recent study, Madu et al. [269] studied

1374 the production of bioethanol from rice husk using different pretreatments and fermentation

1375 conditions. They evaluated the effects of the pretreatment of rice husk feedstock with $\mathrm{H}_{2} \mathrm{O}, \mathrm{HCl}$,

$1376 \mathrm{NaOH}$ and $\mathrm{FeCl}_{3}$ on the production of bioethanol. They found that high quantities of ethanol

1377 were produced with $\mathrm{FeCl}_{3}$ and $\mathrm{NaOH}$ which shows significant differences in the sugar-release 1378 patterns and ethanol produced.

1379 The olive is an evergreen tree cultivated for the production of oil and table olives and is native 1380 to the flora of the Mediterranean basin land [270]. In the present time, over 10 million hectares 1381 are cultivated with more than 900 million olive trees, $98 \%$ of which are located in the 1382 Mediterranean Basin [271]. Each olive tree produces from 15 to $40 \mathrm{~kg}$ of olives per year 1383 depending on the climate conditions. In the Mediterranean basin area, Spain is the main producer 1384 of olive followed by Italy, Greece, Turkey, Morocco and Tunisia [270, 272]. The olive mills 1385 solid waste is the solid residue produced after the olive oil production process. The main 1386 components of olive mill solid residue are cellulose, hemicellulose and lignin with fat and 1387 protein. Potassium, calcium and sodium are the major content of minerals [270]. The chemical 1388 composition of olive mill wastes depends on different factors such as the olive fruit varieties and 1389 cultivation conditions in addition to the extraction method [270]. These solid wastes increase the 1390 environmental problems in the Mediterranean countries due to their high phytotoxicity and due 1391 to phenolic compounds, lipids and organic acids contained in these wastes. However, the olive 1392 mills solid waste represents a promising biomass feedstock that can be valorized through 1393 recycling reuse and up-cycling [270, 272].

1394 The olive mills solid waste contains high percentages of organic matter and a vast range of plant 1395 nutrients which make a candidate for the reuse as plant fertilizers [273]. The conversion of solid 1396 olive mill wastes into a useful energy form can be achieved through different conversion 
1397 processes depending on the type of the feedstock, the available quantities and the desired form

1398 of energy. The conversion of olive mill solid wastes to energy can be carried out using the two

1399 main pathways used with all biomass feedstock which are thermo-chemical (pyrolysis,

1400 gasification and combustion) and biochemical/biological. Many studies in the literature

1401 concentrated in the conversion of olive mill solid wastes to energy and/or value-added compound

1402 using the different conversion methods. Guneser et al.[274] studied the production of flavour

1403 compounds of olive mill waste by fermentation processes using Rhizopus oryzae and Candida

1404 tropicalis. According to the results obtained, 2-pentanone, d-limonene and 2-phenylethanol were

1405 obtained from olive mill waste by fermentation of R. oryzae, while D-limonene and methyl

1406 butanoate were produced by fermentation of C. tropicalis. In a recent study, del Pozo et al. [275]

1407 succeeded in the extraction of value-added products from the intermediate pyrolysis of olive mill

1408 waste. These value-added products are divided into two groups: aqueous phase products and

1409 non-aqueous phase products. The aqueous phase products containing acetic acid,

1410 monosaccharides and phenolic derivatives while the non-aqueous phase products consist of

1411 phenolic derivatives and fatty acids and their methyl esters. In a study carried out by Serrano et

$1412 a l$. [276], to valorize the olive mills solid waste by the recovery of phenols from the solid waste

1413 after the steam explosion. It was found that the steam explosion treatment increased the total

1414 phenol content; twice as much phenol content compared to the raw olive mills solid waste.

1415 Abdelhadi et al. [182] studied the production of biochar from olive mill solid waste for heavy

1416 metal removal from water. They studied the production of biochar from olive solid waste from

1417 two olive cultivars and two oil production process (two- or three-phase) at two temperatures (350

1418 and $\left.450{ }^{\circ} \mathrm{C}\right)$. The yield of biochar was $24-35 \%$ of the biomass, with a low surface area $(1.65-$

$\left.14198.12 \mathrm{~m}^{2} \mathrm{~g}^{-1}\right)$ compared to that of commercial activated carbon $\left(1100 \mathrm{~m}^{2} \mathrm{~g}^{-1}\right)$. However, the

1420 biochar from olive mill solid waste shows a better activity in the removal of heavy metal $\left(\mathrm{Cu}^{+2}\right.$,

$1421 \mathrm{~Pb}^{+2}, \mathrm{Cd}^{+2}, \mathrm{Ni}^{+2}$ and $\mathrm{Zn}^{+2}$ ) with more than $85 \%$ compared to commercial activated carbon. 
1422 According to the results obtained, Abdelhadi et al. suggested that the surface area cannot be used 1423 as a sole predictor of heavy metal removal capacity.

$1424 \mathrm{AD}$ and co-digestion technologies represent important and promising processes to valorize olive 1425 mill solid waste and other biomass. In the anaerobic co-digestion technology, several solid and 1426 liquid organic wastes are treated simultaneously to produce biogas which contributes to more 1427 efficient use of the AD process as multiple streams of wastes can be processed together in the 1428 same plant, at the same time. Carlini et al. [277] studied the production of bio-methane from 1429 anaerobic co-digestion of olive-mill solid waste, with cattle manure and cattle slurry. According 1430 to the results, the optimal mixture was obtained using $23.25 \%$ of olive mill solid waste, $4.65 \%$ 1431 of cattle manure and $72.10 \%$ of cattle slurry. The co-anaerobic digestion of olive mill solid waste 1432 and microalgae, Dunaliella salina, was studied by Fernández-Rodríguez et al. [278] to improve 1433 methane production. According to the results of this study, the highest methane production rate 1434 and the maximum methane yield were obtained for the co-digestion mixture containing $75 \%$ 1435 olive mill solid waste and $25 \%$ Dunaliella salina. The effect of pretreatment of olive mill solid 1436 waste with $\mathrm{NaOH}$ on its anaerobic digestion for methane production was studied by Pellera et 1437 al.[271]. The effect of different $\mathrm{NaOH}$ dosages, process durations and temperatures on waste 1438 biodegradability and methane yields was investigated. The results indicated that the parameters 1439 with the most effective were in the order of $\mathrm{NaOH}$ dosages $>$ temperature $>$ process duration. 1440 The highest yield of methane $\left(242 \mathrm{NmL} \mathrm{CH}_{4} \cdot \mathrm{gVS}^{-1}\right)$ was obtained at a dosage of $1 \mathrm{mmol}^{\mathrm{gVS}} \mathrm{gS}^{-1}$ 1441 (4\% of VS) and a pretreatment temperature of $90{ }^{\circ} \mathrm{C}$.

1442 The date palm tree represents one of humankind's oldest cultivated plants especially in the hot 1443 arid Arab regions where it has an important and essential role in the daily life of the people for 1444 more than 7000 years [279]. The date palm tree is characterised by its ability to adapt to with the 1445 very dry atmosphere and strong sunshine as long as its requirements of water are met. The date 1446 fruits are characterised with its rich content of essential nutrients including carbohydrates, salts, 
1447 minerals, dietary fibre, vitamins, fatty acids, amino acids and protein which make it one of the

1448 most important human nutrients [187]. The wastes generated from date palm tree are leaflets,

1449 rachis, trunks, and date seeds. The date seeds represent about $10 \%$ of the date weight, so that, up

1450 to 900,000 tons of date seeds from the 7 million tons of dates that are produced worldwide every

1451 year. In general, the main constituents of date seeds are hemicellulose (23\%), lignin (15\%),

1452 cellulose (57\%) and ash (5\%) [187]. Date seeds represent a source of environmental problems

1453 in the countries that usually discard them as unwanted waste without strategies for valorisation.

1454 The possibility of extracting oils from date seeds was studied by Elnajjar et al. [280] using two

1455 cultivars of date seeds, namely, Khalas and Allig. Both of Soxhlet and Folch methods were used

1456 for the extraction of oil from date seeds with five different size ranges $(300 \mathrm{~nm}, 0.1-0.3 \mathrm{~mm}$,

$1457 \quad 0.3-0.85 \mathrm{~mm}, 0.85-1.18 \mathrm{~mm}$, and $>1.18 \mathrm{~mm}$ ) in addition to the ungrounded date seeds. The

1458 results indicated that the size of the date seeds particles is an important factor that has clearly

1459 affected the oil extraction yield. It was found that the decrease in the date seed particle size

1460 increased the oil extraction yield percentage except in the case of the nano-particles where the

1461 extracted oil yield was reduced. The maximum oil extraction yields were achieved from Allig

1462 date seeds with the size range of $0.1-0.3 \mathrm{~mm}$, which were 9.0 and $10.4 \%$, using the Folch and

1463 Soxhlet extraction methods, respectively.

1465 The wheat bran is the by-product of the roller milling of wheat grains for the production of white

1466 wheat flour. Millions of tons of wheat are produced every year worldwide, from which the bran

1467 consists about $25 \%$ [281-283]. The composition of wheat bran contains $6.1-6.5 \%$ ash, $5.9-6.8 \%$

1468 lipid, 15-20\% protein, 11-23\% starch, 43-53\% dietary fibre, in addition to other minor

1469 constituents. The dietary fibre consists of (5-20\%) lignin, (16-30\%) cellulose, (38-55\%)

1470 arabinoxylan, in addition to other nonstarch polysaccharides [283]. The main use of wheat bran, 
as a renewable industrial resource, is in animal feeding. However, due to the low value of bran

1472 feed products, the wheat industry aims to convert the wheat bran into products of higher 1473 commercial value $[282,283]$. According to the work reported in the literature, the valorization 1474 of wheat bran is carried out through two main ways. The first one is the biorefinery in which the 1475 wheat bran can be separated into fractions of high purity to produce new chemicals that can be 1476 used as precursors for higher polymerized compounds. The second way is the separation and 1477 purification of substances contained in wheat bran that are valuable, per se [284]. It is clear from 1478 the two main ways for the valorization of wheat bran that the up-cycling way is the main way 1479 used with this industrial bio-waste.

1480 Conversion of wheat bran into ethanol using mild treatments and highly fermentative yeasts was 1481 studied by Favaro et al. [281]. They studied the enzymatic hydrolysis pre-treatment of wheat 1482 bran for high hexose and pentose recovery using optimized dosages of commercial enzymes. 1483 Depending on the total sugar yield and inhibitory by-product release, a comparison between acid 1484 addition, milling and heat treatment was carried out. According to the results, the maximum total 1485 sugar amount was obtained when limited concentrations of acid were added to milled bran at the 1486 pretreatment step. High levels of ethanol production were reached by using highly fermentative 1487 wild-type yeasts for the fermentation of the whole unfiltered hydrolysates. Okamoto et al. [285] 1488 studied the direct production of ethanol from wheat bran and other biomasses by the white rot 1489 fungus Trametes hirsute. According to the results obtained, maximum ethanol concentrations of 14904.3 g... $\mathrm{L}^{-1}$, corresponding to $78.8 \%$ of the theoretical yield, were obtained when the fungus was 1491 grown in a medium containing 20 g.L $\mathrm{L}^{-1}$ wheat bran. The pilot-scale isolation of the major dietary1492 fibre component of wheat bran, glucuronoarabinoxylans was studied by Hollmann et al.[286]. 1493 At first, arabinoxylans was extracted with water followed by purification with boiling 70\% 1494 ethanol. Then, Glucuronoarabinoxylans were extracted with 2\% hydrogen peroxide of pH 11 at 
$40{ }^{\circ} \mathrm{C}$. The final product was precipitated with $70-80 \%$ ethanol and within one week, $350 \mathrm{~g}$ of

1496 glucuronoarabinoxylans were produced.

1497 The extraction of alkylresorcinols from wheat bran with supercritical $\mathrm{CO}_{2}$ was studied by 1498 Rebolleda et al.[287]. They studied the changes in the extraction kinetics under the effect of 1499 different parameters including particle size, static extraction pretreatment with supercritical $\mathrm{CO}_{2}$ 1500 and extraction temperature, all at constant extraction pressure of $40.0 \mathrm{MPa}$. According to the 1501 results of the study, the extraction yield was found to increase by increasing the particle size and 1502 temperature. In a study by Ouyang et al.[288] a set of titania nanocomposites have been prepared 1503 by the incorporation of different $\mathrm{TiO}_{2}$ content on wheat bran residues. The photocatalytic activity 1504 of the prepared titania nanocomposites was investigated in the oxidation of benzyl alcohol under 1505 UV light irradiation. According to the results obtained in this study, the optimum catalyst (10\% 1506 Ti-Bran) produced a $20 \%$ yield of benzaldehyde at $33 \%$ conversion of benzyl alcohol, which is 1507 comparable to that of the commercial titania catalyst under the same conditions. Sayen et al.[289] 1508 reported the use of wheat bran for the production of a lignocellulosic substrate used in the 1509 sorptive removal of enrofloxacin antibiotic from aqueous solutions. The effects of different 1510 experimental factors including contact time, $\mathrm{pH}$ and concentration on the adsorption process 1511 were investigated. The results indicated that the $\mathrm{pH}$ value is the most important factor that affects 1512 the adsorption process where $100 \%$ of enrofloxacin was removed at $\mathrm{pH} 6$ in less than one hour 1513 and more than $80 \%$ was removed above $\mathrm{pH} 4$. In a study by Gopalan et al.[290] ferulic acid was 1514 extracted from destarched wheat bran using a feruloyl esterase enzyme. The effects of enzyme 1515 loading, reaction time, $\mathrm{pH}$ and temperature on the extracted amount of ferulic acid were studied. 1516 It was found that the statistical optimization of the process has improved the yield of extraction 1517 by 2.5 times with the extraction of $34.6 \%$ of total alkali releasable ferulic acid. When the process 1518 is scaled up in a packed column reactor, $32.5 \%$ of total alkali releasable ferulic acid has been 1519 extracted. 
1520 The variation in the utilisation of biomass is phenomenal; such as in the AD plants for the 1521 production of biogas, gasification for the synthesis of hydrogen-based gases and pyrolysis for 1522 the preparation of activated carbon (AC) carbon nanotubes (CNTs). The AC is a porous carbon 1523 that can be prepared using either physical or chemical activation methods and used in the 1524 adsorption of organic and inorganic compounds. The chemical activation method is more 1525 favourable method than that of the physical activation due to its less intensive energy requirement. Physical activation includes carbonisation along with high-temperature pyrolysis 1527 in the temperature range of $800-1000^{\circ} \mathrm{C}$, while in chemical activation method, chemical agents $1528\left(\mathrm{ZnCl}_{2}, \mathrm{H}_{3} \mathrm{PO}_{4}\right.$ and $\left.\mathrm{KOH}\right)$ are used, followed by pyrolysis at a temperature of $\sim 500{ }^{\circ} \mathrm{C}[291]$. 1529 Jadwiga et al., used the physical activation method for the production of AC from waste biomass 1530 in a fluidal reactor using steam or $\mathrm{CO}_{2}$ at atmospheric pressure or in a closed high-pressure 1531 microwave reactor under hydrothermal conditions [292]. The results showed that steam and $\mathrm{CO}_{2}$ 1532 activation gave better results than the microwave reactor with SBET of 749,539 and $430 \mathrm{~m}^{2} \cdot \mathrm{g}^{-1}$, 1533 respectively.

1534 The AC produced via chemical activation showed a high surface area of exceeding $2700 \mathrm{~m}^{2} \cdot \mathrm{g}^{-1}$ 1535 with a pore volume of $1.39 \mathrm{~cm}^{3} \cdot \mathrm{g}^{-1}$ [291]. In the chemical activation method, various dehydrating 1536 agents were used such as $\mathrm{CaO}, \mathrm{H}_{3} \mathrm{PO}_{4}, \mathrm{NaOH}, \mathrm{H}_{2} \mathrm{SO}_{4}, \mathrm{KOH}$ and $\mathrm{ZnCl}_{2}$, while $\mathrm{H}_{3} \mathrm{PO}_{4}$ showed 1537 the best results in activating the woody biomass due to its promotion of the dehydration, de1538 polymerization and redistribution of constituents bipolymers along with its availability and 1539 environmentally safe [291]. Furthermore, $\mathrm{H}_{3} \mathrm{PO}_{4}$ increases the yield of $\mathrm{AC}$ as a result of 1540 favouring the conversion of aliphatic to aromatic compounds. It also promotes not only the 1541 pyrolytic decomposition of the initial material (cellulose, hemicellulose and lignin) but also the 1542 formation of the cross-linked structure during the chemical activation process [291]. Thus it acts 1543 as an acid catalyst to enhance the depolymerization of biomass macromolecules feedstock, while 1544 it also improves the formation of phosphates, phosphates bridges and cross-linked through the 
dehydration, condensation and cyclization processes, thus leads to porous carbon materials

1546 [293]. While in the $\mathrm{KOH}$ activation process, the presence of a nucleophilic $\mathrm{OH}$ group leads to

1547 solubilization and fragmentation of the lignocellulosic biomass. The insertion of K atoms during

1548 the activation process is a result of the removal of carbonate, hydroxide and oxide species during

1549 the initial pyrolysis process which adds stress inside the structure of the produced carbon

1550 material. However, a further increase in the pyrolysis temperature leads to the removal of the $\mathrm{K}$

1551 atoms from the intercalated system forming porous carbon materials [293].

1552 ACs were prepared from woody materials using $\mathrm{ZnCl}_{2}, \mathrm{H}_{3} \mathrm{PO}_{4}$ and $\mathrm{KOH}$ with surface area in the range of $1275-2594 \mathrm{~m}^{2} \cdot \mathrm{g}^{-1}$ and found out that texture and the morphology of the produced AC depend upon the type and the concentration of the activating agent [294]. The surface area along with the porosity increased in this order $\mathrm{KOH}>\mathrm{H}_{3} \mathrm{PO}_{4}>\mathrm{ZnCl}_{2}$. The largest surface area with $155698 \%$ micropore AC structure was obtained by $\mathrm{KOH}$ activation. ACs produced using $\mathrm{H}_{3} \mathrm{PO}_{4}$ 1557 activation via different atmosphere; either self-generated or air flowing atmosphere showed that 1558 the former showed better BET surface area $\left(\mathrm{S}_{\mathrm{BET}}\right)$ results than the latter of 2281 and $1638 \mathrm{~m}^{2} . \mathrm{g}^{-}$ $1559{ }^{1}$, respectively [295]. They used a moderate pyrolysis condition where the acid: precursor ratio $1560=2$ at $450{ }^{\circ} \mathrm{C}$ for $4 \mathrm{hrs}$. Evergreen Oak was used to produce $\mathrm{AC}$ through the impregnation of $1561 \mathrm{H}_{3} \mathrm{PO}_{4}(60 \%)$ at $85^{\circ} \mathrm{C}$ for $2 \mathrm{hrs}$ followed by pyrolysis at $450{ }^{\circ} \mathrm{C}$, resulting in $\mathrm{AC}$ of SBET as high 1562 as $1723 \mathrm{~m}^{2} . \mathrm{g}^{-1}$ ( mainly micro- and mesoporous volume) [296]. Zuo et al. studied the effect of 1563 the heating history along with the pore development during the $\mathrm{H}_{3} \mathrm{PO}_{4}$ activation process. They 1564 recommended of two-step heating program where intermediate isothermal treatment $\left(5^{\circ} \mathrm{C} . \mathrm{min}^{-}\right.$ $1565^{1}$ ) and slow heating rate up to $300^{\circ} \mathrm{C}$, promote the pore development, however, above $300^{\circ} \mathrm{C}$, it 1566 has a detrimental effect [297].

$1567 \mathrm{ZnCl}_{2}$ was used for the production of ACs from Paulownia wood where the optimum conditions 1568 were reported as $400{ }^{\circ} \mathrm{C}$ carbonisation temperature along with the ratio of $\mathrm{ZnCl}_{2}$ : biomass $=4$, 
1569 resulting in AC of SBET as high as $2736 \mathrm{~m}^{2} \cdot \mathrm{g}^{-1}$ with micro- and mesopore surface areas of 1727

1570 and $1009 \mathrm{~m}^{2} \cdot \mathrm{g}^{-1}$, respectively [298].

1571 Further processing of the AC is used for the production of CNTs, by doping the AC with

1572 nitrogen-based compounds such as melamine along with nickel or iron metals [299]. CNTs

1573 possess various characteristics to make them a value-added product in a variety of application

1574 such as electrical and thermal conductivity, high strength, toughness and stiffness [300]. Jiang

1575 et al. prepared an active $\mathrm{Fe}-\mathrm{N}-\mathrm{C}$ electrocatalyst in oxygen reduction reaction through the

1576 pyrolysis of a mixture of glucose coated CNTs, nitrogen and iron-based compounds [301]

1577 Hydrogen production via catalytic reforming of pyrolysis vapour was investigated by Mahmood 1578 et al.[302] where the production of $\mathrm{H}_{2}$ exceeded 50 vol.\%.
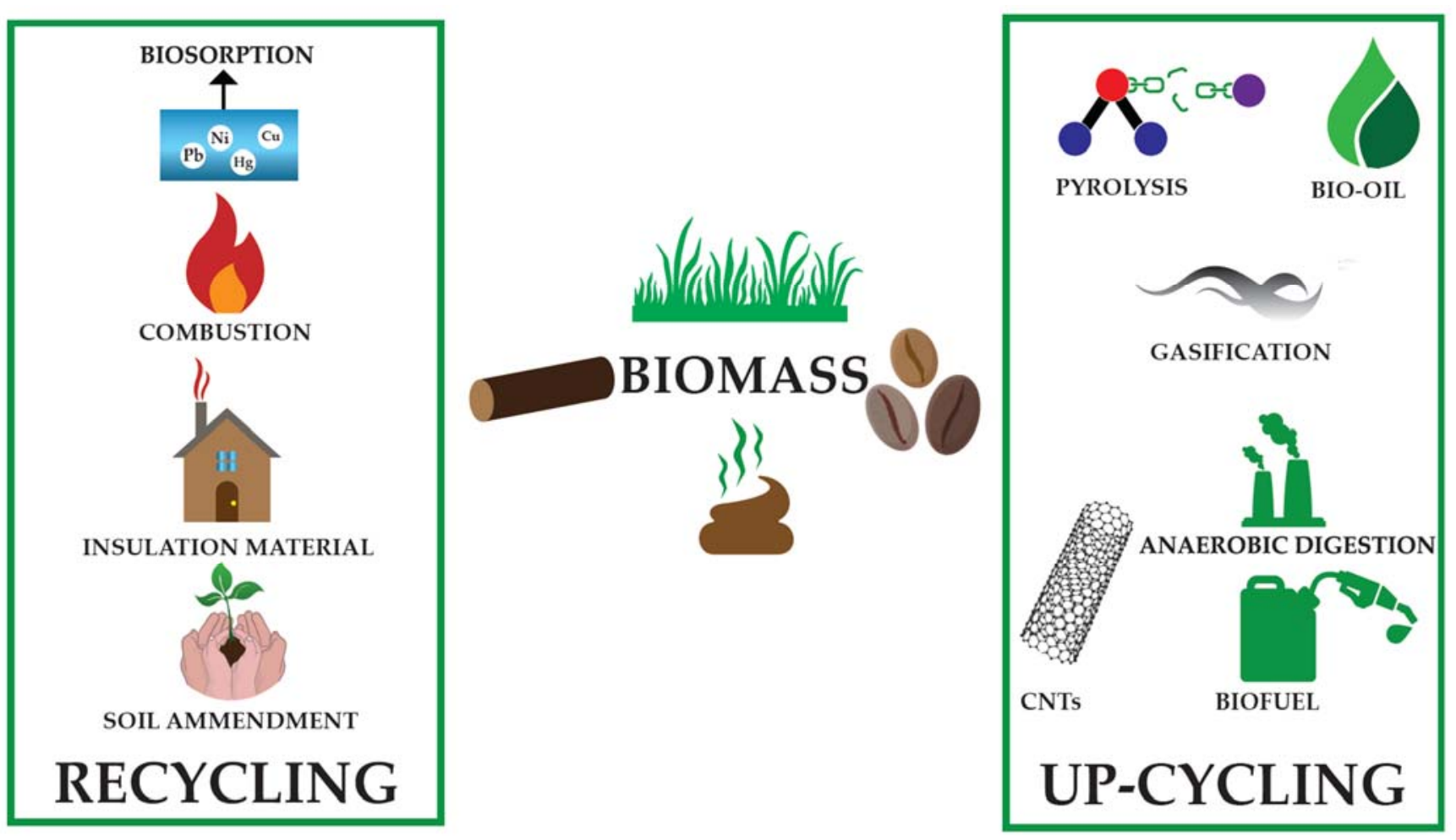

1581 Figure 1: The utilisation of different types of biomass through recycling and upcycling 1582 approaches. 


\section{Prospective overview and conclusion}

1584 A number of different types of biomass have been considered, while various processes have been 1585 discussed for their reuse, recycling an upcycling as seen in Figure 1. Additionally, the prospects 1586 of boosting the circular economy of biomass have been considered. There are significant 1587 literature contributions, of which the references of the current work are not an exhausted list, and 1588 it is clear that there is a strong desire for maximum utilization of biomass. By also considering 1589 the kinetic modelling of some processes it is hoped to demonstrate that such work can and does 1590 play a vital role in the understanding of biomass processing technology. It has also demonstrated 1591 that there is still potential to improve on both the actual technologies as well as the kinetic 1592 models. Finally, while it is clear that biomass is still required for some lower grade uses, it is 1593 preferable to extract the maximum value from the biomass sources if we are truly to achieve a 1594 circular economy. It is clear, however, that there is still some progress which is required in this 1595 field due to the energy-intensive nature of some of the processes.

1596 Acknowledgements: AO and KM wish to acknowledge the support of Sustainable Energy

1597 Research Centre, a Queen's University Belfast Pioneering Research Programme and the Centre 1598 for Advanced Sustainable Energy (CASE). The authors also wish to acknowledge the support of 1599 The Bryden Centre project (Project ID VA5048) which was awarded by The European Union's 1600 INTERREG VA Programme, managed by the Special EU Programmes Body (SEUPB), with 1601 match funding provided by the Department for the Economy in Northern Ireland and the 1602 Department of Business, Enterprise and Innovation in the Republic of Ireland.

1603 Dedication: KM dedicates this review to the memory of Dr Sergiy Shekhtman, one of his PhD 1604 supervisors, who passed away on $8^{\text {th }}$ February 2018. Sergiy was an excellent mentor and teacher 1605 in kinetic modelling which has been the foundation of KM's research to date. His guidance, 1606 support and the many fruitful discussions with J.M. Yoda will be missed. 


\section{References}

1608 [1] K.O. Zacho, M. Mosgaard, H. Riisgaard, Capturing uncaptured values - A Danish case 1609 study on municipal preparation for reuse and recycling of waste, Resources, Conservation and 1610 Recycling, 136 (2018) 297-305.

1611 [2] P. Schroeder, P. Dewick, S. Kusi-Sarpong, J.S. Hofstetter, Circular economy and power 1612 relations in global value chains: Tensions and trade-offs for lower income countries, Resources, 1613 Conservation and Recycling, 136 (2018) 77-78.

1614 [3] Queen's University Belfast gets $£ 1 \mathrm{~m}$ to research plastic waste, https://www.bbc.co.uk/news/uk-northern-ireland-46648020, accessed 30/1/2019 3pm.

1618 [5] A.I. Osman, J.K. Abu-Dahrieh, F. Laffir, T. Curtin, J.M. Thompson, D.W. Rooney, A 1619 bimetallic catalyst on a dual component support for low temperature total methane oxidation, 1620 Applied Catalysis B: Environmental, 187 (2016) 408-418.

1621 [6] A.I. Osman, J. Meudal, F. Laffir, J. Thompson, D. Rooney, Enhanced catalytic activity of Ni on $\eta$-Al 2 O 3 and ZSM-5 on addition of ceria zirconia for the partial oxidation of methane, Applied Catalysis B: Environmental, 212 (2017) 68-79.

[7] G. Kakkar, Understanding Biofuel Classification. Sustainable Innovation Management, https://www.sim.sbio.vt.edu/?p=2341, accessed at 28/01/2019 at 5pm., (2017).

[8] http://www.wrap.org.uk/content/household-food-and-drink-waste-uk-0 $\quad$ (accessed 23/11/2018).

1628 [9] https://weareobeo.com/food-waste-facts/ (accessed 23/11/2018).

1629 [10] Communication from the Commission to the European Parliament, the Council, the 1630 European Economic and Social Committee and the Committee of the Regions; Roadmap to a 1631 Resource Efficient Europe, COM/2011/571 (2011); http://eur-lex.europa.eu/legalcontent/EN/TXT/?uri=CELEX:52011DC0571 (accessed 23/11/2018).

[11] EU Commission decision of 18 November 2011 establishing rules and calculation methods for verifying compliance with the targets set in Article 11(2) of Directive 2008/98/EC of the European Parliament, Document 32011D0753 (2011): https://eur-lex.europa.eu/legalcontent/EN/TXT/?uri=CELEX:32011D0753 (accessed 24/11/2018).

[12] Communication from the Commission to the European Parliament, The Council, The European Economic and Social Committee and the Committee of the Regions; Closing the loop - An EU action plan for the Circular Economy, COM/2015/0614 (2015); https://eurlex.europa.eu/legal-content/EN/TXT/?uri=CELEX:52015DC0614 (accessed 23/11/2018).

[13] W. McDowall, Y. Geng, B. Huang, E. Barteková, R. Bleischwitz, S. Türkeli, R. Kemp, T. Doménech, Circular Economy Policies in China and Europe, Journal of Industrial Ecology, 21 (2017) 651-661.

[14] Z.J.N. Steinmann, M.A.J. Huijbregts, L. Reijnders, How to define the quality of materials in a circular economy?, Resources, Conservation and Recycling, 141 (2019) 362-363.

[15] T. Werpy, a.G. Pedersen, Top value added chemicals from biomass, Results of Screening for Potential Candidates from Sugars and Synthesis Gas, vol. 1 (2004) US Department of Energy., 1 (2004).

1649 [16] C.S. McCallum, N. Strachan, S.C. Bennett, W.G. Forsythe, M.D. Garrett, C. Hardacre, K. 1650 Morgan, G.N. Sheldrake, Catalytic depolymerisation of suberin rich biomass with precious metal 1651 catalysts, Green Chemistry, 20 (2018) 2702-2705.

1652 [17] http://questor.qub.ac.uk/ReNEW/ (accessed 23/11/2018).

1653 [18] A. Geng, H. Yang, J. Chen, Y. Hong, Review of carbon storage function of harvested wood 1654 products and the potential of wood substitution in greenhouse gas mitigation, Forest Policy and Economics, 85 (2017) 192-200. 

thermodynamics, gas evolution and empirical optimization of cattle manure combustion in air and oxy-fuel atmospheres, Applied Thermal Engineering, 149 (2019) 119-131. [20] A.-C. Johansson, H. Wiinikka, L. Sandström, M. Marklund, O.G.W. Öhrman, J. Narvesjö, 1660 Characterization of pyrolysis products produced from different Nordic biomass types in a cyclone pilot plant, Fuel Processing Technology, 146 (2016) 9-19. [21] S. Wu, S. Zhang, C. Wang, C. Mu, X. Huang, High-strength charcoal briquette preparation from hydrothermal pretreated biomass wastes, Fuel Processing Technology, 171 (2018) 293300.

[22] P. Pradhan, S.M. Mahajani, A. Arora, Production and utilization of fuel pellets from biomass: A review, Fuel Processing Technology, 181 (2018) 215-232. [23] A. Saba, P. Saha, M.T. Reza, Co-Hydrothermal Carbonization of coal-biomass blend: Influence of temperature on solid fuel properties, Fuel Processing Technology, 167 (2017) 711720. content of woodchip samples by means of FT-NIR spectroscopy, Fuel Processing Technology, 169 (2018) 77-83.

[25] J.M. Ashman, J.M. Jones, A. Williams, Some characteristics of the self-heating of the large scale storage of biomass, Fuel Processing Technology, 174 (2018) 1-8.

[26] J.R. Opfermann, E. Kaisersberger, H.J. Flammersheim, Model-free analysis of thermoanalytical data-advantages and limitations, Thermochimica Acta, 391 (2002) 119-127. [27] X. Huang, G. Rein, Thermochemical conversion of biomass in smouldering combustion across scales: The roles of heterogeneous kinetics, oxygen and transport phenomena,

[28] A.I. Osman, A. Abdelkader, C.R. Johnston, K. Morgan, D.W. Rooney, Thermal Investigation and Kinetic Modeling of Lignocellulosic Biomass Combustion for Energy Production and Other Applications, Industrial \& Engineering Chemistry Research, 56 (2017) 12119-12130.

[29] M. Vazquez-Pufleau, T.S. Chadha, G. Yablonsky, P. Biswas, Carbon elimination from silicon kerf: Thermogravimetric analysis and mechanistic considerations, Scientific Reports, 7 (2017) 40535.

[30] Y.-H. Sun, T.-L. Zhang, J.-G. Zhang, L. Yang, X.-J. Qiao, Decomposition kinetics of manganese tris (carbohydrazide) perchlorate (MnCP) derived from the filament control voltage of the T-jump/FTIR spectroscopy, International Journal of Thermal Sciences, 45 (2006) 814818.

[31] P. Le Bideau, J.-P. Ploteau, P. Dutournié, P. Glouannec, Experimental and modelling study of superficial elastomer vulcanization by short wave infrared radiation, International Journal of Thermal Sciences, 48 (2009) 573-582.

[32] A. Iliyas, K. Hawboldt, F. Khan, Thermal stability investigation of sulfide minerals in DSC, Journal of Hazardous Materials, 178 (2010) 814-822.

[33] P. Zou, S. Tang, Z. Fu, H. Xiong, Isothermal and non-isothermal crystallization kinetics of modified rape straw flour/high-density polyethylene composites, International Journal of Thermal Sciences, 48 (2009) 837-846.

[34] A.M. Cortes, A.V. Bridgwater, Kinetic study of the pyrolysis of miscanthus and its acid hydrolysis residue by thermogravimetric analysis, Fuel Processing Technology, 138 (2015) 184193.

[35] S. Vyazovkin, Chapter 4 - Modern Isoconversional Kinetics: From Misconceptions to Advances, in: S. Vyazovkin, N. Koga, C. Schick (Eds.) Handbook of Thermal Analysis and Calorimetry, Elsevier Science B.V., 2018, pp. 131-172. 
[36] C. Ferraro, S. Sands, J. Brace-Govan, The role of fashionability in second-hand shopping motivations, Journal of Retailing and Consumer Services, 32 (2016) 262-268.

1707 [37] B. Addis, Building with reclaimed components and materials. A design handbook for reuse and recycling, Earthscan, London, UK (2006). p. 208. [38] J. Weinstein, Reframe, Reuse, and Re-Style: (De)Constructing the Sustainable SecondHand Consumer. Doctoral Dissertation, Wesleyan University, Middletown, Connecticut, USA (2014).

https://wesscholar.wesleyan.edu/cgi/viewcontent.cgi?referer $=\&$ httpsredir=1\&article=2220\&co ntext=etd hon theses (accessed 24/11/2018).

[39] D. Guiot, D. Roux, A Second-hand Shoppers' Motivation Scale: Antecedents, Consequences, and Implications for Retailers, Journal of Retailing, 86 (2010) 355-371. [40] L.M. Fortuna, V. Diyamandoglu, Disposal and acquisition trends in second-hand products, Journal of Cleaner Production, 142 (2017) 2454-2462. [41] B. Tuttle, The Rise of Snobby Secondhand Fashion Retail, Time (2014). http://business.time.com/2014/02/25/the-rise-of-snobby-secondhand-fashion-retail/ (accessed 24/11/2013. .

[42] L.M. Fortuna, V. Diyamandoglu, Optimization of greenhouse gas emissions in second-hand consumer product recovery through reuse platforms, Waste Management, 66 (2017) 178-189.

[43] A.M. Souza, M.F. Nascimento, D.H. Almeida, D.A. Lopes Silva, T.H. Almeida, A.L. Christoforo, F.A.R. Lahr, Wood-based composite made of wood waste and epoxy based inkwaste as adhesive: A cleaner production alternative, Journal of Cleaner Production, 193 (2018) 549-562. [44] J.F. Horta, F.J. Simões, A. Mateus, Study of Wood-Plastic Composites with Reused High Density Polyethylene and Wood Sawdust, Procedia Manufacturing, 12 (2017) 221-229. [45] C. Croitoru, A.M. Varodi, M.C. Timar, I.C. Roata, E.M. Stanciu, A. Pascu, Wood-plastic composites based on HDPE and ionic liquid additives, Journal of Materials Science, 53 (2018) 4132-4143.

[46] V. Diyamandoglu, L.M. Fortuna, Deconstruction of wood-framed houses: Material recovery and environmental impact, Resources, Conservation and Recycling, 100 (2015) 21-30.

[47] U. Hossain, L. Wang, I.K.M. Yu, D.C.W. Tsang, C.-S. Poon, Environmental and technical feasibility study of upcycling wood waste into cement-bonded particleboard, 173 (2018) 474480.

[48] M. Pavlíková, L. Zemanová, J. Pokorný, M. Záleská, O. Jankovský, M. Lojka, D. mortar mix design, Waste Management, 80 (2018) 89-100.

[49] R. Husgafvel, L. Linkosalmi, M. Hughes, J. Kanerva, O. Dahl, Forest sector circular economy development in Finland: A regional study on sustainability driven competitive advantage and an assessment of the potential for cascading recovered solid wood, Journal of Cleaner Production, 181 (2018) 483-497.

[50] W.-H. Chen, J. Peng, X.T. Bi, A state-of-the-art review of biomass torrefaction, densification and applications, Renewable and Sustainable Energy Reviews, 44 (2015) 847-866. [51] M. Sami, K. Annamalai, M. Wooldridge, Co-firing of coal and biomass fuel blends, Progress in Energy and Combustion Science, 27 (2001) 171-214.

[52] C. Mayer-Laigle, N. Blanc, K.R. Rajaonarivony, X. Rouau, Comminution of Dry Lignocellulosic Biomass, a Review: Part I. From Fundamental Mechanisms to Milling Behaviour, Bioengineering, 5 (2018).

[53] Z. Miao, T.E. Grift, A.C. Hansen, K.C. Ting, Energy requirement for comminution of biomass in relation to particle physical properties, Industrial Crops and Products, 33 (2011) 504513. 
[54] C. Igathinathane, A.R. Womac, S. Sokhansanj, S. Narayan, Size reduction of high- and lowmoisture corn stalks by linear knife grid system, Biomass and Bioenergy, 33 (2009) 547-557. [55] A. Sarvaramini, G.P. Assima, F. Larachi, Dry torrefaction of biomass - Torrefied products and torrefaction kinetics using the distributed activation energy model, Chemical Engineering Journal, 229 (2013) 498-507.

[56] S. Ren, H. Lei, L. Wang, Q. Bu, S. Chen, J. Wu, Thermal behaviour and kinetic study for woody biomass torrefaction and torrefied biomass pyrolysis by TGA, Biosystems Engineering, 116 (2013) 420-426.

[57] R.B. Bates, A.F. Ghoniem, Modeling kinetics-transport interactions during biomass torrefaction: The effects of temperature, particle size, and moisture content, Fuel, 137 (2014) 216-229.

[58] J. Klinger, B. Klemetsrud, E. Bar-Ziv, D. Shonnard, Temperature dependence of aspen torrefaction kinetics, Journal of Analytical and Applied Pyrolysis, 110 (2014) 424-429.

[59] S. Gul, N. Ramzan, M.A. Hanif, S. Bano, Kinetic, volatile release modeling and optimization of torrefaction, Journal of Analytical and Applied Pyrolysis, 128 (2017) 44-53. [60] A. Friedl, E. Padouvas, H. Rotter, K. Varmuza, Prediction of heating values of biomass fuel from elemental composition, Analytica Chimica Acta, 544 (2005) 191-198.

[61] R. Radmanesh, Y. Courbariaux, J. Chaouki, C. Guy, A unified lumped approach in kinetic modeling of biomass pyrolysis, Fuel, 85 (2006) 1211-1220.

[62] C. Di Blasi, M. Lanzetta, Intrinsic kinetics of isothermal xylan degradation in inert atmosphere, Journal of Analytical and Applied Pyrolysis, 40-41 (1997) 287-303. [63] M.J. Prins, K.J. Ptasinski, F.J.J.G. Janssen, Torrefaction of wood: Part 1. Weight loss kinetics, Journal of Analytical and Applied Pyrolysis, 77 (2006) 28-34.

[64] P.S. Lam, P.Y. Lam, S. Sokhansanj, X.T. Bi, C.J. Lim, Mechanical and compositional characteristics of steam-treated Douglas fir (Pseudotsuga menziesii L.) during pelletization, Biomass and Bioenergy, 56 (2013) 116-126.

[65] Z. Tooyserkani, S. Sokhansanj, X. Bi, J. Lim, A. Lau, J. Saddler, L. Kumar, P.S. Lam, S. Melin, Steam treatment of four softwood species and bark to produce torrefied wood, Applied Energy, 103 (2013) 514-521.

[66] J. Wojtasz-Mucha, M. Hasani, H. Theliander, Hydrothermal pretreatment of wood by mild steam explosion and hot water extraction, Bioresource Technology, 241 (2017) 120-126.

[67] T.N. Cong, A thermogravimetric and kinetic study on devolatilization of biomass, Masters https://brage.bibsys.no/xmlui/bitstream/handle/11250/2504845/18838 FULLTEXT.pdf?seque nce $=1 \&$ isAllowed $=y$ (accessed 28/11/2018).

[68] P.S. Lam, S. Sokhansanj, C.J. Lim, X. Bi, S. Melin, Kinetic Modeling of Pseudolignin Formation in Steam Exploded Woody Biomass, 8th World Congress of Chemical Engineering (2009) 23-27.

[69] F. Ahmad, E.L. Silva, M.B.A. Varesche, Hydrothermal processing of biomass for anaerobic digestion - A review, Renewable and Sustainable Energy Reviews, 98 (2018) 108-124.

[70] K. Kucharska, I. Hołowacz, D. Konopacka-Łyskawa, P. Rybarczyk, M. Kamiński, Key issues in modeling and optimization of lignocellulosic biomass fermentative conversion to gaseous biofuels, Renewable Energy, 129 (2018) 384-408.

[71] L. Matsakas, V. Raghavendran, O. Yakimenko, G. Persson, E. Olsson, U. Rova, L. Olsson, P. Christakopoulos, Lignin-first biomass fractionation using a hybrid organosolv - Steam explosion pretreatment technology improves the saccharification and fermentability of spruce biomass, Bioresource Technology, 273 (2019) 521-528.

[72] A. Romaní, G. Garrote, I. Ballesteros, M. Ballesteros, Second generation bioethanol from steam exploded Eucalyptus globulus wood, Fuel, 111 (2013) 66-74. 
1803 [73] C. Asada, C. Sasaki, T. Hirano, Y. Nakamura, Chemical characteristics and enzymatic 1804 saccharification of lignocellulosic biomass treated using high-temperature saturated steam: Comparison of softwood and hardwood, Bioresource Technology, 182 (2015) 245-250.

[74] D. Jung, A. Kruse, Evaluation of Arrhenius-type overall kinetic equations for hydrothermal carbonization, Journal of Analytical and Applied Pyrolysis, 127 (2017) 286-291.

[75] H.P. Ruyter, Coalification model, Fuel, 61 (1982) 1182-1187.

[76] R. Becker, U. Dorgerloh, M. Helmis, J. Mumme, M. Diakité, I. Nehls, Hydrothermally carbonized plant materials: Patterns of volatile organic compounds detected by gas chromatography, Bioresource Technology, 130 (2013) 621-628.

[77] S.K. Hoekman, A. Broch, C. Robbins, Hydrothermal Carbonization (HTC) of Lignocellulosic Biomass, Energy \& Fuels, 25 (2011) 1802-1810.

[78] S.K. Hoekman, A. Broch, C. Robbins, B. Zielinska, L. Felix, Hydrothermal carbonization (HTC) of selected woody and herbaceous biomass feedstocks, Biomass Conversion and Biorefinery, 3 (2013) 113-126.

[79] M.T. Reza, W. Yan, M.H. Uddin, J.G. Lynam, S.K. Hoekman, C.J. Coronella, V.R. Vásquez, Reaction kinetics of hydrothermal carbonization of loblolly pine, Bioresource Technology, 139 (2013) 161-169.

[80] M. Röder, P. Thornley, Waste wood as bioenergy feedstock. Climate change impacts and related emission uncertainties from waste wood based energy systems in the UK, Waste Management, 74 (2018) 241-252.

[81] A.I. Moreno, R. Font, J.A. Conesa, Physical and chemical evaluation of furniture waste briquettes, Waste Management, 49 (2016) 245-252.

[82] A.I. Moreno, R. Font, J.A. Conesa, Combustion of furniture wood waste and solid wood: Kinetic study and evolution of pollutants, Fuel, 192 (2017) 169-177.

[83] X. Fang, L. Jia, L. Yin, A weighted average global process model based on two-stage kinetic scheme for biomass combustion, Biomass and Bioenergy, 48 (2013) 43-50.

[84] A. Álvarez, C. Pizarro, R. García, J.L. Bueno, A.G. Lavín, Determination of kinetic parameters for biomass combustion, Bioresource Technology, 216 (2016) 36-43.

[85] S.Y. Yorulmaz, A.T. Atimtay, Investigation of combustion kinetics of treated and untreated waste wood samples with thermogravimetric analysis, Fuel Processing Technology, 90 (2009) 939-946.

[86] M. Gao*, S. Li, C. Sun, THERMAL DEGRADATION OF WOOD IN AIR AND NITROGEN TREATED WITH BASIC NITROGEN COMPOUNDS AND PHOSPHORIC ACID, Combustion Science and Technology, 176 (2004) 2057-2070.

[87] J. Reina, E. Velo, L. Puigjaner, Thermogravimetric study of the pyrolysis of waste wood, Thermochimica Acta, 320 (1998) 161-167.

[88] M. Deka, C.N. Saikia, K.K. Baruah, Studies on thermal degradation and termite resistant properties of chemically modified wood, Bioresource Technology, 84 (2002) 151-157.

[89] A.P. Schniewind, Concise Encyclopedia ofWood and Wood Based Materials, 1st ed. Pergamon Press, Elmsford, 1989.

[90] R. Zakrzewski, Pyrolysis kinetics of wood comparison of iso and polythermal thermogravimetric methods, Electronic Journal of Polish Agricultural Universities, 6 (2003) 2. [91] M. Gao, a.D.X. Pan, Study on the thermal degradation of wood treated with amino resin and amino resin modified with phosphoric acid, Journal of Fire Sciences, 21 (2003) 189-201.

[92] D.P. Koullas, N. Nikolaou, E.G. Koukios, Modelling non-isothermal kinetics of biomass prepyrolysis at low pressure, Bioresource Technology, 63 (1998) 261-266.

[93] Q. Wang, W. Zhao, H. Liu, C. Jia, H. Xu, Reactivity and Kinetic Analysis of Biomass during Combustion, Energy Procedia, 17 (2012) 869-875. 

Biomass Valorization, 2018 https://doi.org/10.1007/s12649-018-0407-6 (accessed 4/12/2018). [95] M. Lanfranchi, E. Schimmenti, C. Giannetto, Economic analysis and energy valorisation of by-products of the wine supply chain: the case of the 'Mamertino wine PDO', International Journal of Environmental Studies, 75 (2018) 800-811. [96] M. Fernández-Delgado Juárez, P. Mostbauer, A. Knapp, W. Müller, S. Tertsch, A. Bockreis, H. Insam, Biogas purification with biomass ash, Waste Management, 71 (2018) 224-232. [97] N. Klinghoffer, M.J. Castaldi, A. Nzihou, Beneficial Use of Ash and Char from Biomass Gasification, Proceedings of the 19th Annual North American Waste-to-Energy Conference, http:/www.seas.columbia.edu/earth/wtert/sofos/nawtec/nawtec19(new)/NAWTEC19-5421.pdf (accessed 4/12/2018). [98] Z. Abu El-Rub, E.A. Bramer, G. Brem, Experimental comparison of biomass chars with other catalysts for tar reduction, Fuel, 87 (2008) 2243-2252. [99] A. Dhahak, R. Bounaceur, C. Le Dreff-Lorimier, G. Schmidt, G. Trouve, F. Battin-Leclerc, Development of a detailed kinetic model for the combustion of biomass, Fuel, 242 (2019) 756774.

[100] Kim, G.-M.; Lee, D.-G.; Jeon, C.-H. Fundamental Characteristics and Kinetic Analysis of Lignocellulosic Woody and Herbaceous Biomass Fuels. Energies 2019, 12, 1008.

[101] L.J. Naimi, S. Sokhansanj, Data-based equation to predict power and energy input for grinding wheat straw, corn stover, switchgrass, miscanthus, and canola straw, Fuel Processing Technology, 173 (2018) 81-88. [102] J. F. Arthur, R. A. Kepner, J. B. Dobie, G. E. Miller, P. S. Parsons, Tub Grinder Performance with Crop and Forest Residues, Transactions of the ASAE, 25 (1982) 1488-1494. [103] M. Sajdak, Development and validation of new methods for identification of bio-char as an alternative solid bio-fuel for power generation, Fuel Processing Technology, 167 (2017) 229240.

[104] J. Kaknics, R. Michel, J. Poirier, Miscanthus ash transformation and interaction with bed materials at high temperature, Fuel Processing Technology, 141 (2016) 178-184.

1881

1882 [105] X.-H. Pham, B. Piriou, S. Salvador, J. Valette, L. Van de Steene, Oxidative pyrolysis of pine wood, wheat straw and miscanthus pellets in a fixed bed, Fuel Processing Technology, 178 (2018) 226-235. [106] E.G.A. Forbes, D.L. Easson, G.A. Lyons, W.C. McRoberts, Physico-chemical characteristics of eight different biomass fuels and comparison of combustion and emission results in a small scale multi-fuel boiler, Energy Conversion and Management, 87 (2014) 11621169.

[107] M.K.a.M. Fechter, Treatment of Digestates from Biogas Production - Status and Trends, https://docplayer.net/28539259-Treatment-of-digestates-from-biogas-production-status-andtrends.html, accessed on the 23-10 2018 at 3pm., (2014).

1891 of herbaceous crops, Fuel, 88 (2009) 1491-1497.

1892 [109] M. Jeguirim, S. Dorge, T. Gwenaelle, Thermogravimetric analysis and emission characteristics of two energy crops in air atmosphere: Arundo donax and Miscanthus giganthus, Bioresource Technology, 101 (2010) 788-793.

[110] Y.J. Bae, C. Ryu, J.K. Jeon, J. Park, D.J. Suh, Y.W. Suh, D. Chang, Y.K. Park, The characteristics of bio-oil produced from the pyrolysis of three marine macroalgae, Bioresour Technol, 102 (2011) 3512-3520. behaviour of brown algae before and after pre-treatment using PY-GC/MS and TGA, J Anal Appl Pyrol, 85 (2009) 3-10. 

determination of the carbohydrate composition of brown seaweeds (Laminariaceae), Rsc Adv, 4 (2014) 25736-25746.

1904 [113] N.C. Moroney, M.N. O'Grady, S. Lordan, C. Stanton, J.P. Kerry, Seaweed polysaccharides (laminarin and fucoidan) as functional ingredients in pork meat: an evaluation of anti-oxidative potential, thermal stability and bioaccessibility, Mar Drugs, 13 (2015) 2447-2464.

[114] M. Broström, Aspects of alkali chloride chemistry on deposit formation and high temperature corrosion in biomass and waste fired boilers, http://www.divaportal.org/smash/get/diva2:317028/FULLTEXT01.pdfMarkusMarkus, Energy Technology and Thermal Process Chemistry, Academic dissertation 2010 (2010). [115] N. Skoglund, K. Werner, G.M. Nylund, H. Pavia, E. Albers, M. Broström, Combustion of seaweed - A fuel design strategy, Fuel Process Technol, 165 (2017) 155-161.

[116] A.B. Ross, J.M. Jones, M.L. Kubacki, T. Bridgeman, Classification of macroalgae as fuel and its thermochemical behaviour, Bioresour Technol, 99 (2008) 6494-6504.

[117] H. Haykiri-Acma, S. Yaman, S. Kucukbayrak, Production of biobriquettes from carbonized brown seaweed, Fuel Process Technol, 106 (2013) 33-40.

[118] M. Aresta, A. Dibenedetto, G. Barberio, Utilization of macro-algae for enhanced CO2 fixation and biofuels production: Development of a computing software for an LCA study, Fuel Process Technol, 86 (2005) 1679-1693.

1920 [119] A.B. Ross, C. Hall, K. Anastasakis, A. Westwood, J.M. Jones, R.J. Crewe, Influence of cation on the pyrolysis and oxidation of alginates, J Anal Appl Pyrol, 91 (2011) 344-351.

[120] K. Anastasakis, A.B. Ross, J.M. Jones, Pyrolysis behaviour of the main carbohydrates of brown macro-algae, Fuel, 90 (2011) 598-607.

[121] M.R. Tabassum, A. Xia, J.D. Murphy, Biomethane production from various segments of brown seaweed, Energ Convers Manage, 174 (2018) 855-862.

[122] A.E. Burns, J.H. Bradbury, T.R. Cavagnaro, R.M. Gleadow, Total cyanide content of cassava food products in Australia, J Food Compos Anal, 25 (2012) 79-82.

[123] O.L. Ki, A. Kurniawan, C.X. Lin, Y.H. Ju, S. Ismadji, Bio-oil from cassava peel: a potential renewable energy source, Bioresour Technol, 145 (2013) 157-161.

1930 [124] M. Van de Velden, J. Baeyens, I. Boukis, Modeling CFB biomass pyrolysis reactors, 1931 Biomass and Bioenergy, 32 (2008) 128-139.

1932 [125] S. Ismadji, S.K. Bhatia, Characterization of activated carbons using liquid phase adsorption 1933 Carbon, 39 (2001) 1237-1250.

1934 [126] F. Suarez-Garcia, A. Martinez-Alonso, J.M.D. Tascon, Pyrolysis of apple pulp: chemical activation with phosphoric acid, J Anal Appl Pyrol, 63 (2002) 283-301.

[127] Y. Sudaryanto, S.B. Hartono, W. Irawaty, H. Hindarso, S. Ismadji, High surface area activated carbon prepared from cassava peel by chemical activation, Bioresour Technol, 97 (2006) 734-739.

[128] J. Gañan, C.M. González-García, J.F. González, E. Sabio, A. Macías-García, M.A. DíazDíez, Preparation of activated carbons from bituminous coal pitches, Appl Surf Sci, 238 (2004) 347-354.

[129] J.C. Moreno-Piraján, L. Giraldo, Adsorption of copper from aqueous solution by activated carbons obtained by pyrolysis of cassava peel, J Anal Appl Pyrol, 87 (2010) 188-193.

[130] P. Perumal, s.s.b. Vasanthakumar, K.V. Thiruvengadaravi, J. Nandagopal, M. Palanichamy, S. Sivanesan, The removal of copper ions from aqueous solution using phosphoric acid modified $\beta$ - zeolites Indian Journal of Science and Technology

$1947 \quad 2(2009) 63-66$. 

CAPACITY OF COPPER OF NATURAL AND MODIFIED RADIATA BARK PINE, Journal of the Chilean Chemical Society, 48 (2003) 11-16. [132] F. Ekmekyapar, A. Aslan, Y.K. Bayhan, A. Cakici, Biosorption of $\mathrm{Pb}(\mathrm{II})$ by Nonliving Lichen Biomass of Cladonia rangiformis Hoffm, Int J Environ Res, 6 (2012) 417-424. $\mathrm{Cu}(\mathrm{II})$ from aqueous solution using cassava peel (Manihot esculenta), J Hazard Mater, 180 (2010) 366-374.

1956 [134] A. Kurniawan, A.N. Kosasih, J. Febrianto, Y.-H. Ju, J. Sunarso, N. Indraswati, S. Ismadji, 1957 Evaluation of cassava peel waste as lowcost biosorbent for Ni-sorption: Equilibrium, kinetics, thermodynamics and mechanism, Chem Eng J, 172 (2011) 158-166.

1959 [135] N. Feng, X. Guo, S. Liang, Y. Zhu, J. Liu, Biosorption of heavy metals from aqueous solutions by chemically modified orange peel, J Hazard Mater, 185 (2011) 49-54.

[136] A. Bhatnagar, A.K. Minocha, Biosorption optimization of nickel removal from water using Punica granatum peel waste, Colloids Surf B Biointerfaces, 76 (2010) 544-548.

[137] A.P. Moshi, S.G. Temu, I.A. Nges, G. Malmo, K.M.M. Hosea, E. Elisante, B. Mattiasson, Combined production of bioethanol and biogas from peels of wild cassava Manihot glaziovii, Chem Eng J, 279 (2015) 297-306.

[138] A. Adekunle, V. Orsat, V. Raghavan, Lignocellulosic bioethanol: A review and design conceptualization study of production from cassava peels, Renew Sust Energ Rev, 64 (2016) 518-530.

1969 [139] J.P. Bok, H.S. Choi, Y.S. Choi, H.C. Park, S.J. Kim, Fast pyrolysis of coffee grounds: Characteristics of product yields and biocrude oil quality, Energy, 47 (2012) 17-24.

[140] D. Pujol, C. Liu, J. Gominho, M.À. Olivella, N. Fiol, I. Villaescusa, H. Pereira, The chemical composition of exhausted coffee waste, Ind Crop Prod, 50 (2013) 423-429.

[141] R. Campos-Vega, G. Loarca-Piña, H.A. Vergara-Castañeda, B.D. Oomah, Spent coffee grounds: A review on current research and future prospects, Trends Food Sci Tech, 45 (2015) 24-36.

1978

[142] S.I. Mussatto, L.M. Carneiro, J.P.A. Silva, I.C. Roberto, J.A. Teixeira, A study on chemical constituents and sugars extraction from spent coffee grounds, Carbohyd Polym, 83 (2011) 368374.

1979 [143] S.B. Kang, H.Y. Oh, J.J. Kim, K.S. Choi, Characteristics of spent coffee ground as a fuel and combustion test in a small boiler (6.5 kW), Renew Energ, 113 (2017) 1208-1214.

[144] P. Jutakridsada, C. Prajaksud, L. Kuboonya-Aruk, S. Theerakulpisut, K. Kamwilaisak, Adsorption characteristics of activated carbon prepared from spent ground coffee, Clean Technologies and Environmental Policy, 18 (2015) 639-645.

[145] A. Naga Babu, D.S. Reddy, G.S. Kumar, K. Ravindhranath, G.V. Krishna Mohan, Removal of lead and fluoride from contaminated water using exhausted coffee grounds based bio-sorbent, Journal of environmental management, 218 (2018) 602-612.

[146] J. Chen, J. Liu, Y. He, L. Huang, S. Sun, J. Sun, K. Chang, J. Kuo, S. Huang, X. Ning, Investigation of co-combustion characteristics of sewage sludge and coffee grounds mixtures using thermogravimetric analysis coupled to artificial neural networks modeling, Bioresour Technol, 225 (2017) 234-245.

[147] C.T. Primaz, T. Schena, E. Lazzari, E.B. Caramão, R.A. Jacques, Influence of the temperature in the yield and composition of the bio-oil from the pyrolysis of spent coffee grounds: Characterization by comprehensive two dimensional gas chromatography, Fuel, 232 (2018) 572-580.

[148] F. Codignole Luz, S. Cordiner, A. Manni, V. Mulone, V. Rocco, Biomass fast pyrolysis in screw reactors: Prediction of spent coffee grounds bio-oil production through a monodimensional model, Energ Convers Manage, 168 (2018) 98-106. 
[149] M. Jahirul, M. Rasul, A. Chowdhury, N. Ashwath, Biofuels Production through Biomass Pyrolysis - A Technological Review, Energies, 5 (2012) 4952-5001.

[150] I. Demiral, E.A. Ayan, Pyrolysis of grape bagasse: effect of pyrolysis conditions on the product yields and characterization of the liquid product, Bioresour Technol, 102 (2011) 39463951.

[151] J. Kim, H. Kim, G. Baek, C. Lee, Anaerobic co-digestion of spent coffee grounds with different waste feedstocks for biogas production, Waste Manag, 60 (2017) 322-328.

[152] F.C. Luz, S. Cordiner, A. Manni, V. Mulone, V. Rocco, Anaerobic digestion of coffee grounds soluble fraction at laboratory scale: Evaluation of the biomethane potential, Appl Energ, 207 (2017) 166-175.

[153] A.E. Pütün, A. Özcan, E. Pütün, Pyrolysis of hazelnut shells in a fixed-bed tubular reactor: yields and structural analysis of bio-oil J Anal Appl Pyrol, 52 (1999) 33-49.

[154] E.Z. Hoşgün, D. Berikten, M. Kıvanç, B. Bozan, Ethanol production from hazelnut shells through enzymatic saccharification and fermentation by low-temperature alkali pretreatment, Fuel, 196 (2017) 280-287.

[155] H. Haykiri-Acma, S. Yaman, S. Kucukbayrak, Combustion characteristics of sodium-free pyrolytic char from hazelnut shell, Fuel Process Technol, 96 (2012) 169-174.

[156] J. Kaknics, F. Defoort, J. Poirier, Inorganic Phase Transformation in Miscanthus Ash, Energy \& Fuels, 29 (2015) 6433-6442.

[157] A.I. Osman, A.T. Ahmed, C.R. Johnston, D.W. Rooney, Physicochemical characterization of miscanthus and its application in heavy metals removal from wastewaters, Environmental Progress \& Sustainable Energy, 37 (2018) 1058-1067.

[158] A. Hlavsová, A. Corsaro, H. Raclavská, S. Vallová, D. Juchelková, The effect of feedstock composition and taxonomy on the products distribution from pyrolysis of nine herbaceous plants, Fuel Processing Technology, 144 (2016) 27-36.

[159] S. Kumar, P. Ghosh, Sustainable bio-energy potential of perennial energy grass from reclaimed coalmine spoil (marginal sites) of India, Renewable Energy, 123 (2018) 475-485.

[160] L.I.N. Li, H. Zhang, Production and Characterization of Pyrolysis Oil from Herbaceous Biomass (Achnatherum Splendens), Energy Sources, 27 (2005) 319-326.

[161] L. Sulas, A. Franca, F. Sanna, G.A. Re, R. Melis, C. Porqueddu, Biomass characteristics in Mediterranean populations of Piptatherum miliaceum-A native perennial grass species for bioenergy, Industrial Crops and Products, 75 (2015) 76-84.

[162] A. Panahi, Y.A. Levendis, N. Vorobiev, M. Schiemann, Direct observations on the combustion characteristics of Miscanthus and Beechwood biomass including fusion and spherodization, Fuel Processing Technology, 166 (2017) 41-49.

[163] G. Gozaydin, A. Yuksel, Valorization of hazelnut shell waste in hot compressed water, Fuel Process Technol, 166 (2017) 96-106.

[164] C. Xue, T. Xu, J. Wang, J. Zheng, X. Hao, G. Guan, Direct synthesis of alkaline earth metal Ca incorporated KHSi2O5 layered silicate, Materials Letters, 161 (2015) 530-533.

[165] J.S. Lim, Z. Abdul Manan, S.R. Wan Alwi, H. Hashim, A review on utilisation of biomass from rice industry as a source of renewable energy, Renewable and Sustainable Energy Reviews, 16 (2012) 3084-3094.

[166] I. Quispe, R. Navia, R. Kahhat, Energy potential from rice husk through direct combustion and fast pyrolysis: A review, Waste Management, 59 (2017) 200-210.

[167] T. Madhiyanon, P. Sathitruangsak, S. Soponronnarit, Combustion characteristics of ricehusk in a short-combustion-chamber fluidized-bed combustor (SFBC), Applied Thermal Engineering, 30 (2010) 347-353.

[168] P. Ninduangdee, V.I. Kuprianov, Fluidized bed co-combustion of rice husk pellets and moisturized rice husk: The effects of co-combustion methods on gaseous emissions, Biomass and Bioenergy, 112 (2018) 73-84. 
[169] S.J. Yoon, Y.-I. Son, Y.-K. Kim, J.-G. Lee, Gasification and power generation characteristics of rice husk and rice husk pellet using a downdraft fixed-bed gasifier, Renewable Energy, 42 (2012) 163-167.

[170] G.B. García, M. Calero de Hoces, C. Martínez García, M.T. Cotes Palomino, A.R. Gálvez, M.Á. Martín-Lara, Characterization and modeling of pyrolysis of the two-phase olive mill solid waste, Fuel Processing Technology, 126 (2014) 104-111.

[171] A.E. Erdogdu, R. Polat, G. Ozbay, Pyrolysis of goat manure to produce bio-oil, Engineering Science and Technology, an International Journal, (2018).

[172] C.T. Chong, G.R. Mong, J.-H. Ng, W.W.F. Chong, F.N. Ani, S.S. Lam, H.C. Ong, Pyrolysis characteristics and kinetic studies of horse manure using thermogravimetric analysis, Energy Conversion and Management, 180 (2019) 1260-1267.

2059 [173] B. Janković, Devolatilization kinetics of swine manure solid pyrolysis using deconvolution procedure. Determination of the bio-oil/liquid yields and char gasification, Fuel Processing Technology, 138 (2015) 1-13.

[174] B.S. Thomas, Green concrete partially comprised of rice husk ash as a supplementary cementitious material - A comprehensive review, Renewable and Sustainable Energy Reviews, 82 (2018) 3913-3923.

[175] S.-H. Kang, S.-G. Hong, J. Moon, The use of rice husk ash as reactive filler in ultra-high performance concrete, Cement and Concrete Research, 115 (2019) 389-400.

[176] I. Quispe, R. Navia, R. Kahhat, Life Cycle Assessment of rice husk as an energy source. A Peruvian case study, Journal of Cleaner Production, 209 (2019) 1235-1244.

2069 [177] H. Weldekidan, V. Strezov, G. Town, T. Kan, Production and analysis of fuels and chemicals obtained from rice husk pyrolysis with concentrated solar radiation, Fuel, 233 (2018) 396-403.

[178] A.C.R. Lim, B.L.F. Chin, Z.A. Jawad, K.L. Hii, Kinetic Analysis of Rice Husk Pyrolysis Using Kissinger-Akahira-Sunose (KAS) Method, Procedia Engineering, 148 (2016) 1247-1251. [179] R. Khonde, A. Chaurasia, Rice husk gasification in a two-stage fixed-bed gasifier: Production of hydrogen rich syngas and kinetics, International Journal of Hydrogen Energy, 41 (2016) 8793-8802.

[180] A.B. Alias, D.C. Shallcross, A.S.A.K. Sharifah, Rice husk combustion evolved gas analysis experiments and modelling, Biomass and Bioenergy, 78 (2015) 36-47.

[181] E. Christoforou, A. Kylili, P.A. Fokaides, Technical and economical evaluation of olive mills solid waste pellets, Renewable Energy, 96 (2016) 33-41.

[182] S.O. Abdelhadi, C.G. Dosoretz, G. Rytwo, Y. Gerchman, H. Azaizeh, Production of biochar from olive mill solid waste for heavy metal removal, Bioresource Technology, 244 (2017) 759-767.

[183] H.I. Elkhouly, R.K. Abdel-Magied, M.F. Aly, Date palm seed as suitable filler material in glass-epoxy composites, Iranian Polymer Journal, (2018).

[184] S.M. Sirry, F. Aldakhil, O.M.L. Alharbi, I. Ali, Chemically treated date stones for uranium (VI) uptake and extraction in aqueous solutions, Journal of Molecular Liquids, 273 (2019) 192202.

[185] N.E. Messaoudi, M.E. Khomri, S. Bentahar, A. Dbik, A. Lacherai, B. Bakiz, Evaluation of performance of chemically treated date stones: Application for the removal of cationic dyes from aqueous solutions, Journal of the Taiwan Institute of Chemical Engineers, 67 (2016) 244253.

[186] S.A.B. Al-Omari, Evaluation of the biomass "date stones" as a fuel in furnaces: A comparison with coal combustion, International Communications in Heat and Mass Transfer, 36 (2009) 956-961. 

Preparation and characterization of an activated carbon from a date stones variety by physical activation with carbon dioxide, Journal of Analytical and Applied Pyrolysis, 99 (2013) 155-160. [188] S. Rezma, I.B. Assaker, Y. litaiem, R. Chtourou, A. Hafiane, H. Deleuze, Microporous activated carbon electrode derived from date stone without use of binder for capacitive deionization application, Materials Research Bulletin, 111 (2019) 222-229.

[189] A.F. Abbas, M.J. Ahmed, Mesoporous activated carbon from date stones (Phoenix dactylifera L.) by one-step microwave assisted K2CO3 pyrolysis, Journal of Water Process Engineering, 9 (2016) 201-207.

2103

2104

2105

2106

[190] Z. He, P.H. Pagliari, H.M. Waldrip, Applied and Environmental Chemistry of Animal Manure: A Review, Pedosphere, 26 (2016) 779-816.

2107

2108

2109

2110

2111

2112

2113

2114 520.

[192] S.A. Neshat, M. Mohammadi, G.D. Najafpour, P. Lahijani, Anaerobic co-digestion of animal manures and lignocellulosic residues as a potent approach for sustainable biogas production, Renewable and Sustainable Energy Reviews, 79 (2017) 308-322.

[193] M. Svanberg, C. Finnsgård, J. Flodén, J. Lundgren, Analyzing animal waste-to-energy supply chains: The case of horse manure, Renewable Energy, 129 (2018) 830-837.

[194] A. Hadin, O. Eriksson, Horse manure as feedstock for anaerobic digestion, Waste Management, 56 (2016) 506-518.

[195] V. Burg, G. Bowman, M. Haubensak, U. Baier, O. Thees, Valorization of an untapped resource: Energy and greenhouse gas emissions benefits of converting manure to biogas through anaerobic digestion, Resources, Conservation and Recycling, 136 (2018) 53-62.

[196] N. Scarlat, F. Fahl, J.-F. Dallemand, F. Monforti, V. Motola, A spatial analysis of biogas potential from manure in Europe, Renewable and Sustainable Energy Reviews, 94 (2018) 915930.

[197] J. Lee, D. Choi, Y.S. Ok, S.-R. Lee, E.E. Kwon, Enhancement of energy recovery from chicken manure by pyrolysis in carbon dioxide, Journal of Cleaner Production, 164 (2017) 146152.

[198] S. Xiu, A. Shahbazi, V. Shirley, D. Cheng, Hydrothermal pyrolysis of swine manure to bio-oil: Effects of operating parameters on products yield and characterization of bio-oil, Journal of Analytical and Applied Pyrolysis, 88 (2010) 73-79.

[199] N. Ruiz-Gómez, V. Quispe, J. Ábrego, M. Atienza-Martínez, M.B. Murillo, G. Gea, Copyrolysis of sewage sludge and manure, Waste Management, 59 (2017) 211-221.

[200] Y. Yue, Q. Lin, Y. Xu, G. Li, X. Zhao, Slow pyrolysis as a measure for rapidly treating cow manure and the biochar characteristics, Journal of Analytical and Applied Pyrolysis, 124 (2017) 355-361.

[201] K.G. Burra, M.S. Hussein, R.S. Amano, A.K. Gupta, Syngas evolutionary behavior during chicken manure pyrolysis and air gasification, Applied Energy, 181 (2016) 408-415.

[202] M. Fernandez-Lopez, G.J. Pedrosa-Castro, J.L. Valverde, L. Sanchez-Silva, Kinetic analysis of manure pyrolysis and combustion processes, Waste Management, 58 (2016) 230-240. [203] M. Fernandez-Lopez, M. Puig-Gamero, D. Lopez-Gonzalez, A. Avalos-Ramirez, J. Valverde, L. Sanchez-Silva, Life cycle assessment of swine and dairy manure: Pyrolysis and combustion processes, Bioresource Technology, 182 (2015) 184-192.

[204] J. Lundgren, E. Pettersson, Combustion of horse manure for heat production, Bioresource Technology, 100 (2009) 3121-3126.

[205] D. Cheng, L. Wang, A. Shahbazi, S. Xiu, B. Zhang, Catalytic cracking of crude bio-oil from glycerol-assisted liquefaction of swine manure, Energy Conversion and Management, 87 (2014) 378-384. 

to bio-oil: Effects of conversion parameters on bio-oil yield and characterization of bio-oil, [207] N. Wiangkham, B. Prapagdee, Potential of Napier grass with cadmium-resistant bacterial inoculation on cadmium phytoremediation and its possibility to use as biomass fuel, Chemosphere, 201 (2018) 511-518.

[208] J.A. Conesa, A. Domene, Biomasses pyrolysis and combustion kinetics through n-th order parallel reactions, Thermochimica Acta, 523 (2011) 176-181.

[209] Y. Xu, I. Keresztes, A.M. Condo, D. Phillips, P. Pepiot, C.T. Avedisian, Droplet combustion characteristics of algae-derived renewable diesel, conventional \#2 diesel, and their mixtures, Fuel, 167 (2016) 295-305.

[210] H. Haykiri-Acma, A. Baykan, S. Yaman, S. Kucukbayrak, Effects of fragmentation and particle size on the fuel properties of hazelnut shells, Fuel, 112 (2013) 326-330.

[211] L. Jin, H. Zhang, Z. Ma, Study on capacity of coffee grounds to be extracted oil, produce biodiesel and combust, Energy Procedia, 152 (2018) 1296-1301.

[212] M.M. Rahman, R. Liu, J. Cai, Catalytic fast pyrolysis of biomass over zeolites for high quality bio-oil - A review, Fuel Processing Technology, 180 (2018) 32-46.

[213] H. Yang, R. Yan, H. Chen, D.H. Lee, C. Zheng, Characteristics of hemicellulose, cellulose and lignin pyrolysis, Fuel, 86 (2007) 1781-1788.

[214] A.O. Balogun, F. Sotoudehniakarani, A.G. McDonald, Thermo-kinetic, spectroscopic study of brewer's spent grains and characterisation of their pyrolysis products, Journal of Analytical and Applied Pyrolysis, 127 (2017) 8-16.

[215] D.C. Kalyani, T. Fakin, S.J. Horn, R. Tschentscher, Valorisation of woody biomass by combining enzymatic saccharification and pyrolysis, Green Chemistry, 19 (2017) 3302-3312.

[216] A.V. Bridgwater, Review of fast pyrolysis of biomass and product upgrading, Biomass and Bioenergy, 38 (2012) 68-94.

[217] K.B. Ansari, V.G. Gaikar, Investigating production of hydrocarbon rich bio-oil from grassy biomass using vacuum pyrolysis coupled with online deoxygenation of volatile products over metallic iron, Renewable Energy, 130 (2019) 305-318.

[218] I.Y. Mohammed, Y.A. Abakr, S. Yusup, F.K. Kazi, Valorization of Napier grass via intermediate pyrolysis: Optimization using response surface methodology and pyrolysis products characterization, Journal of Cleaner Production, 142 (2017) 1848-1866.

[219] D. Özçimen, A. Ersoy-Meriçboyu, Characterization of biochar and bio-oil samples obtained from carbonization of various biomass materials, Renew Energ, 35 (2010) 1319-1324. [220] T.N. Trinh, P.A. Jensen, K. Dam-Johansen, N.O. Knudsen, H.R. Sørensen, S. Hvilsted, Comparison of Lignin, Macroalgae, Wood, and Straw Fast Pyrolysis, Energy \& Fuels, 27 (2013) 1399-1409.

[221] C. Hognon, F. Delrue, J. Texier, M. Grateau, S. Thiery, H. Miller, A. Roubaud, Comparison of pyrolysis and hydrothermal liquefaction of Chlamydomonas reinhardtii. Growth studies on the recovered hydrothermal aqueous phase, Biomass and Bioenergy, 73 (2015) 23-31. [222] W. Cai, L. Dai, R. Liu, Catalytic fast pyrolysis of rice husk for bio-oil production, Energy, 154 (2018) 477-487.

[223] M.S. Hossain, M.R. Islam, M.S. Rahman, M.A. Kader, H. Haniu, Biofuel from Copyrolysis of Solid Tire Waste and Rice Husk, Energy Procedia, 110 (2017) 453-458.

[224] G. Qi, P. Dong, M. Zhai, L. Wang, Experimental Study on Rice Husk Flash Pyrolysis with Discontinuity Feed for Production of Bio-oil, in: K. Cen, Y. Chi, F. Wang (Eds.) Challenges of Power Engineering and Environment, Springer Berlin Heidelberg, Berlin, Heidelberg, 2007, pp. 135-138.

[225] B.M. Jenkins, R.R. Bakker, J.B. Wei, On the properties of washed straw, Biomass and Bioenergy, 10 (1996) 177-200. 
[226] S.W. Banks, D.J. Nowakowski, A.V. Bridgwater, Fast pyrolysis processing of surfactant washed Miscanthus, Fuel Processing Technology, 128 (2014) 94-103. [227] H. Tan, S.-r. Wang, Experimental study of the effect of acid-washing pretreatment on biomass pyrolysis, Journal of Fuel Chemistry and Technology, 37 (2009) 668-672. [228] Z.A. Mayer, A. Apfelbacher, A. Hornung, Effect of sample preparation on the thermal degradation of metal-added biomass, Journal of Analytical and Applied Pyrolysis, 94 (2012) 170-176.

[229] N. Özbay, A.E. Pütün, B.B. Uzun, E. Pütün, Biocrude from biomass: pyrolysis of cottonseed cake, Renewable Energy, 24 (2001) 615-625. [230] A.E. Pütün, B.B. Uzun, E. Apaydin, E. Pütün, Bio-oil from olive oil industry wastes: Pyrolysis of olive residue under different conditions, Fuel Processing Technology, 87 (2005) 2532.

[231] J.M. Encinar, J.F. González, G. Martínez, S. Román, Catalytic pyrolysis of exhausted olive oil waste, Journal of Analytical and Applied Pyrolysis, 85 (2009) 197-203.

[232] Q. Lu, X.-1. Yang, X.-f. Zhu, Analysis on chemical and physical properties of bio-oil pyrolyzed from rice husk, Journal of Analytical and Applied Pyrolysis, 82 (2008) 191-198. [233] H.J. Park, K.-H. Park, J.-K. Jeon, J. Kim, R. Ryoo, K.-E. Jeong, S.H. Park, Y.-K. Park, Production of phenolics and aromatics by pyrolysis of miscanthus, Fuel, 97 (2012) 379-384. [234] N. Brosse, A. Dufour, X. Meng, Q. Sun, A. Ragauskas, Miscanthus: a fast-growing crop for biofuels and chemicals production, Biofuels, Bioproducts and Biorefining, 6 (2012) 580-598. [235] İ. Demiral, S. Şensöz, Fixed-Bed Pyrolysis of Hazelnut (Corylus Avellana L.) Bagasse: Influence of Pyrolysis Parameters on Product Yields, Energy Sources, Part A: Recovery, Utilization, and Environmental Effects, 28 (2006) 1149-1158. [236] A. Demirbas, Effects of temperature and particle size on bio-char yield from pyrolysis of agricultural residues, Journal of Analytical and Applied Pyrolysis, 72 (2004) 243-248.

[237] B. Girisuta, K.G. Kalogiannis, K. Dussan, J.J. Leahy, M.H.B. Hayes, S.D. Stefanidis, C.M. Michailof, A.A. Lappas, An integrated process for the production of platform chemicals and diesel miscible fuels by acid-catalyzed hydrolysis and downstream upgrading of the acid hydrolysis residues with thermal and catalytic pyrolysis, Bioresource Technology, 126 (2012) 92-100.

[238] P.T. Williams, N. Nugranad, Comparison of products from the pyrolysis and catalytic pyrolysis of rice husks, Energy, 25 (2000) 493-513.

[239] S. Du, Y. Sun, D.P. Gamliel, J.A. Valla, G.M. Bollas, Catalytic pyrolysis of miscanthus $\times$ giganteus in a spouted bed reactor, Bioresource Technology, 169 (2014) 188-197. [240] G.W. Huber, S. Iborra, A. Corma, Synthesis of Transportation Fuels from Biomass: Chemistry, Catalysts, and Engineering, Chemical Reviews, 106 (2006) 4044-4098.

[241] Z. Li, J.-S. Choi, H. Wang, A.W. Lepore, R.M. Connatser, S.A. Lewis, H.M. Meyer, D.M. Santosa, A.H. Zacher, Sulfur-Tolerant Molybdenum Carbide Catalysts Enabling LowTemperature Stabilization of Fast Pyrolysis Bio-oil, Energy \& Fuels, 31 (2017) 9585-9594.

[242] G. Duman, C. Okutucu, S. Ucar, R. Stahl, J. Yanik, The slow and fast pyrolysis of cherry seed, Bioresource Technology, 102 (2011) 1869-1878.

[243] H. Ben, A.J. Ragauskas, Comparison for the compositions of fast and slow pyrolysis oils by NMR characterization, Bioresource Technology, 147 (2013) 577-584.

[244] İ. Demiral, S. Şensöz, The effects of different catalysts on the pyrolysis of industrial wastes (olive and hazelnut bagasse), Bioresource Technology, 99 (2008) 8002-8007.

[245] A. Zheng, Z. Zhao, S. Chang, Z. Huang, H. Wu, X. Wang, F. He, H. Li, Effect of crystal size of ZSM-5 on the aromatic yield and selectivity from catalytic fast pyrolysis of biomass, Journal of Molecular Catalysis A: Chemical, 383-384 (2014) 23-30.

[246] J. Fermoso, H. Hernando, S. Jiménez-Sánchez, A.A. Lappas, E. Heracleous, P. Pizarro, J.M. Coronado, D.P. Serrano, Bio-oil production by lignocellulose fast-pyrolysis: Isolating and 
comparing the effects of indigenous versus external catalysts, Fuel Processing Technology, 167 (2017) 563-574.

[247] S. Liang, A.G. McDonald, Chemical and Thermal Characterization of Potato Peel Waste and Its Fermentation Residue as Potential Resources for Biofuel and Bioproducts Production, Journal of Agricultural and Food Chemistry, 62 (2014) 8421-8429.

[248] C.M. Santos, J. Dweck, R.S. Viotto, A.H. Rosa, L.C. de Morais, Application of orange peel waste in the production of solid biofuels and biosorbents, Bioresource Technology, 196 (2015) 469-479.

[249] C. Vasile, a.M.A. Brebu, Thermal Valorisation of biomass and of synthetic polymer waster. Upgrading of pyrolysis oils, Cellulose Chemistry and Technology, 40 (2006) 489-512. [250] S. Xiu, A. Shahbazi, Bio-oil production and upgrading research: A review, Renewable and Sustainable Energy Reviews, 16 (2012) 4406-4414.

[251] D.C. Elliott, P. Biller, A.B. Ross, A.J. Schmidt, S.B. Jones, Hydrothermal liquefaction of biomass: Developments from batch to continuous process, Bioresource Technology, 178 (2015) 147-156.

2260

[252] M.K. Jindal, a.M.K. Jha, Hydrothermal liquefaction of wood: a critical review Reviews in Chemical Engineering, 32 (2016) 459-488.

[253] A.R.K. Gollakota, N. Kishore, S. Gu, A review on hydrothermal liquefaction of biomass, Renewable and Sustainable Energy Reviews, 81 (2018) 1378-1392. [254] E. Ranzi, A. Cuoci, T. Faravelli, A. Frassoldati, G. Migliavacca, S. Pierucci, S. Sommariva, Chemical Kinetics of Biomass Pyrolysis, Energy \& Fuels, 22 (2008) 4292-4300. [255] T. Willner, G. Brunner, Pyrolysis Kinetics of Wood and Wood Components, Chemical Engineering \& Technology, 28 (2005) 1212-1225. [256] G. Mazziotti di Celso, S. Rapagnà, M. Prisciandaro, E.F. Zanoelo, Kinetics of pyrolysis and combustion of spherical wood particles in a fluidized bed, Energy Conversion and Management, 82 (2014) 27-36. Eucalyptus wood by whey incorporation, Bioresource Technology, 250 (2018) 256-264. [258] R.A. Sheldon, Green chemistry, catalysis and valorization of waste biomass, Journal of Molecular Catalysis A: Chemical, 422 (2016) 3-12. [259] I.M. Aroso, A.R. Araújo, R.A. Pires, R.L. Reis, Cork: Current Technological Developments and Future Perspectives for this Natural, Renewable, and Sustainable Material, ACS Sustainable Chemistry \& Engineering, 5 (2017) 11130-11146. [260] N. Cordeiro, M.N. Belgacem, A. Gandini, C.P. Neto, Urethanes and polyurethanes from suberin: 1. Kinetic study, Industrial Crops and Products, 6 (1997) 163-167.

[261] M.D. Garrett, S.C. Bennett, C. Hardacre, R. Patrick, G.N. Sheldrake, New methods in biomass depolymerisation: catalytic hydrogenolysis of barks, RSC Advances, 3 (2013) 21552 21557.

[262] M. Evtiouguina, A. Margarida Barros, J.J. Cruz-Pinto, C. Pascoal Neto, N. Belgacem, C. Pavier, A. Gandini, The oxypropylation of cork residues: preliminary results, Bioresource Technology, 73 (2000) 187-189.

[263] M.M. Mateus, N.F. Acero, J.C. Bordado, R.G. dos Santos, Sonication as a foremost tool to improve cork liquefaction, Industrial Crops and Products, 74 (2015) 9-13.

[264] A.V. Marques, H. Pereira, Aliphatic bio-oils from corks: A Py-GC/MS study, Journal of Analytical and Applied Pyrolysis, 109 (2014) 29-40.

[265] M. Evtiouguina, A. Gandini, C.P. Neto, N.M. Belgacem, Urethanes and polyurethanes based on oxypropylated cork: 1. Appraisal and reactivity of products, Polymer International, 50 (2001) 1150-1155. 

characteristics of co-pyrolysis of municipal sewage sludge and hazelnut shell, Bioresour Technol, 247 (2018) 21-29.

[267] D. Licursi, C. Antonetti, S. Fulignati, S. Vitolo, M. Puccini, E. Ribechini, L. Bernazzani, A.M. Raspolli Galletti, In-depth characterization of valuable char obtained from hydrothermal conversion of hazelnut shells to levulinic acid, Bioresour Technol, 244 (2017) 880-888. [268] A. Abbas, S. Ansumali, Global Potential of Rice Husk as a Renewable Feedstock for Ethanol Biofuel Production, BioEnergy Research, 3 (2010) 328-334. [269] J.O. Madu, B.O. Agboola, Bioethanol production from rice husk using different pretreatments and fermentation conditions, 3 Biotech, 8 (2017) 15. [270] E. Christoforou, P.A. Fokaides, A review of olive mill solid wastes to energy utilization techniques, Waste Management, 49 (2016) 346-363.

[271] F.-M. Pellera, S. Santori, R. Pomi, A. Polettini, E. Gidarakos, Effect of alkaline pretreatment on anaerobic digestion of olive mill solid waste, Waste Management, 58 (2016) $160-168$.

[272] S. Dermeche, M. Nadour, C. Larroche, F. Moulti-Mati, P. Michaud, Olive mill wastes: Biochemical characterizations and valorization strategies, Process Biochemistry, 48 (2013) 1532-1552.

[273] Y. Kavdır, D. Killi, Influence of olive oil solid waste applications on soil pH, electrical conductivity, soil nitrogen transformations, carbon content and aggregate stability, 2008.

[274] O. Guneser, A. Demirkol, Y.K. Yuceer, S.O. Togay, M.I. Hosoglu, M. Elibol, Production of flavor compounds from olive mill waste by Rhizopus oryzae and Candida tropicalis, Brazilian Journal of Microbiology, 48 (2017) 275-285.

[275] C. del Pozo, J. Bartrolí, N. Puy, E. Fàbregas, Separation of value-added chemical groups from bio-oil of olive mill waste, Industrial Crops and Products, 125 (2018) 160-167.

[276] A. Serrano, F.G. Fermoso, B. Alonso-Fariñas, G. Rodríguez-Gutierrez, J. FernandezBolaños, R. Borja, Phenols recovery after steam explosion of Olive Mill Solid Waste and its influence on a subsequent biomethanization process, Bioresource Technology, 243 (2017) 169178.

[277] M. Carlini, S. Castellucci, M. Moneti, Anaerobic Co-digestion of Olive-mill Solid Waste with Cattle Manure and Cattle Slurry: Analysis of Bio-methane Potential, Energy Procedia, 81 (2015) 354-367.

[278] M.J. Fernández-Rodríguez, B. Rincón, F.G. Fermoso, A.M. Jiménez, R. Borja, Assessment of two-phase olive mill solid waste and microalgae co-digestion to improve methane production and process kinetics, Bioresource Technology, 157 (2014) 263-269.

[279] M. Chandrasekaran, A.H. Bahkali, Valorization of date palm (Phoenix dactylifera) fruit processing by-products and wastes using bioprocess technology - Review, Saudi Journal of Biological Sciences, 20 (2013) 105-120.

[280] E. Elnajjar, S. Hasan, A. Hilal Alnaqbi, S.A.A. Omari, S. Al-Zuhair, Optimizing the Extraction of Oils from Date Seeds for Biodiesel Production, International Journal of Environmental Research, 12 (2018) 101-108.

[281] L. Favaro, M. Basaglia, S. Casella, Processing wheat bran into ethanol using mild treatments and highly fermentative yeasts, Biomass and Bioenergy, 46 (2012) 605-617.

[282] M. Reisinger, Ö. Tirpanalan, M. Prückler, F. Huber, W. Kneifel, S. Novalin, Wheat bran biorefinery - A detailed investigation on hydrothermal and enzymatic treatment, Bioresource Technology, 144 (2013) 179-185.

[283] X. Zhao, C. Dong, Extracting xylooligosaccharides in wheat bran by screening and cellulase assisted enzymatic hydrolysis, International Journal of Biological Macromolecules, 92 (2016) 748-752. 
2343 Novalin, W. Kneifel, Wheat bran-based biorefinery 2: Valorization of products, LWT - Food Science and Technology, 56 (2014) 222-231. wheat bran and rice straw by the white rot fungus Trametes hirsuta, Enzyme and Microbial Technology, 48 (2011) 273-277.

[286] J. Hollmann, M.G. Lindhauer, Pilot-scale isolation of glucuronoarabinoxylans from wheat bran, Carbohydrate Polymers, 59 (2005) 225-230.

[287] S. Rebolleda, S. Beltrán, M.T. Sanz, M.L. González-Sanjosé, Á.G. Solaesa, Extraction of alkylresorcinols from wheat bran with supercritical CO2, Journal of Food Engineering, 119 (2013) 814-821. [288] W. Ouyang, J.M. Reina, E. Kuna, A. Yepez, A.M. Balu, A.A. Romero, J.C. Colmenares, R. Luque, Wheat bran valorisation: Towards photocatalytic nanomaterials for benzyl alcohol photo-oxidation, Journal of Environmental Management, 203 (2017) 768-773.

[289] S. Sayen, M. Ortenbach-López, E. Guillon, Sorptive removal of enrofloxacin antibiotic from aqueous solution using a ligno-cellulosic substrate from wheat bran, Journal of Environmental Chemical Engineering, 6 (2018) 5820-5829.

[290] N. Gopalan, K.M. Nampoothiri, Biorefining of wheat bran for the purification of ferulic acid, Biocatalysis and Agricultural Biotechnology, 15 (2018) 304-310.

[291] M. Danish, T. Ahmad, A review on utilization of wood biomass as a sustainable precursor for activated carbon production and application, Renewable and Sustainable Energy Reviews, $236387(2018) 1-21$.

2364 [292] J. Skubiszewska-Zięba, B. Charmas, M. Kołtowski, P. Oleszczuk, Active carbons from waste biochars, Journal of Thermal Analysis and Calorimetry, 130 (2017) 15-24.

[293] M. Gueye, Y. Richardson, F.T. Kafack, J. Blin, High efficiency activated carbons from African biomass residues for the removal of chromium(VI) from wastewater, Journal of Environmental Chemical Engineering, 2 (2014) 273-281.

[294] A. Heidari, H. Younesi, A. Rashidi, A. Ghoreyshi, Adsorptive removal of CO2 on highly microporous activated carbons prepared from Eucalyptus camaldulensis wood: Effect of chemical activation, Journal of the Taiwan Institute of Chemical Engineers, 45 (2014) 579-588. [295] J. de Celis, N.E. Amadeo, A.L. Cukierman, In situ modification of activated carbons developed from a native invasive wood on removal of trace toxic metals from wastewater, Journal of Hazardous Materials, 161 (2009) 217-223.

[296] M. del Mar Gómez-Tamayo, A. Macías-García, M.A. Díaz Díez, E.M. Cuerda-Correa, Adsorption of $\mathrm{Zn}(\mathrm{II})$ in aqueous solution by activated carbons prepared from evergreen oak (Quercus rotundifolia L.), Journal of Hazardous Materials, 153 (2008) 28-36.

[297] S. Zuo, J. Yang, J. Liu, Effects of the heating history of impregnated lignocellulosic material on pore development during phosphoric acid activation, Carbon, 48 (2010) 3293-3295. [298] S. Yorgun, N. Vural, H. Demiral, Preparation of high-surface area activated carbons from Paulownia wood by $\mathrm{ZnCl} 2$ activation, Microporous and Mesoporous Materials, 122 (2009) 189194.

[299] Y. Yao, J. Zhang, G. Wu, S. Wang, Y. Hu, C. Su, T. Xu, Iron encapsulated in 3D N-doped carbon nanotube/porous carbon hybrid from waste biomass for enhanced oxidative activity, Environmental Science and Pollution Research, 24 (2017) 7679-7692.

[300] E.T. Thostenson, Z. Ren, T.-W. Chou, Advances in the science and technology of carbon nanotubes and their composites: a review, Composites Science and Technology, 61 (2001) 18991912.

2390 [301] W.-J. Jiang, L. Gu, L. Li, Y. Zhang, X. Zhang, L.-J. Zhang, J.-Q. Wang, J.-S. Hu, Z. Wei, L.-J. Wan, Understanding the High Activity of Fe-N-C Electrocatalysts in Oxygen Reduction: 
$2391 \mathrm{Fe} / \mathrm{Fe} 3 \mathrm{C}$ Nanoparticles Boost the Activity of $\mathrm{Fe}-\mathrm{Nx}$, Journal of the American Chemical Society, $2392138(2016) 3570-3578$.

2393 [302] A.S.N. Mahmood, J.G. Brammer, A. Hornung, A. Steele, S. Poulston, The intermediate 2394 pyrolysis and catalytic steam reforming of Brewers spent grain, Journal of Analytical and 2395 Applied Pyrolysis, 103 (2013) 328-342.

2396 